\title{
OBJECTIVE MORPHOMETRIC ANALYSIS OF DIFFERENT GLOTTIS ENLARGING PROCEDURES AND CLINICAL VALIDATION BY IMAGING, SPIROMETRIC ASSESSMENT AND PHONIATRIC PANEL
}

Ph.D. Thesis

László Szakács M.D.

Department of Oto-Rhino-Laryngology, Head and Neck Surgery University of Szeged

University of Szeged, Faculty of Medicine

Clinical Medical Sciences Doctoral School

Ph.D. Program:

Clinical and Experimental Research for Reconstructive and Organ-sparing Surgery

Program director: Prof. György Lázár M.D.

Supervisor: Prof. László Rovó M.D.,

Balázs Sztanó M.D. PhD

Szeged

2015 


\section{PUBLICATIONS related to the PhD Thesis}

I. Szakács L, Sztanó B, Matievics V, Bere Z, Bach A, Castellanos PF, Rovó L.

A comparison between transoral glottis-widening techniques for bilateral vocal fold immobility.

Laryngoscope. 2015 Jun 8. [Epub ahead of print]

II. Sztanó B, Szakács L, Madani S, Tóth F, Bere Z, Castellanos PF, Rovó L

Comparison of endoscopic techniques designed for posterior glottic stenosis--a cadaver morphometric study.

Laryngoscope. 2014 Mar;124(3):705-10

\section{CITABLE ABSTRACTS}

I. Szakács L, Smehák G, Torkos A., Rovó L

Simple suure's optimal position for glottis widening. Experimental study for cadavers EUFOS 2007 6th European Congress of Oto-Rhino-Laryngology Head and Neck Surgery June 30th - July 4Th 2007 Vienna/Austria Eur Arch Otorhinolaryngol (2007) (Suppl 1) 264: HP 62

II. B. Sztanó, L. Szakács, G. Smehák, S. Madani, L. Rovó

A morphometric cadaver study for the improvement of simple suture vocal cord lateralisation

8th Congress of the European Laryngological Society, Vienna Eur Arch Otorhinolaryngol (2010)

III. L. Rovo, S. Madani, L. Szakacs, B. Sztano, J. Jori

New instruments for endoscopic arytenoid lateropexy

8th Congress of the European Laryngological Society, Vienna

Eur Arch Otorhinolaryngol (2010)

IV. G. Smehak, L. Szakacs, B. Sztano, A. Szamoskozi, L. Rovo 
Is a deteriorated voice quality necessary after glottis enlarging procedures?

8th Congress of the European Laryngological Society, Vienna

Eur Arch Otorhinolaryngol (2010)

V. B. Sztanó, L. Szakács, S. Madani, G. Smehák, L. Rovó

Minimally invasive endoscopic arytenoid lateropexy as revision surgery for bilateral vocal cord impairment

1st Congress of CE-ORL-HNS, Barcelona

VI. L. Rovó, B. Sztanó, S. Madani, G. Smehák, L. Szakács, J. Jóri

Endoscopic arytenoid lateropexy - sixty cases

1st Congress of CE-ORL-HNS, Barcelona

VII. L. Szakács, B. Sztanó, G. Smehák, S. Madani, L. Rovó

Morphometric comparison cadaver study of different glottis widening procedures

1st Congress of CE-ORL-HNS, Barcelona

VIII. G. Smehák, L. Szakács, B. Sztanó, A. Szamosközi, L. Rovó

Endoscopic arytenoid lateropexy - long term phoniatric results

1st Congress of CE-ORL-HNS, Barcelona

IX. L Rovó, L Szakács, S Madani, B Sztanó

Endoscopic arytenoid lateropexy - Revision surgery after glottis enlarging procedures with unsatisfactory results

9th ELS Congress, Helsinki

X. B Sztanó, L Szakács, S Madani, V Majoros, L Rovó

Endoscopic arytenoid lateropexy for the treatment of bilateral vocal cord immobility pediatric cases

9th ELS Congress, Helsinki

XI. L Rovó, L Szakács, S Madani, B Sztanó 
Endoscopic arytenoid lateropexy - Revision surgery after glottis enlarging procedures with unsatisfactory results

9th ELS Congress, Helsinki

XII. B Sztanó, L Szakács, S Madani, V Majoros, L Rovó

Endoscopic arytenoid lateropexy for the treatment of bilateral vocal cord immobility pediatric cases

9th ELS Congress, Helsinki

XIII. Sztanó B, Szakács L, Madani S, Bach Á, Bere Zs, Rovó L

Endoscopic arytenoid abduction lateropexy for the treatment of bilateral vocal cord immobility - pediatric application

2nd Congress of CE-ORL-HNS, Nice

XIV. L. Rovó, L. Szakács, S. Madani, B. Sztanó

Endoscopic arytenoid abduction lateropexy for bilateral vocal cord immobility secondary surgery after glottis enlarging procedures with unsatisfactory results 2nd Congress of CE-ORL-HNS, Nice

XV. Matievics Vera, Szakács László, Sztanó Balázs, Szamosközi Alice, Rovó László

Arytenoid lateropexy in unilateral vocal cord palsy patients with effort dyspnoea 11th EFAS Congress, Budapest

XVI. Bach Á, Sztanó B, Matievics V, Szakács L, Rovó L

Life quality before and after a reversible glottis enlarging procedure (PP82)

10th Congress of the European Laryngological Society

9-12 April, 2014, Antalya, Turkey

XVII. Bach Á, Sztanó B, Szakács L, Rovó L

Function preserving solution of a chondrosarcoma of the cricoid cartilage ((PP80)

10th Congress of the European Laryngological Society

9-12 April, 2014, Antalya, Turkey 
XVIII. Szakács L., Sztanó B., Madani S., Rovó L.

Objective comparison of different glottis widening procedures- 3D radiological and cadaver morphometric study

3rd Congress of European ORL-HNS, Praha

\section{PUBLICATION not directly related to the PhD thesis:}

I. Rovó L, Madani S, Sztanó B, Majoros V, Smehák G, Szakács L, Jóri J.

A new thread guide instrument for endoscopic lateropexy

Laryngoscope. 2010 Oct;120(10):2002-7

II. Sztanó B., Szakács L., Smehák Gy., Madani S., Jóri J., Rovó L.

Hangréstágító mütétek hatásosságának vizsgálata cadaver gégéken morphometriás módszerrel I. - a hátsó commissura konfigurációjának változása

(Surgical anatomical morphometric studies in cadaver larynges - the posterior commissure)

Fül-orr-gégegyógyászat 2011; 57(2):48-53

III. Rovó L, Madani S, Sztanó B, Majoros V, Smehák Gy, Szakács L, Jóri J

Új, fonalvezető eszköz az endoszkópos arytenoid lateropexia céljára (referátum).

(New endolaryngeal thread guide instrument designed for endoscopic arytenoid lateropexy)

Fül-Orr-Gégegyógyászat 2011; 57(1):47-48

IV. Furák J, Szakács L, Nagy A, Rovó L.

Multiple costal cartilage graft reconstruction for the treatment of a full-length laryngotracheal stenosis after an inhalation burn.

Interact Cardiovasc Thorac Surg. 2011 Oct;13(4):453-5

V. Venczel K, Szakács L, Rovó L

A percutan tracheotomiás eljárások és szövődményeik, különös tekintettel a cricotrachealis szükületek kialakulására 
Fül-orr-gégegyógyászat 52:(6) PP. 120-124. (2006)

VI. Csanády M, Kiss J G, Szakács L, Paczona R, Jóri J

Diagnosztikus autofluoreszcenciás (dafe) vizsgálat gége- és garatdaganatokban Fül-orr-gégegyógyászat 1: pp. 41-16. (2006) 


\section{ABBREVIATIONS}

BVCI

BVCP

EAAL

VCL1

VCL2

SELP

TC

AE

cMAE

PEF

FEV1

FVC

PIF

HNR

$\mathbf{F}_{\mathbf{0}}$
Bilateral Vocal Cord Immobility

Bilateral Vocal Cord Palsy

Endoscopic Arytenoid Abduction Lateropexy

Vocal Cord Laterofixation with 1 suture

Vocal Cord Laterofixation with 2 suture

Schobel's External Arytenoid Lateropexy

Transverse Cordotomy

Arytenoidectomy

Calculated Medial Arytenoidectomy

Peak Exspiratory Flow

Forced Exspiratory Volume in $1 \mathrm{sec}$

Forced Vital Capacity

Peak Ispiratory Flow

Harmony and Noise Rate

Pitch frequency 


\section{CONTENT}

1. INTRODUCTION 1

2. SURGICAL PROCEDURES FOR THE TREATMENT OF BILATERAL VOCAL CORD IMMOBILTY 3

2.1. Open neck procedures 3

2.2. Minimally invasive, dominantly endolaryngeal procedures 5

2.3. Vocal cord laterofixation as early treatment for acute bilateral abductor paralysis as an alternative to tracheostomy 6

2.4. Endoscopic arytenoid abduction lateropexy (EAAL) 8

$\begin{array}{ll}\text { 2.5. The ideal position of the lateralising loop } & 8\end{array}$

3. AIMS OF THE THESIS

4. METHODS AND SUBJECTS

4.1. Surgical anatomical morphometric studies - comparison of endoscopic glottis enlarging techniques on cadaver larynges $\quad 11$

4.1.1. Suture lateralization procedures $\quad 12$

$\begin{array}{ll}\text { 4.1.2. Irreversible resection procedures } & 13\end{array}$

$\begin{array}{ll}\text { 4.1.3. Digital image analysis } & 14\end{array}$

4.1.3.1. Measurement of glottis enlargement 14

4.1.3.2. Proposed phoniatric effect 14

4.2. Endoscopic arytenoid abduction lateropexy - clinical results 16

4.2.1. Selection of the patients 16

4.2.2. Analysis of the postoperative laryngeal configuration - 3D-CT $\begin{array}{ll}\text { reconstruction } & 17\end{array}$

4.2.3. Evaluation of spirometric results 18

$\begin{array}{ll}\text { 4.2.4. Evaluation of the phoniatric results } & 19\end{array}$

4.3. Comparison of the results of cadaver and 'real patients' studies 21

5. RESULTS 22

5.1. Surgical anatomical morphometric studies - comparison of endoscopic glottis enlarging techniques on cadaver larynges

5.1.1. Glottic enlargement 22

5.1.2. Phoniatric parameters 23

5.2. Endoscopic arytenoid abduction lateropexy - clinical results 24 
5.2.1. Analysis of the postoperative laryngeal configuration - 3D-CT reconstruction

5.2.2. Evaluation of spirometric results 25

5.2.3. Evaluation of the phoniatric results 26

5.3. Comparison of the results of cadaver and 'real patients' studies 27

6. DISCUSSION 29

6.1. Surgical anatomical morphometric studies - comparison of endoscopic glottis enlarging techniques on cadaver larynges 29

6.2. Endoscopic arytenoid abduction lateropexy - clinical results 31

6.2.1. Analysis of the postoperative laryngeal configuration - 3D-CT $\begin{array}{ll}\text { reconstruction } & 31\end{array}$

6.2.2. Evaluation of spirometric results 33

6.2.3. Evaluation of the phoniatric results 33

6.3. Comparison of the results of cadaver and 'real patients' studies 34

7. CONCLUSIONS AND NEW RESULTS 36

7.1. Surgical anatomical morphometric studies - comparison of endoscopic glottis enlarging techniques on cadaver larynges 36

7.2. Endoscopic arytenoid abduction lateropexy - clinical results 36

7.3. Comparison of the results of cadaver and 'real patients' studies 36

8. ACKNOWLEDGEMENT 38

9. REFERENCES 39

$\begin{array}{ll}\text { 10. APPENDIX } & 48\end{array}$ 


\section{INTRODUCTION}

In the treatment of bilateral vocal cord immobility (BVCI) it is a great surgical challenge to find the ideal balance between breathing and voicing (1). Since the mid- $20^{\text {th }}$ century there have been surgical innovations such as the tracheostomy, once done purely by open techniques to the common use of minimally invasive endoscopic techniques $(2,3)$. Recently, there have been experimental trials to reanimate the neurologically impaired larynx by reinnervation procedures $(4,5)$ or laryngeal pacing (6). Additionally, endoscopic glottic aperture enlarging procedures can also be the basis for the treatment of BVCI. The surgical choice should depend on the patient's overall health and the personal voicing needs since the airway achieved is considered inversely proportional with the postoperative voice.

The efficacy of different glottis enlarging techniques cannot be easily compared clinically. Generally, only one procedure can be performed on one patient, and considering the variable anatomical factors (7) and evaluation methods, clinical case series are often statistically insufficient. This results in difficulties in the creation of proper study groups for the meta-analysis.

By assessing the efficacy of different endoscopic procedures, each being performed on the same cadaver larynx, an easier objective comparison would be possible. The glottic area achieved is proportional with the breathing improvement, but voicing effects are a more complex question. One of the most predictive factors is the postoperative angle of the vocal cords at the anterior commissure (8). Conversely, Isshiki described the importance of the integrity, tension, and the mass in paralyzed vocal cord dynamics during phonosurgery (9). Additionally, studies in the last decades have revealed that vocal cord paralysis is not a static condition. Possible residual motion $(10,11)$ due to additional or residual innervation (12), reinnervation (10), and synkinesis (13) might influence the postoperative voice, especially in larynges with otherwise intact structures.

In our clinic we designed cadaver morphometric studies to provide objective answers to these questions $(14,15)$.

In the 100-year-old history of airway stenosis surgery several important works of Hungarian authors (Rethi, Lichtenberger, Pytel) are found (1, 2). In Szeged we have been working in this field since the 1990s, we had several publications in prestigious journals (11, $16,17,18,19,20,21,22)$. The minimally invasive endoscopic arytenoid abduction lateropexy 
was introduced as a treatment of vocal cord impairment. Over 300 patients were successfully operated.

In previous works our team has already suggested an evaluation panel for the other important aspects of these surgeries, the phoniatric and spirometric outcomes $(22,23)$. The efficacy of the procedure can be evaluated by these laryngeal function measuring tests, the pre- and postoperative conditions are easily comparable $(25,26)$. Modern, non-invasive high resolution imaging procedures (Computer Tomography, Magnetic Resonance Imaging) may be useful tools for in vivo morphometric analyses (27).

I have been working in the Department of Otorhinolaryngology, Head and Neck Surgery, University of Szeged since 2001. I have joined to the 'airway stenosis surgical team' under the supervision of Professor Czigner, Professor Jóri and Professor Rovó. I took part in several operations of different types of stenosis. One of my main tasks was to perform the preand postoperative laryngeal functional examinations for measuring the airway improvement of these surgeries.Our clinic has been participated in the development of the Slicer 3D, which is an open source software permits analysis and three dimensional reconstruction of the CT and MRI scans. I have been the member of this group since 2009. This tool provides great opportunity to evaluate the efficacy of different airway stenosis surgical procedures. 


\section{SURGICAL PROCEDURES FOR THE TREATMENT OF BILATERAL VOCAL CORD IMMOBILTY}

The history of major groups of interventions (28) include the followings:

(1) resection of anatomical structures;

(2) retailoring and displacing the existing structures, with minimal tissue removal;

(3) displacing existing structures, without tissue resection;

(4) restoration or substitution of the missing innervations of the laryngeal musculature.

Procedures which utilize suture loop(s) for lateralization of glottis structures alone or in combination with other resection methods can be trace back to the beginning of the $20^{\text {th }}$ century. The technological evolution of the diagnostic methods, the anesthesia, and the surgical devices can be demonstrated well by their development. These interventions can be classified according to the required open or endoscopic approach; the targeted glottis structure; the need for tracheostomy; the duration: reversible, temporary, definitive; static or dynamic in terms of phonation.

\subsection{OPEN NECK PROCEDURES}

Documentation of suture lateralization of vocal cord can be found as early as the second decades of $20^{\text {th }}$ century (29). Erwin Payr (Vienna) described the endo-external procedure and the paralyzed vocal cord was sutured to the thyroid ala. Rethi (30) found the outcome of this procedure uncertain, however, in his first suggested procedure it was applied as part of his concept in 1922. Via laryngofissure (median splitting of thyroid and cricoid cartilage) approach a curved incision was made starting from the incisura interarytenoidea below the vocal cord then the lateral thyroarytenoid, the interarytenoid and the lateral cricoarytenoid muscles were extirpated. The cricoarytenoid joint was opened, well preserving the arytenoid cartilage and the overlying mucosa. In one of his modifications after muscle extirpation the overlying mucosa and the arytenoid were adapted and sutured temporary over 
a rubber tube placed on the skin of the neck for days till the healing process completed. The mobilized arytenoid cartilage was turned with the vocal process in lateral position this way.

External procedures made from lateral approach (lateral trans-thyroid or behind the posterior edge of thyroid cartilage) has become more popular. These procedures left the mucosal line intact so the risk of infection could be diminished which was a significant factor especially before the modern antibiotic era. Moreover, the direct targeting of arytenoid cartilage (partial or complete arytenoidopexy) provided better results: dilating more effectively the respiratory glottis and left the phonatory structures mainly intact. One of the earliest techniques is King's transposition of the omohyoid muscle to the arytenoid cartilage (31), which could produce only a passive abduction not the improved motility as it was primarily expected. Woodman (32) suggested the suturing of the vocal process to the inferior cornu of thyroid cartilage following subtotal arytenoidectomy. Newman (33) used a window on the thyroid ala at the level of the thyroid joint for the lateralization of the vocal process. The vocal cord remained at the level of the contralateral side facilitating a better voice production. The later modifications with the complete preservation of the arytenoid cartilage have become popular from the 1970s. These techniques leave the laryngeal mucosa maximally undisturbed, so in $50-80 \%$ of the cases preliminary tracheotomy became unnecessary $(28,34)$, which was considered to be obligatory in the earlier interventions. Schobel's technique (28) consists of preservation of the posterior crico-arytenoid ligament as a hinge as well as turning and tilting of the arytenoid cartilage laterally. It is held in this position with three permanent retention sutures, two of them armed with heavy knots. These knots reinforced the lateral rotation of the arytenoid cartilage. These sutures run in the submucosa horizontally along the anterior surface of the arytenoid cartilage and are fixed through burr holes on the posterior margin of the thyroid cartilage. In the majority of cases the operation could be performed under local anaesthesia which helped to establish proper voice function. In 2007, Woodson and Weiss (35) described a simplified surgical method for this concept considering the physiological abduction axis of the joint attaching the muscular process of the arytenoid by a suture to the inferior cornu of the thyroid cartilage. This leaves largely intact the periarytenoid musculature which might be advantageous for the dynamic voicing in partial recovery of paralyzes.

These latter, really effective procedures seem to be advantageous even in pediatric cases, although their application is generally not the first of choices nowadays because of the relatively long and challenging surgical intervention, their high tracheostomy dependency and their potentially low reversibility. 


\subsection{MINIMALLY INVASIVE, DOMINANTLY ENDOLARYNGEAL PROCEDURES}

The introduction of the endoscopic surgical techniques from the middle of $20^{\text {th }}$ century basically changed the laryngeal surgery, including the procedures for BVFP. These were generally the reconsideration of the well-known external resection procedures and they got boost especially after the introduction of laser technology. Attempts to apply suture lateralization can be found relatively early in the literature as well. The main part of these surgeries is performed from an endolaryngeal approach but more-or-less additional external access is generally required. Cancura (36) in 1969 reported on endoscopic laterofixation technique with wires passed through under and over the vocal cord from the laryngeal cavity out to the skin by a bend pipe and a drill. Then a third wire was pulled in through the oral cavity into thelarynx and out of the skin by knotting its ends to the previous ones. This made a creation a lateralizing wire loop possible. This study was demonstrated on animals but at the end of the 90's he reported on successful human application (personal information).

In the clinical practice ten years later Kirchner (37)introduced the endolaryngeal lateralization of the vocal ligament after the removal of a pre-assessed amount of thyroarytenoid muscle with laryngeal microcautery. A temporary suturing technique was described with guided nylon sutures by two externally inserted needles. An endoscopic guided the nylon thread from the lower needle to the upper one to form a loop around the vocal process. After the withdrawn of the needles padded buttons were used plus lead fishing sinkers to adjust the tension and secure these sutures on the surface of the neck. In his study, all patients required tracheostomy. Ejnell et al. (38) reported on first a case series with a similar technique of permanent simple suture lateralization but without any resection of glottic structures. The thread was tightened just outside of the cartilage from a larger external incision. Using a small endotracheal tube the tracheostomy could be avoided. The long term reliability was also proven by the team (39).

In 1983, Lichtenberger (40) introduced a needle carrier device (Richard Wolf Medical Instruments, Knitlingen, Germany), which was designed for his endo-extralaryngeal concept. The procedure was capable of passing a needle and suture endolaryngeally through the thyroid to the skin, significantly simplifying and making more precise the loop creation 
around the vocal process $(16,17,18,41)$. The created suture loop was tightened on the cartilage according to Ejnell et al.(38). His preclinical animal experiments brought out controversial results with simple suture lateralization thus in human application in the 90's he coupled his technique with different additional resection procedures according to the mobility of the arytenoid cartilage (42). In case of a mobile joint he performed a submucosal cordectomy (endo-extralaryngeal laryngomicrosurgical lateralization) and completed it with arytenoidectomy (endo-extralaryngeal laryngomicrosurgical lateralization with arytenoidectomy) if the joints were ankylotic. The suture loops were tightened on an external silicon tube ergo they served as a temporary fixation for the preserved laryngeal mucosal flaps during the healing process. Out of their first 54 patients 49required tracheostomy in this series.

\subsection{VOCAL CORD LATEROFIXATION AS EARLY TREATMENT FOR ACUTE BILATERAL ABDUCTOR PARALYSIS AS AN ALTERNATIVE TO TRACHEOSTOMY}

In the event of bilateral vocal cord palsy, the resultant airway obstruction may necessitate tracheostomy, but often the patient cannot be extubated. In many cases, however, the recurrent nerve lesion is transient $(43,44)$. Temporary vocal cord paralysis is probably due to neuropraxic injury, resulting from intraoperative stretching, compression or ischemia of the recurrent laryngeal nerve. Some degree of nerve regeneration may require weeks or months, even when a lesion is mild. However, the animal experiments performed by Zealear et al. (45) indicated that atrophy of the laryngeal muscles becomes irreversible after 7 months of inactivation. Although the results of animal experiments cannot be applied directly to humans, clinical observations have shown that it is worth waiting for 6-12 months for spontaneous recovery of vocal cord function before performing resection glottis enlarging procedures. These latter methods cause irreversible damage to the larynx and phonation proportional with the extent of resection $(3,46)$. This means that the patient may have to bear an airway cannula for at least 6 months, with all the somatic and psychological side effects or the applied "watch and wait" policy may severely restricts their life quality. However, tracheostomy can have a number of complications. Most important of these are intra- and postoperative hemorrhage, as well as the later complications of tracheomalacia and tracheal stenosis due to scarring. For these various reasons it was necessary to seek for methods that 
permit the avoidance of tracheostomy and provide patients an early alternative to airway cannula.

Ejnell and Tisell (47) first suggested their simple suture procedure for acute laterofixation of the vocal cord on four patients. According to this straight forward concept, after the endoscopically proven recovery of the vocal cord(s), the fixating sutures can be easily removed that makes this procedure reversible to a large extent. In 1997, Jóri et al. (16) reported on a successful application of a modification of the Lichtenberger's procedure for acute vocal cord immobility. The effect was essentially similar to Ejnell et al.'s $(38,47)$ method but their cases demonstrated that the fixing thread could be inserted more easily and precisely this way. The fixing thread was buried and knotted above the prelaryngeal muscles from a $1 \mathrm{~cm}$ skin incision instead of the originally suggested $5-6 \mathrm{~cm}(47,48)$, so the atrophy of the cartilage could be avoided without the use of an external silicone platelet. The slight but effective modifications diminished the surgical time and made this procedure really minimally invasive. These studies supported the reversibility of the procedure even after several months after the intervention. Later Lichtenberger (48) and Werner and Lippert (49) also supported the reliability of this concept.

The main advantage of the simple suture vocal cord lateralization procedures is their potential reversibility, so it serves as an alternative to tracheostomy in potentially reversible BVCI. The more than twenty-year experience with this concept, however, has revealed the possible complications as well. According to Tucker (50) the major drawback of them is that in many cases they do not yield adequate improvement because the suture slips to and may tear the mucosal part of the vocal cord resulting remedialization in the long run. Perichondritis due to salivary contamination of the orally delivered thread might be another factor. For this reason this method requires a careful peri- and postoperative care with parenteral administration of steroids and antibiotics for days. A dominant synkinetic reinnervation of adductor muscle which may cause an increased medialization force $(19,35)$ might also play role especially in late postoperative remedializations. Suture breakage has been also reported $(20,39,41)$. The need for revision, or secondary procedures, including tracheostomy, in large series varies from 13 to $38 \%(41,48)$. Revision surgery may be a bilateral application of the same technique or it can be coupled to additional resection procedures such as submucosal resection of thyroarytenoid muscle or arytenoidectomy.

Hoarseness is an expected effect of this operation considering the unfavorable postoperative glottic configuration. The voice may improve over time, in concert with mild remedialization or secondary to recovery from paralysis $(19,39)$. There is no significant 
complaints concerning swallowing even in case of bilateral application (21) because the mucosa of the arytenoid region, which is the main trigger zone of laryngeal protective reflex, remained intact (51). The chronic aspiration can probably be explained in some elderly patients by the age-related decrease of this reflex circle.

\subsection{ENDOSCOPIC ARYTENOID ABDUCTION LATEROPEXY (EAAL)}

The functional superiority especially in breathing improvement of the earlier mentioned external abduction lateropexy procedures compared to endolaryngeal vocal cord simple suture laterofixation procedures has been demonstrated in accordance of clinical (35, 39) and objective cadaver morphometric studies (15). The key for their successful application is the fixation of the arytenoid cartilages toward the physiologically maximal abducted position. The simple rotation around the vertical axis, which is generally considered to be the theoretical basis for simple vocal cord laterofixation techniques, is often described in standard anatomy textbooks (52) but not found in investigations on the subject. A helical axis close to vertical has been suggested $(29,53,54)$. Wang (44) has convincingly demonstrated that during abduction the lateral sliding motion of the vocal process is accompanied by an upward and occasionally slightly posterior movement simultaneously, with the arytenoid cartilage turning laterally and upward on the cricoid cartilage facet. On full abduction the arytenoid cartilage lies laterally at the upper and outer cricoid facet, having moved superiorly, posteriorly, and laterally. Thus the external procedures, which attach the arytenoid to the lower posterior part of thyroid cartilage, provide a more effective abduction than the endolaryngeal ones with suture loops, which were tightened at the level of the mid-portion of thyroid ala.It is obvious that the lower resistance against the fixating sutures arises, if the joint was moved in its natural way.

Endoscopically inserted suture which directly lateralizes the arytenoid cartilage to the normal abducted position (41) may provide long-term dependable results as studies demonstrated not only in BVCP $(4,19)$ but even in severe cases of MF after proper mobilization of the cricoarytenoidal joint $(\mathrm{CAJ})(21)$.

\subsection{THE IDEAL POSITION OF THE LATERALISING LOOP}

Nevertheless, the correct creation of this more posterior fixating loop location is practically impossible through an externally inserted needle (38) or by the original 
Lichtenberger's device (21) because the thyroid cartilage is more dense in that area.Moreover, the salivary contamination remained a possible risk for perichondritis. For this reason, a new endolaryngeal thread guide instrument (ETGI) (11) was introduced. (Fig. 1) This device is purposely designed for a more safe, accurate and fast suture loop creation for this procedure.

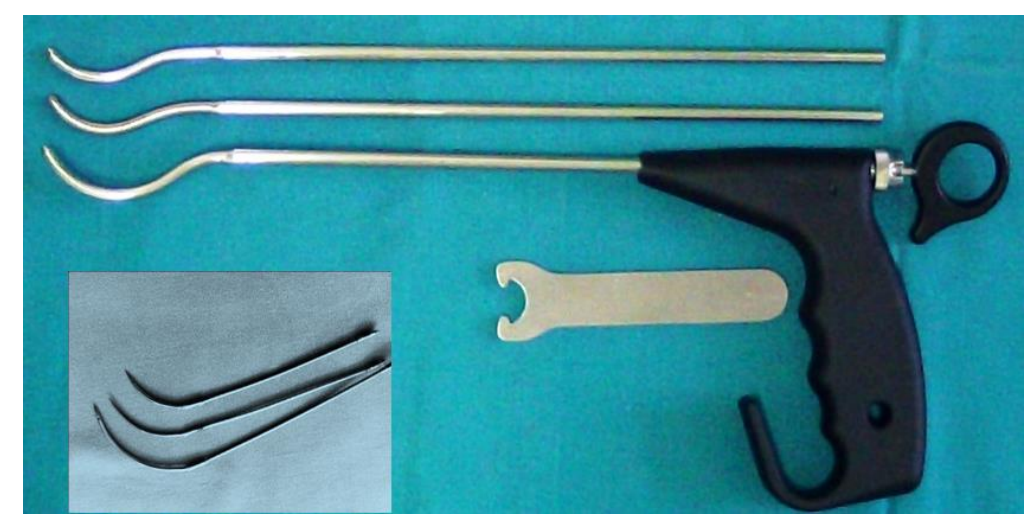

Fig. 1: Endolaryngeal thread guide instrument (ETGI)

Different size of steel pipes and curved blades suitable for infant-to-adult larynges

Recently, there have been experimental trials to reanimate the neurologically impaired larynx by reinnervation procedures $(39,47)$ or laryngeal pacing $(2)$. 


\section{AIM OF THE THESIS}

- $\quad$ Cadaver morphometric studies were performed to compare the efficacy of different glottis enlarging procedures for the treatment of BVCI.

- The evaluation of glottis enlargement.

- Proposed phoniatric effect

- In our clinic the minimally invasive endoscopic arytenoid abduction latreopexy was introduced. In 'real patients' the efficacy of this method was measured, the pre- and postoperative status was evaluated.

- Analysis of the laryngeal configuration. $3 \mathrm{~d}$ reconstruction of postoperative CT scans.

- Evaluation of the spirometric results

- Evaluation of the phoniatrtic results

- $\quad$ Comparison of the results of cadaver and 'real patients' studies. 


\section{METHODS AND SUBJECTS}

\subsection{SURGICAL ANATOMICAL MORPHOMETRIC STUDIES - COMPARISON OF ENDOSCOPIC GLOTTIS ENLARGING TECHNIQUES ON CADAVER LARYNGES}

One-hundred freshly excised cadaver larynges (50 male and 50 female) were analyzed. For a better view of the glottic area the epiglottis and the vestibular folds were removed (Fig 2). Larynges were inserted into a fixation device and secured with three screws along the cricoid cartilage avoiding deformation caused by the screws. The screw positions were always kept constant in each larynx. High-resolution digital photos were taken from a top view by Nikon D60 ${ }^{\circledR}$ camera fixed onto a tripod. This made possible to take all photos from a constant perspective.

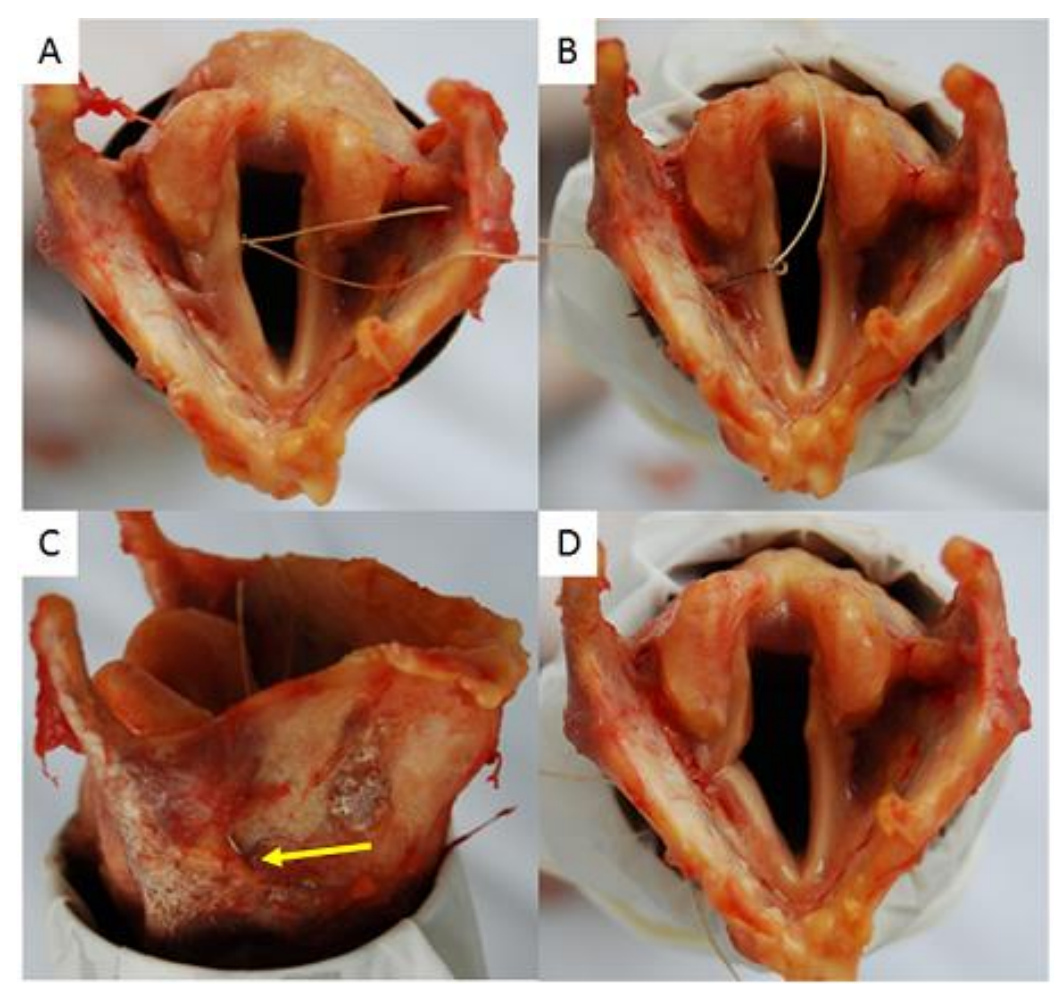

Fig. 2.: Lateralisation of the right vocal cord (Larynx No. 5, male, $57 \mathrm{Y}$ ).

A, B: Insertion of the thread below and above the vocal cord

C: the yellow arrow shows the appearing needle through thyroid cartilage

D: The lateralized vocal cord (op. sec Lichtenberger) 
The effect of "simple" suture-based techniques was measured in 60 larynges (30 male and 30 female). First, the normal cadaveric position of the larynges was documented. Then four different suture lateralization maneuvers were performed one by one on the left side on each larynx (Fig. 3). Suture placement was performed according to the techniques described in the literature by typical needle holders and suture materials.

\subsubsection{Suture lateralization procedures}

1. Classic vocal cord laterofixation (VCL-Suture1). The vocal cord is lateralized and fixed by a thread loop inserted at or just anterior to the vocal process $(38,55)$. The suture loop was placed according to Lichtenberger's endo-extralaryngeal concept (55), which allows for a more precise loop formation around the vocal process (Fig.3B).

2. Modified vocal cord laterofixation (VCL-Suture2) (50), in which a second suture was inserted anteriorly from the original position (Fig. 3C).

3. Endoscopic arytenoid abduction lateropexy (EAAL) (21). The arytenoid cartilage was rocked into its abducted position and then a suture loop was placed round the vocal process(Fig. 3D) (see in page 7).
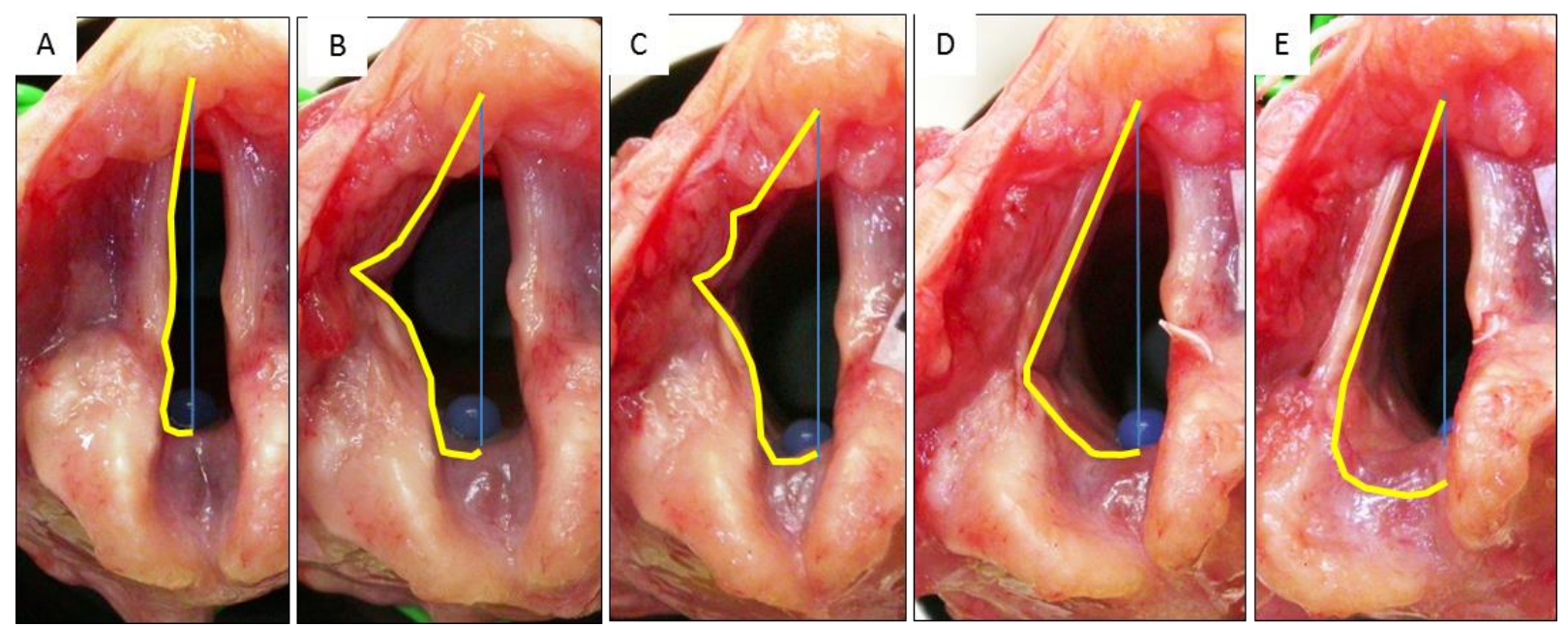

Fig. 3: Four different suture lateralizing techniques performed on the left side of the same cadaver larynx (Larynx No. 19, male, 67 Y).

The analyzed half of the glottic gap is labelled.

A: CP: cadaver position $(38,78 \mathrm{~mm} 2), \mathrm{B}$ : VCL 1 suture $(78,60 \mathrm{~mm} 2), \mathrm{C}$ : VCL 2 sutures 76,33mm2), D: EAAL $(132,18 \mathrm{~mm} 2), \mathrm{E}: \mathrm{SELP}(113,50 \mathrm{~mm} 2$

These minimally destructive procedures (\#'s 1-3) were performed on each larynx. They were taken in a quasi-random sequence (See \#4 below for the exception) so that the 
prior surgical technique would not affect the results (Fig. 3). The suture loops were knotted on the outer surface of the thyroid cartilage till maximal lateralization occurred.

4. Schobel's trans-cervical lateralization procedure (SELP) exposes the arytenoid body posteriorly (56). Then it is tilted and fixed laterally by $2-3$ horizontal submucosal suture-loops to the posterior margin of thyroid cartilage(Fig. 3E).

\subsubsection{Irreversible resection procedures}

Because of the irreversibility of the subsequent procedures, two subgroups were created: the transverse cordectomy (TC) and the total arytenoidectomy (AE). The glottic area created was measured after each surgery on 20-20 cadaver larynges.

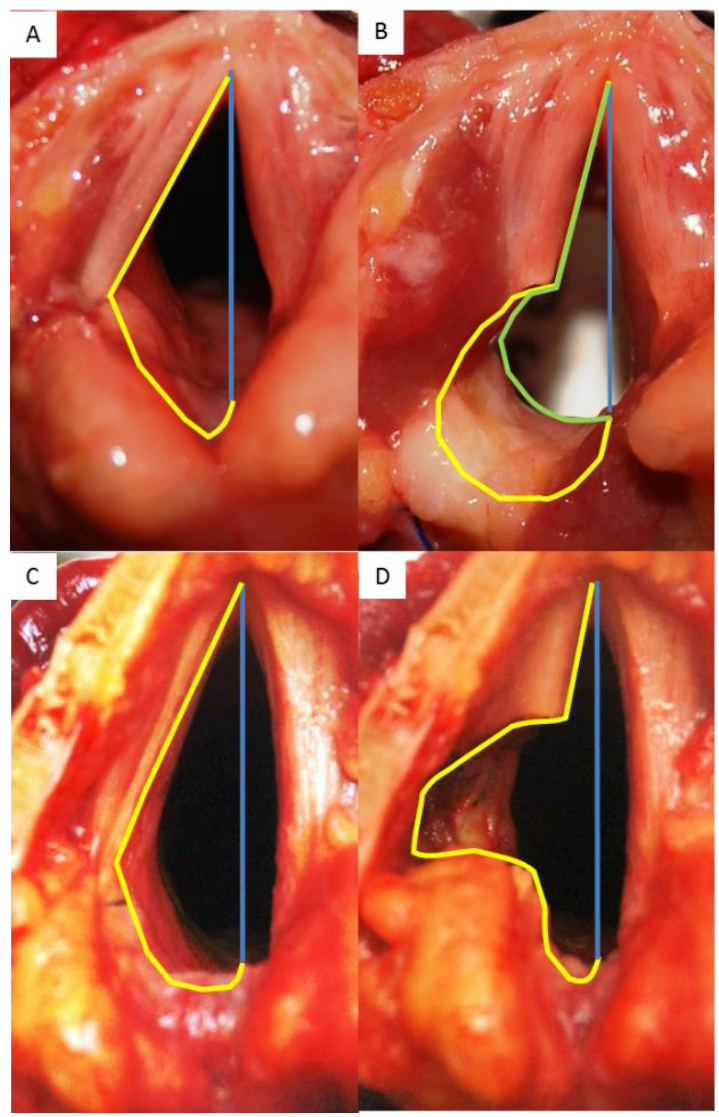

Fig. 4: EAAL and resection methods

EAAL (A) and AE (B)(Larynx No. 86, female, 68Y; EAAL: 131,43mm2, AE: 161,35mm2, cMAE: $114,63 \mathrm{~mm} 2)$

EAAL (C) and TC (D) (Larynx No. 69, male, 71Y; EAAL: 131,80mm2, TC: 101,84mm2)

The analyzed glottic gap is labelled. In B calculated medial arytenoidectomy (cMAE) is also shown (green). 
5. Transverse cordectomy (TC) (57). A wedge-shaped defect was created by the removal of the middle third of the vocal cord till the thyroid cartilage (Fig. 4D).

6. Arytenoidectomy procedures

A. Total Arytenoidectomy (AE) (58). In order to simplify the procedure and for the maximal efficacy, the left arytenoid was completely removed along with the surface mucosa (Fig. 4B).

B. Calculated Medial Arytenoidectomy (cMAE) according to Crumley (51).

The partial resection of arytenoid cartilage is presently considered a popular method. The images gained after total AE provided a simple calculation for their efficacy as well. Considering the anatomical structure of the cricoarytenoideal joint, only the real airway improvement was measured (see on Fig. 4B), which could be achieved by the removal of the medial obstructing part of the arytenoid cartilage (51).

\subsubsection{Digital image analysis}

4.1.3.1. Measurement of glottic enlargement

In our prior morphometric study the parameters describing the posterior commissure were analyzed (15, II). A task-orientated modification was used. "Fuji" digital image analyzing software was used to measure the glottic configuration changes. First, the glottic area changed was measured on the lateralized side of the larynx from the midline (Fig. $3,4)$.

\subsubsection{2. $\quad$ Proposed phoniatric effect}

According to Isshiki's and Woodson's suggestion the most important determining parameters were examined (9) (Fig. 5,6):

(1) The angle (A) at the anterior commissure between the lateralized vocal cord and the midline (Fig. 5,6-red $\alpha$ angle).

(2) The length of vibrating part of the vocal cord (L) is determined by the two fixation points, which are normally the anterior commissure and the vocal process. This value is proportional to the passive (e.g. not neuro-muscular) strain of the vocal cord. After 
SLP the vibration length is reduced to the anterior commissure and the closest lateralizing suture (Fig. 5B, C-yellow line).In the case of $\mathrm{AE}$ and $\mathrm{TC}$, the anterior fixation point remains unchanged; but the posterior fixation point changes to the attachment of remaining vocal cord at the thyroid cartilage (Fig. 6). Theoretically, in case of cMAE, this latter point stays at the remnant of vocal process.

(3) The maximal deviation (D) of the free margin of the vibrating part from the line between the two fixating points (Fig. 5, 6-small yellow arrows).

(4) Maximal deviation to length ratio (D/L) provides a more precise comparison. The length and the deviation together determine the possible outcome, so their proportion is the normalization of deviation to the actual vibrating length of the vocal folds (e.g. the same deviation on a shorter vocal fold segment can cause a more chaotic vibrating pattern).

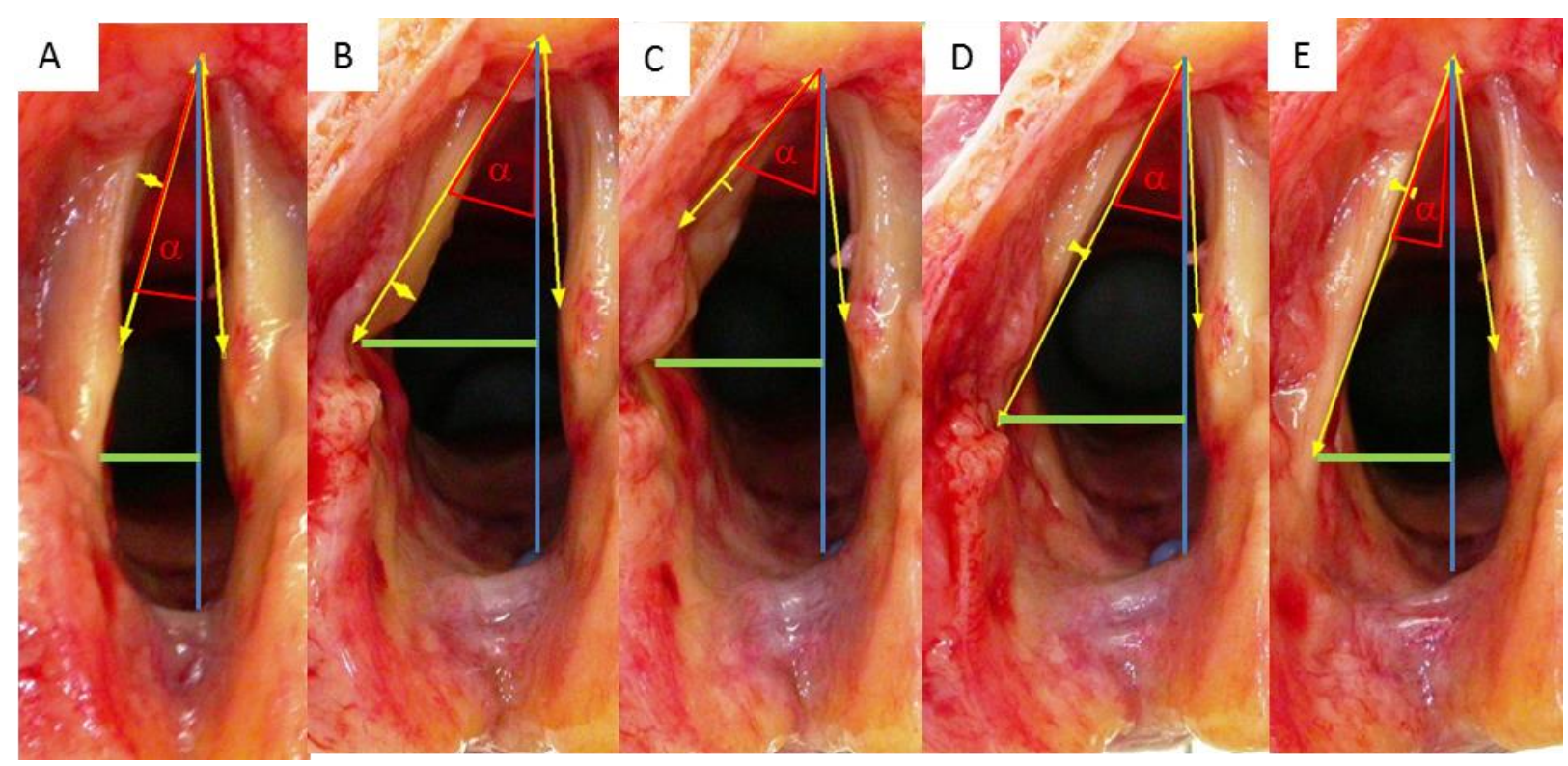

Fig. 5: Parameters determining the phoniatric outcome - comparison of different glottis enlarging procedures

Angle of the "half" anterior commissure (red angle); length of the vibrating part of vocal cord (yellow arrow); maximal deviation of the vocal cord's free edge from the line of the fixating points (short yellow arrow).

A: CP, B: VCL1; C: VCL2; D: EAAL; E: SELP 


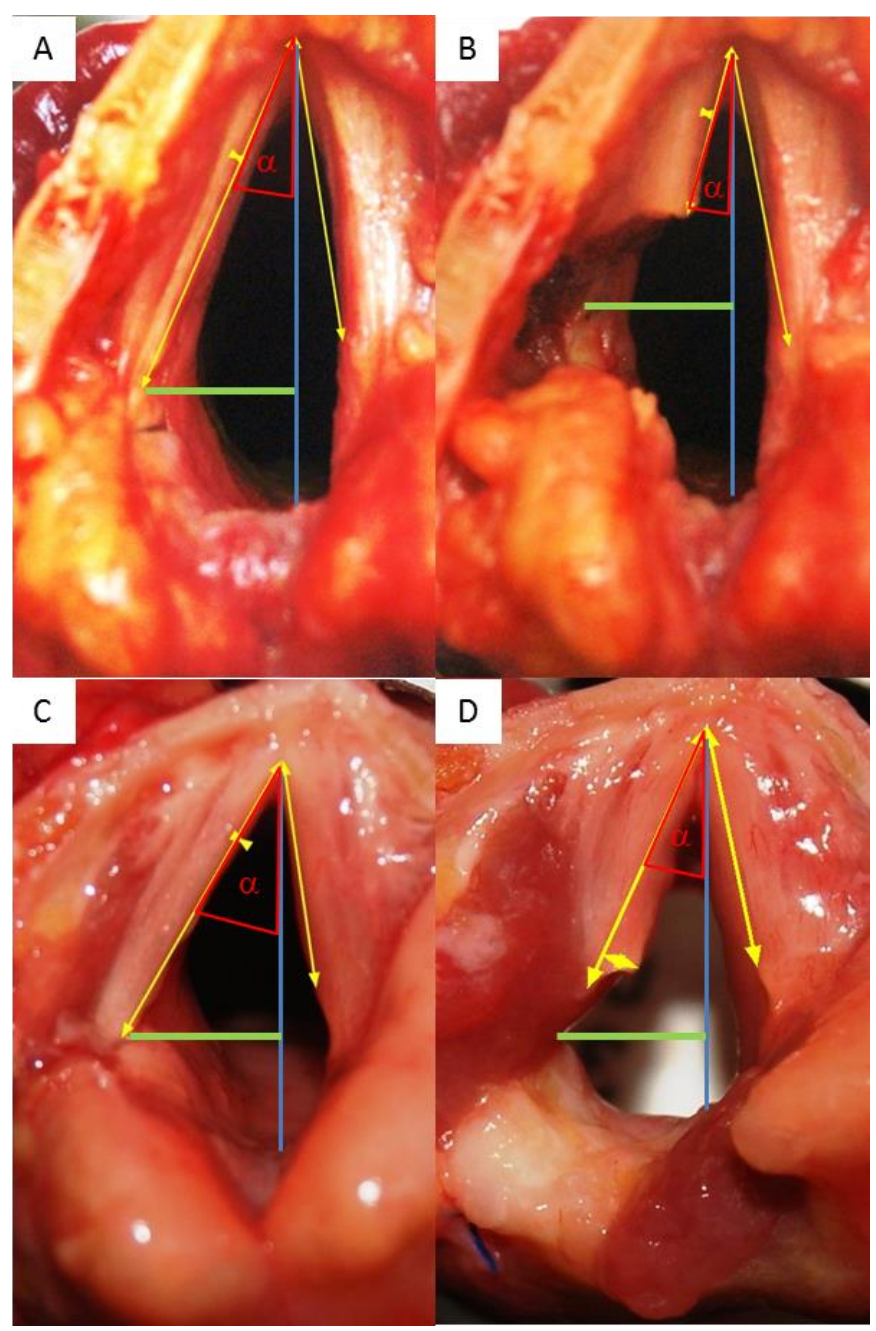

Fig. 6: Parameters determining the phoniatric outcome - comparison of EAAL and resection methods Angle of the "half" anterior commissure (red angle); length of the vibrating part of vocal cord (yellow arrow); maximal deviation of the vocal cord's free edge from the line of the fixating points (short yellow arrow). A: EAAL, B: AE (Larynx No. 69, male, 71Y) C: EAAL; D: TC (Larynx No. 86, female, 68Y)

Statistical analysis was performed (pairwise comparisons; repeated measure ANOVA; Sidak adjustment for multiple comparisons) by SPSS 20.0.

\subsection{ENDOSCOPIC ARYTENOID ABDUCTION LATEROPEXY - CLINICAL RESULTS}

\subsubsection{Selection of the patients}

In our department since 1989 endoscopic abduction arytenoid lateropexy has been applied as the treatment of bilateral vocal cord immobility, more than 300 patients have been operated successfully. 
In this study ten patients, who underwent bilateral thyroidectomy because of malignant thyroid gland tumour in other surgical departments were chosen (eight women, two men, mean age 57,1 year). Each patient had postoperative bilateral vocal cord palsy without any preoperative hoarseness and/or dyspnoe. Eight patients had moderate or severe postoperative dyspnoe, two patients could not be extubated after thyroid surgery because of suffocation. The sudden onset of the breathing complaints required rapid intervention, the average time between the thyroid surgery and glottis enlarging procedure was 2,1 days ( $0-8$ days). The lateralisation side was determined by the surgical chart describing the intraoperative thyroid surgery conditions, especially the possible injury of the inferior laryngeal nerve.

After EAAL the breathing of all patients improved significantly, none of them required any other airway maintenance.

To quantify the clinical results spirometric, phoniatric tests and postoperative CT examination were performed.

\subsubsection{Analysis of the postoperative laryngeal configuration - 3D-CT reconstruction}

Thyroid tumor patients, who required postoperative CT for oncologic staging, were selected. So unnecessary CT examinations with their radiation exposure could be avoided. The examination was taken in the postoperative $1^{\text {st }}-10^{\text {th }}$ month (mean 3,8 months).

The finest available CT scans were performed $(0,4-2,5 \mathrm{~mm}$ slice thickness). This resolution made a good three dimensional reconstruction of the glottic chink possible.

Slicer 3D open source software was used for the anatomic reconstruction of the glottic airway. The horizontal slices were applied for the segmentation. The optimal range of the Hounsfield Unit (HU) was between -130 to -1200 . The range of interest (ROI) was signed by the upper and the lower borders of the glottis. These were 2 to 11 slices depended on the thickness of the slices. The volume of the ROI was defined in cubic millimeters.

The same parameters were analyzed as in the cadaver study: glottic area, angle of the anterior commissure, maximal deviation from the midline.

First, the midline of the larynx was marked, it was the line between the anterior commissure and the inner surface of the crycoid cartilage. The midline divided the unoperated and the lateralized side of the larynx. The glottic area with air density (the glottic air shadow) was defined automatically by the program. It was settled on each assessed slice. The 'area slices' were summed resulted in glottic volume of both unoperated and lateralized halves. 
Then the mean area was calculated; it was the quotient of the glottic volume and the height of the glottis. (The glottic height $=$ slide thickness $\mathrm{x}$ number of slides).

Maximal deviation (in millimeters) is the distance between the midline and the most lateral point of the glottis surface.

Angle of the anterior commissure: the lateral arm of the angle was the lateral border of the glottic airway, the medial arm was the midline (Fig. 7)

Bilateral analysis was performed, the operated and the untreated half glottis could be evaluated, which is similar to pre- and postoperative status.

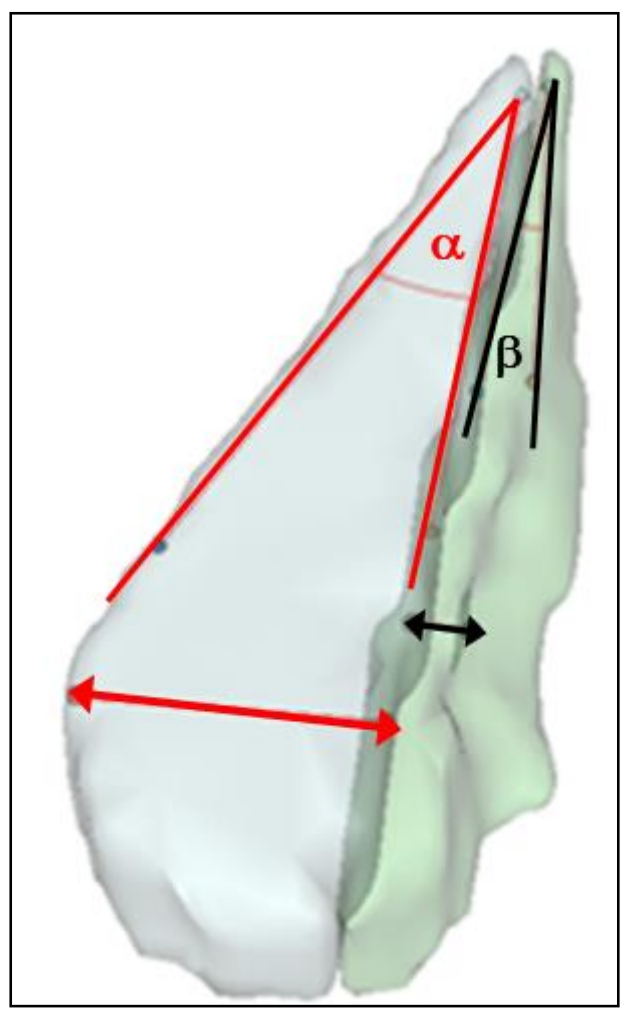

Fig. 7: 3D reconstruction of the glottic airway after left side EAAL (K.E. 28 Y, female)

Angle of the "half" anterior commissure (red: left side, black: right side); maximal deviation of the vocal process from the midline (purle arrow: left side, yellow arrow: right side).

Statistical analysis was performed (pairwise comparisons; repeated measure ANOVA; Sidak adjustment for multiple comparisons) by SPSS 20.0.

\subsubsection{Evaluation of spirometric results}

The spirometric examination is highly dependent on patient cooperation and effort (25, 59), and spirometry can only be used on patients who are able to understand and follow instructions. The maneuver requires maximal effort from the patient and it takes time to 
perform a quality spirometry. It is essential the procedure carefully and clearly to explain and to actively coach and motivate the patient to perform maximally.

The performance of spirometry while seated upright in a chair is preferable to standing as this is the most stable position should the patient experience dizziness during the test. The key steps are to urge the patient to breathe in fully (the lungs must be absolutely full, seal the lips around the mouthpiece and immediately blast the air out as fast and as far as possible until the lungs are completely empty. Then breathe in fully again as fast and as far as possible. The test is repeated until three acceptable results are obtained. The best results, the highest values were chosen.

The peak inspiratory flow (PIF) was measured in all patients. The preoperative evaluations - if possible - was made on the day before the operation. The postoperative measures were established on the first and the tenth postoperative weeks. Thor Soft spirometer was used in the study (Fig. 8).
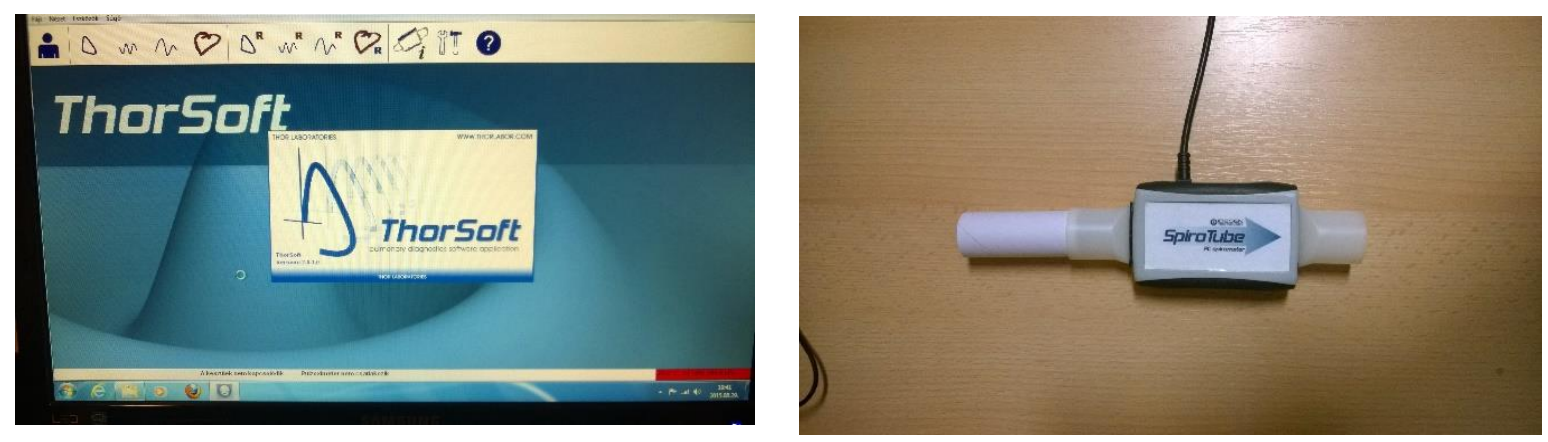

Fig. 8: Thor Soft spirometer

Statistical analysis was performed (pairwise comparisons; repeated measure ANOVA; Sidak adjustment for multiple comparisons) by SPSS 20.0.

\subsubsection{Evaluation of the phoniatric results}

The recording of the patients' voice was analyzed by Praat software (Boersma and Weenink, 2009) and the Tascam US 122 MkII PC audio interface (TEAC America, Inc. 1834 Gage Road Montebello, CA 90640). The preoperative voice - if possible - was recorded on the day before the operation. The postoperative recording was in the first month (early postoperative recording) and in the third postoperative month (late postoperative recording).

The examination setting can be seen below (Fig. 9). 

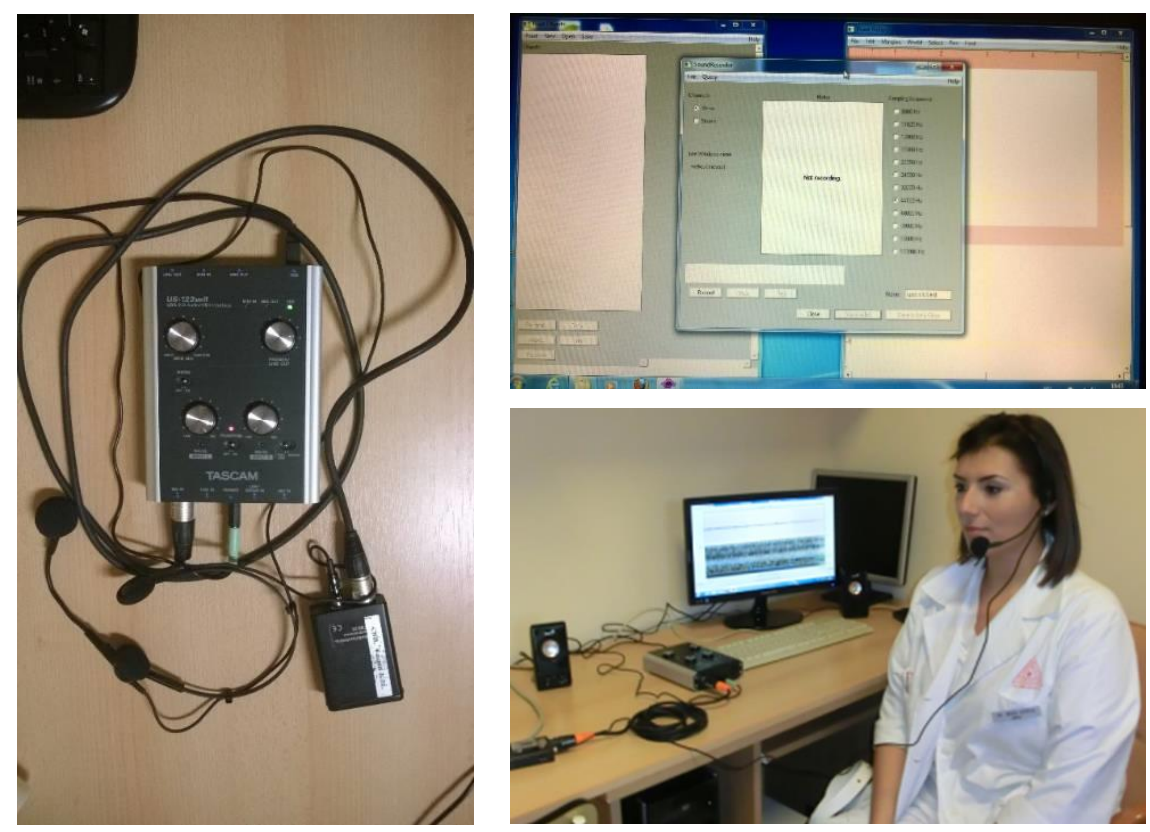

Fig. 9: Tascam US 122 MkII PC audio interface and Praat software. The picture right below presents the examination setting.

For the record the patients had to say a sustained vowel [:a]. In our clinic Standard Voice Panel was suggested, containing the following objective and subjective tests (22):

- MPT: maximal phonation time, ideal at the range of 15-20 sec.

- HNR: harmonic-to-noise ratio, acceptable if more than $12 \mathrm{~dB}$

- Jitter: cycle-to-cycle variation of fundamental frequency, i.e. the average absolute difference between consecutive periods contributes to the perception of a rough or harsh voice quality. acceptable at the human voice if less than 1,04\%

- Shimmer: the variability of the peak-to-peak amplitude in decibels, i.e. the average absolute base-10 logarithm of the difference between the amplitudes of consecutive periods, acceptable if less than $3,81 \%$

- Pitch $\left(F_{0}\right)$ : base frequency, in adult male $128 \mathrm{~Hz}$, female $225 \mathrm{~Hz}$

Further examinations were the $V H I$ and the VQL questionnaries. (Appendix 1)

Statistical analysis was performed (pairwise comparisons; repeated measure ANOVA; Sidak adjustment for multiple comparisons) by SPSS 20.0. 


\subsection{COMPARISON OF THE RESULTS OF CADAVER AND 'REAL PATIENTS' STUDIES}

Finally, the results of the cadaver morphometric study and the CT assessment were compared. First, ten cadaver larynges similar to the ten real patients' organs (gender, age, length of the glottis) were chosen. The cadaver and lateralized positions were compared to the unoperated and the operated glottic halves. The glottic volume, the angle of anterior commissure and maximal deviation were analysed. 


\section{RESULTS}

\subsection{SURGICAL ANATOMICAL MORPHOMETRIC STUDIES - COMPARISON OF ENDOSCOPIC GLOTTIS ENLARGING TECHNIQUES ON CADAVER LARYNGES}

\subsubsection{Glottic enlargement}

All SLP provided larger glottic area compared to cadaveric position (Fig. 10). However, a significant enlargement $(\mathrm{P}<0,05)$ was found with EAAL, SELP and AE. At the glottic level, AE provided the largest gap; but considering the anatomy of the cricoarytenoid joint, the large part of the improvement is located on the cricoid plate on the lower facet of the joint. Therefore, the real improvement was effectively the same as achieved by cMAE. There was no significant difference comparing CP, VCLs, TC, and cMAE. The arytenoid abduction methods produced the largest area increases $(\mathrm{p}<0.05)$. EAAL was found to be a bit more effective than SELP. This was thought to be due to the more effective rotation of the arytenoid but the difference was not statistically significant (Fig. 10B).

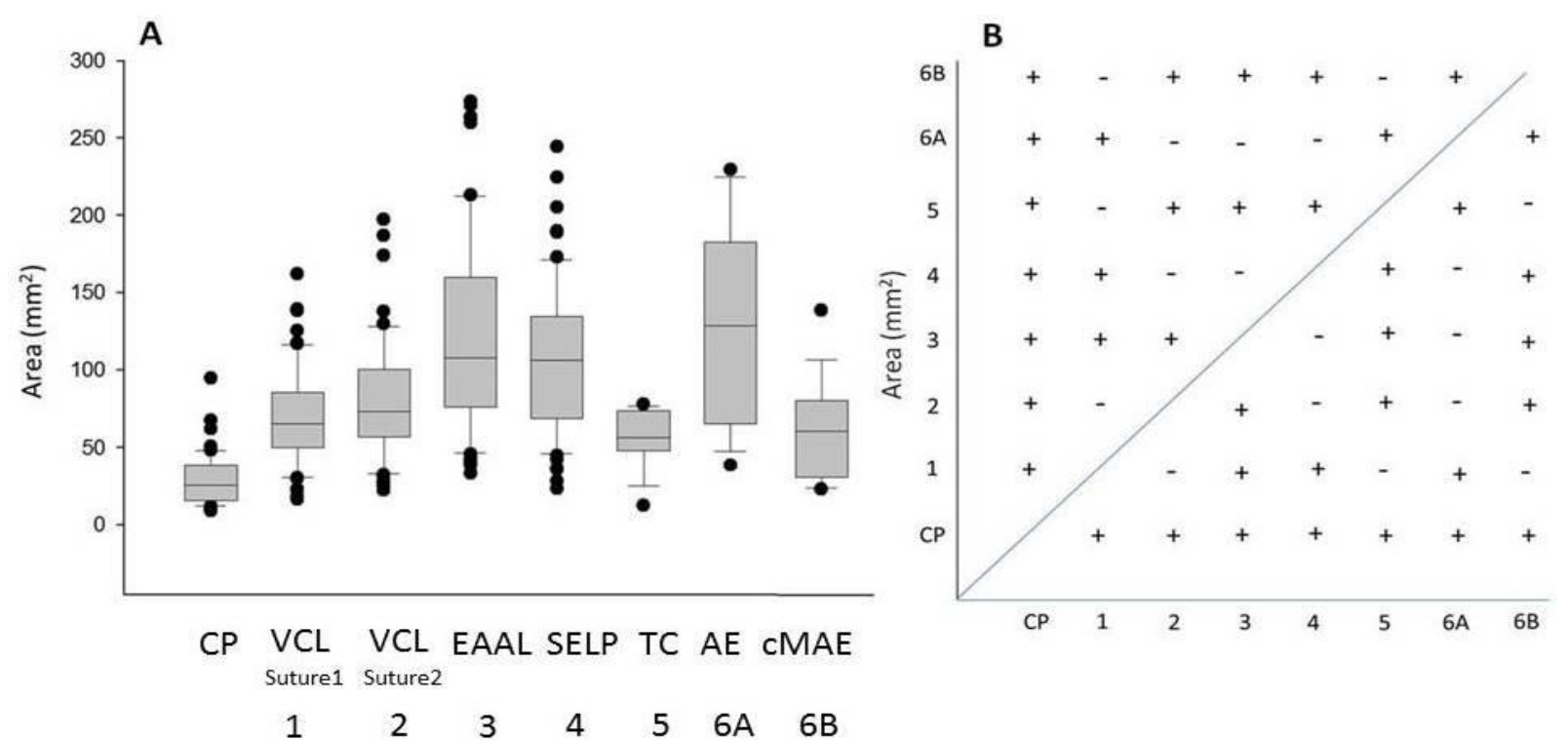

Fig. 10: The area of half glottis after different glottis enlarging procedures

A: Box plot displaying the extremes, upper and lower quartiles and the medians.

B: Intergroup significance. Numbers of the axis represent the groups as presented in Table (A).

(+) indicates significant differences, (-) indicates no significance between tested groups. ANOVA, $\mathrm{p}<0.05$.

1-CP: cadaver position, 2-VCL: vocal cord laterofixation, 3-SELP: Schobel's method,

4-EAAL: endoscopic arytenoid abduction lateropexy, 5-TC: transverse chordotomy, 
6-AE: arytenoidectomy, 7-cMAE: calculated medial arytenoidectomy

\subsubsection{Phoniatric parameters}
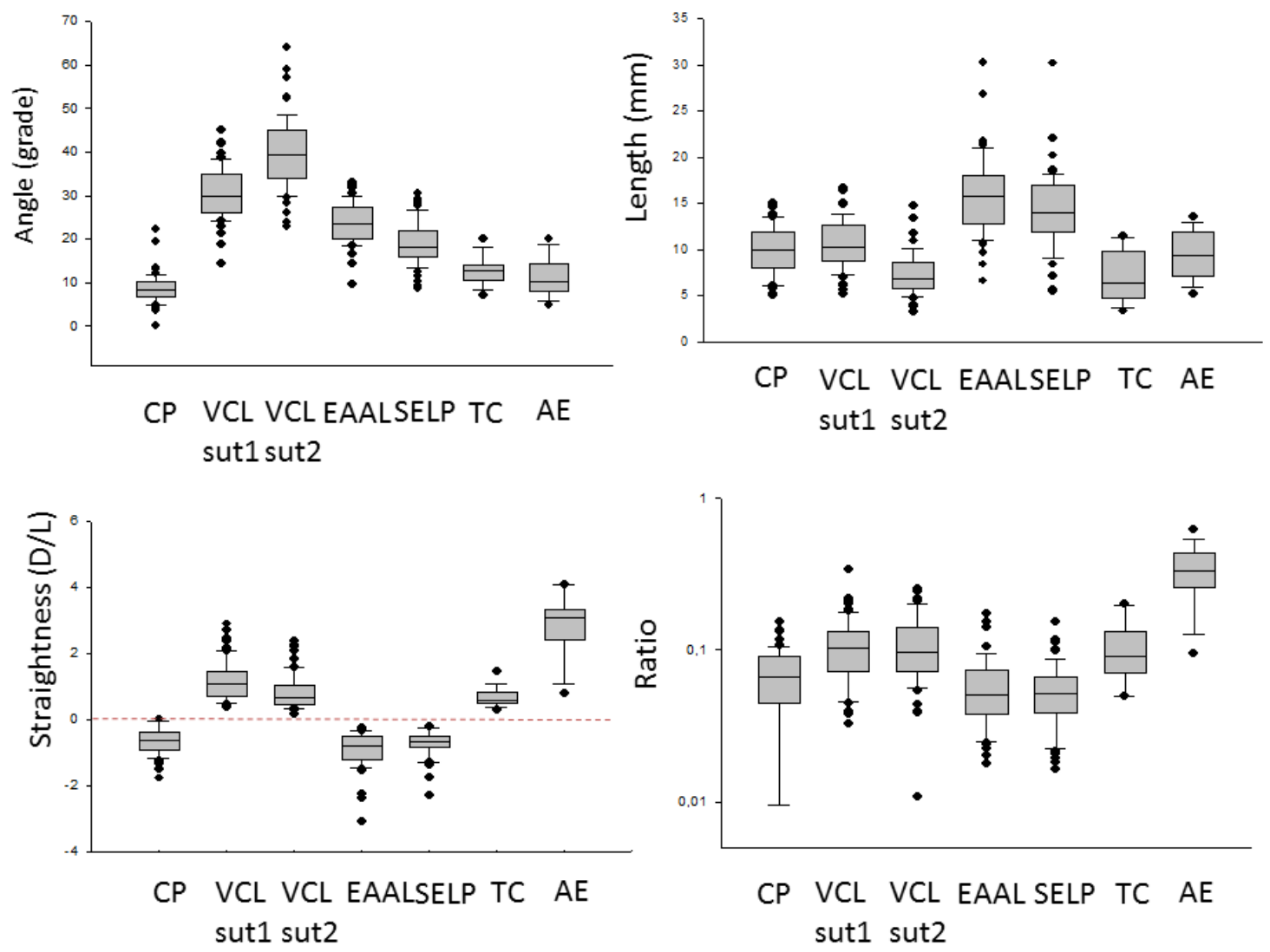

Fig. 11: Parameters determining the phoniatric outcome - comparison of different glottis enlarging procedures

A: Angle of the "half" anterior commissure

B: Length of the membranous (vibrating) vocal cord;

C: Maximal deviation of the vocal cord's free edge from the line of the fixating points $(\mathrm{D} / \mathrm{L})$ (negative: lateral deviation or concavity, positive: medial deviation or convexity);

$\mathrm{D}$ : The phonation closure ratio is a function of the proportion of the effective maximal curve (deviation of vibrating vocal cord position divided by its length) and its length $(\mathrm{C} / \mathrm{L})$ with " $\mathrm{C}$ " being the curve of the cord $(\mathrm{D} / \mathrm{L})$ in panel C:

Box plot displaying the extremes, upper and lower quartiles and the medians.

CP: cadaver position, VCL: vocal cord laterofixation, SELP: Schobel's method, EAAL:

endoscopic arytenoid abduction lateropexy, TC: transverse chordotomy, AE: arytenoidectomy.

All suture lateralizing procedures significantly increased the anterior glottic commissure's angle; however, TC and AE did not significantly change it $(\mathrm{p}<0,05)$ (Fig. 11,12).

The largest angle, the worst configuration from a voicing perspective, was found after VCL-Suture2. SELP provided a smaller angle change than EAAL due to the slightly more medial vocal process $(\mathrm{p}<0,05)$. 
The length of the vibrating cord: The VCL-Suture2 and TC significantly shortened the vocal cord length. VCL-Suture1 and AE caused insignificant changes. The vocal cord length was significantly greater, higher in tension, after SELP and EAAL.

Unfavorable curving of the altered cord resulted from the VCLs, TC, and AE. This curving was negligible after EAAL and SELP. AE caused the maximal deviation (from straightness) in this series. Considering D/L, SELP and EAAL were the most advantageous $(\mathrm{p}<0.05)$ (Fig. 11,12).
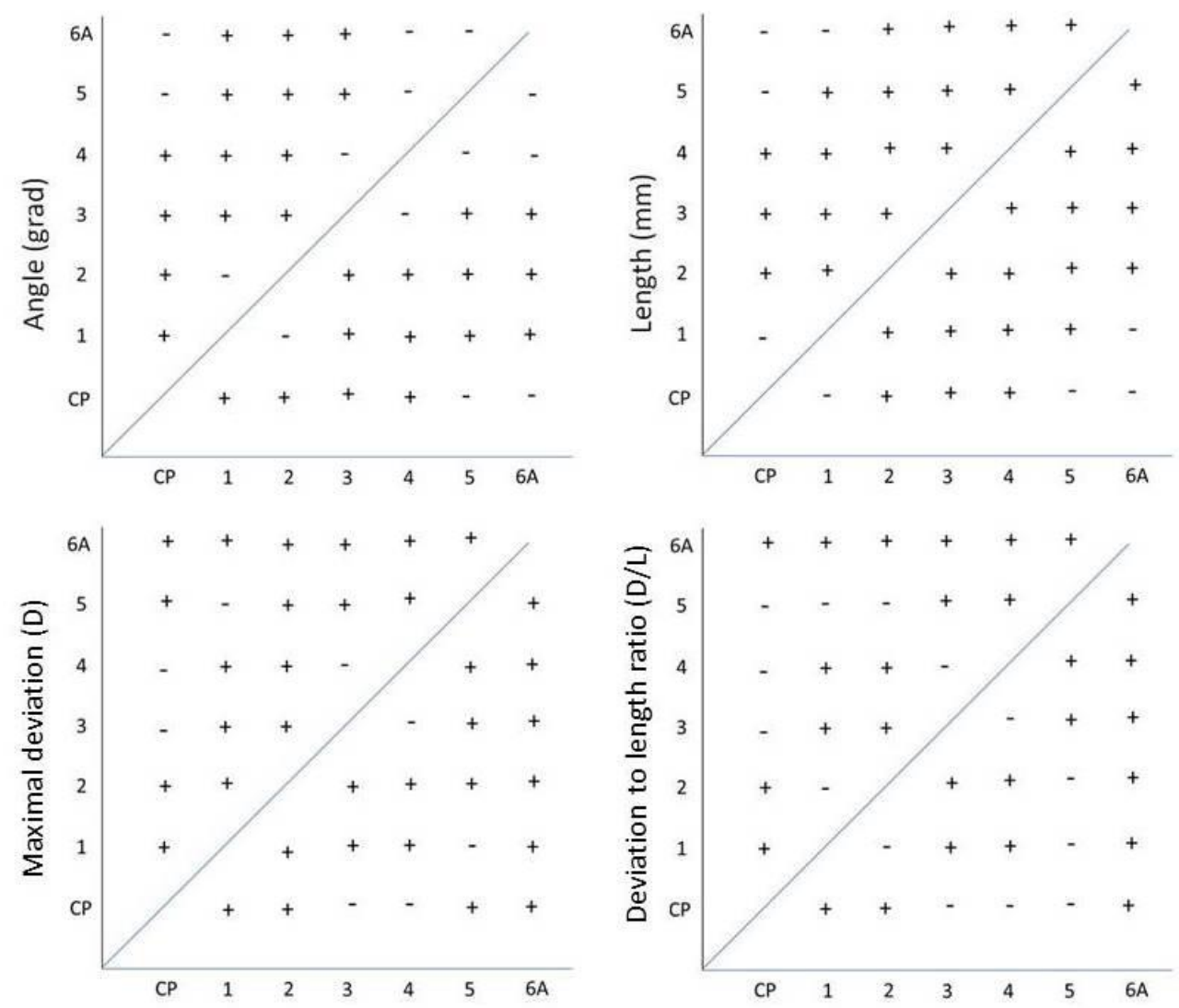

Fig. 12: Statistical supplement for Fig. 11. - Parameters determining the phoniatric outcome

Numbers of the axis represent the tested groups: (+) significant difference, (-) no significant difference between groups. ANOVA, $\mathrm{p}<0.05$.

CP: cadaveric position, 1. VCL-1: 2. VCL-2: vocal cord laterofixation, 3. SELP: Schobel's method, 4. EAAL:endoscopic arytenoid abduction lateropexy, 5. TC: transverse chordotomy, 6. AE: arytenoidectomy,

\subsection{ENDOSCOPIC ARYTENOID ABDUCTION LATEROPEXY - CLINICAL RESULTS}

\subsubsection{Analysis of the postoperative laryngeal configuration - 3D-CT reconstruction}


All examined parameters of the operated 'lateralized half' glottis was found significantly larger (Fig. 13).

\begin{tabular}{|l|l|}
\hline untreated & lateralized \\
\hline $180.41 \pm 34.57$ & $360.9 \pm 51.87$ \\
\hline
\end{tabular}

\begin{tabular}{|c|c|c|}
\hline & untreated & lateralized \\
\hline meant: & $38.97 \pm 4.33$ & $81.47 \pm 4.04$ \\
\hline
\end{tabular}
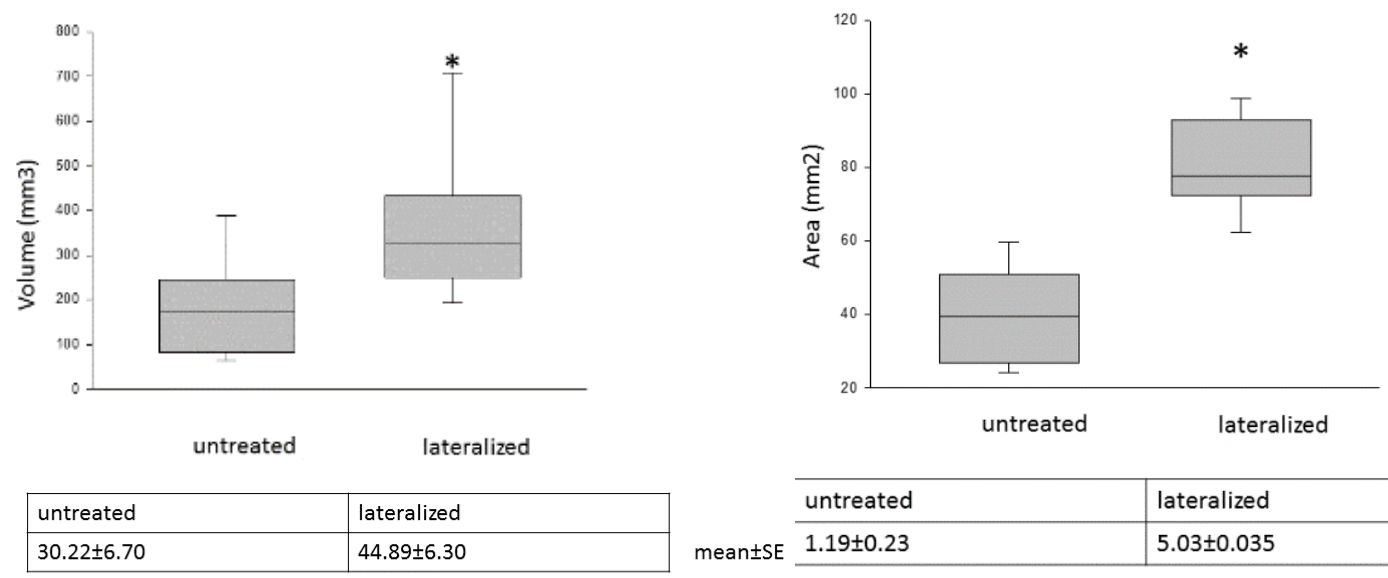

\begin{tabular}{l|l|}
\hline untreated & lateralized \\
\hline $1.19 \pm 0.23$ & $5.03 \pm 0.035$ \\
\hline & $* 0.001$
\end{tabular}

mean \pm SE
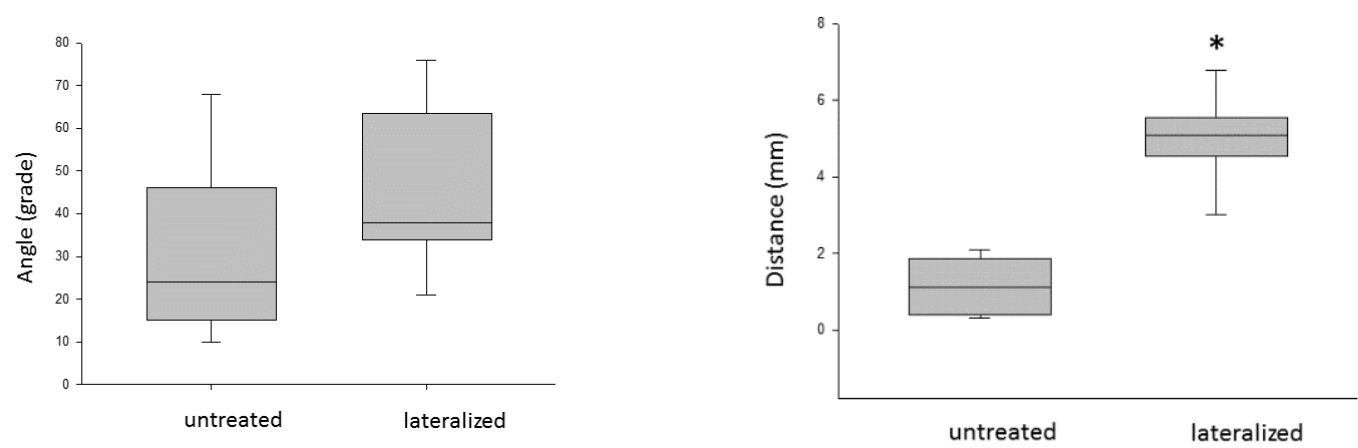

Fig. 13: Comparison of the 'lateralized half' and the 'untreated half' glottis. The examined parameters: volume, area, anterior angle, maximal deviation

\subsubsection{Evaluation of spirometric results}

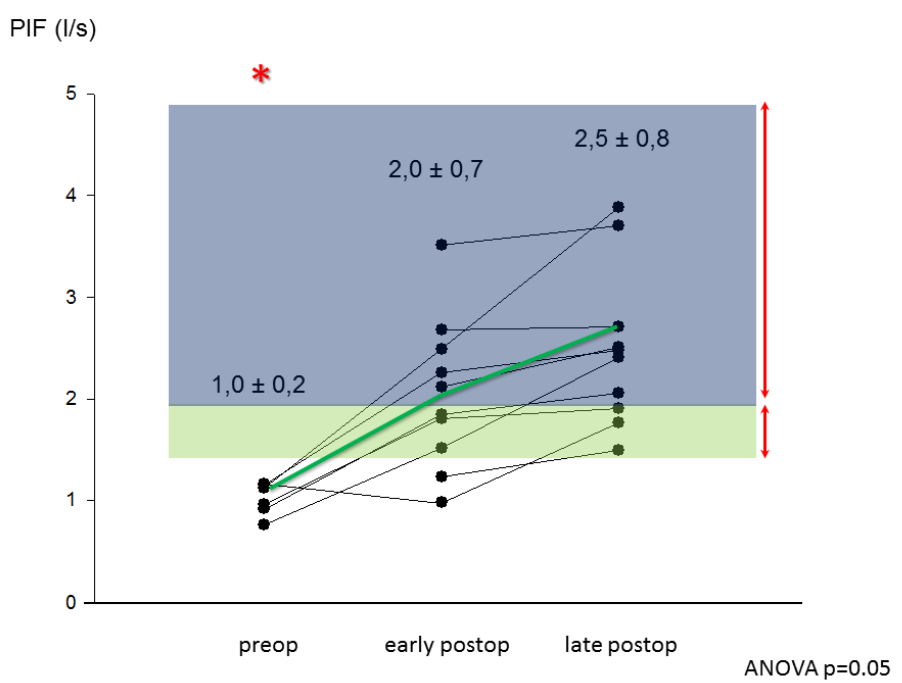

Fig.14: Spirometric examination, the change of the PIF

The mean values were marked (green line). The blue area is the normal range, the green area means acceptable breathing. 
Because of severe dyspnoe or intubated status of the patients the preoperative spirometric examination could be performed in six out of ten patients. All the ten persons participated in the postoperative spirometric tests (Fig. 14).

Significant PIF improvement was found in all cases after EAAL, and the late values were even better.

\subsubsection{Evaluation of the phoniatric results}
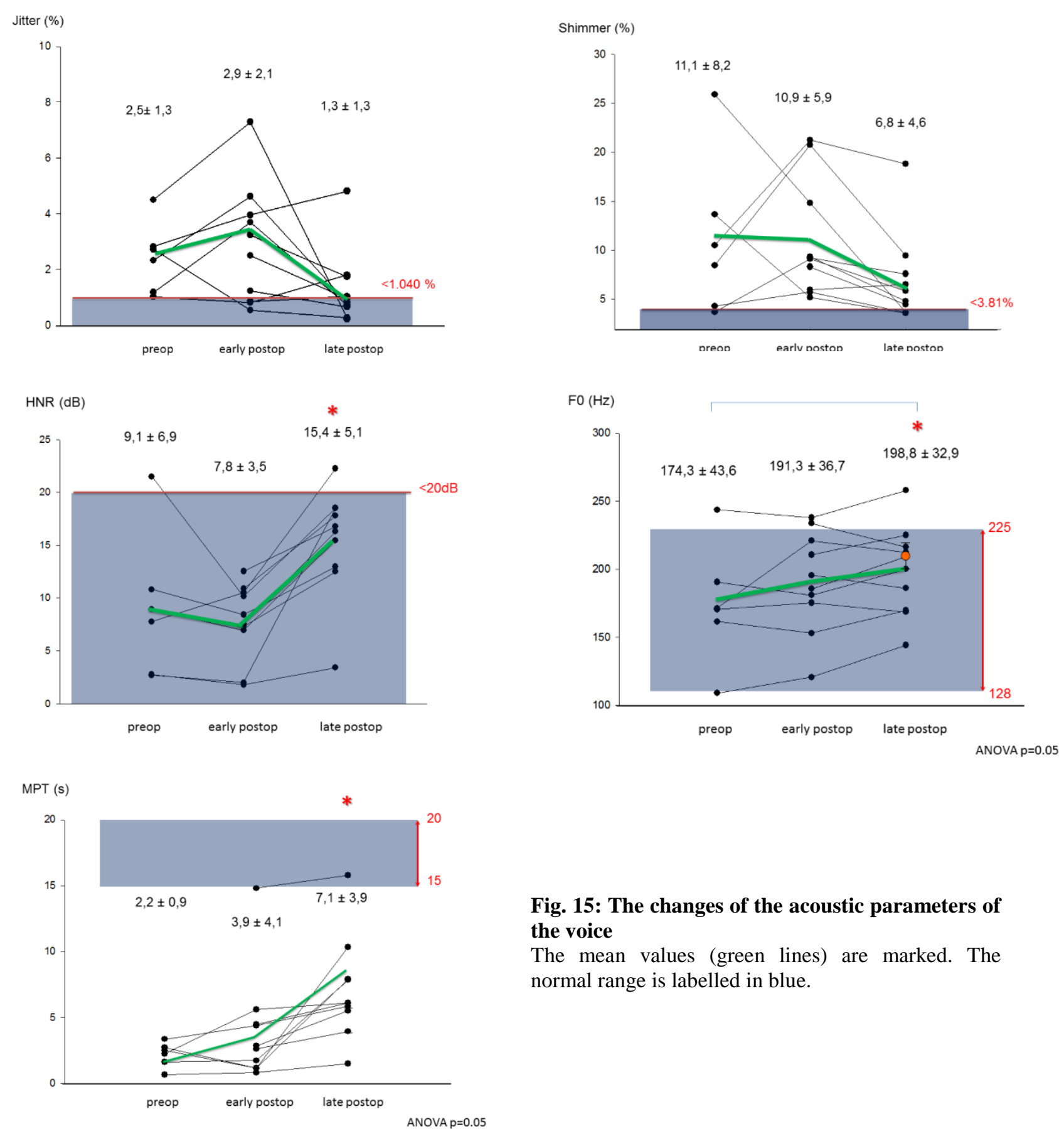

Fig. 15: The changes of the acoustic parameters of the voice The mean values (green lines) are marked. The normal range is labelled in blue. 
Similar to spirometry the phoniatric evaluation could be done only on six patients preoperatively.

After the intervention Jitter and HNR values were wrecked in all cases in the early postoperative period. But the late postoperative values were even better than the preoperative ones. Shimmer and MPT values improved immediately. The pitch frequency $\left(\mathrm{F}_{0}\right)$ increased $\mathrm{HNR}$ and $\mathrm{F}_{0}$ were in the normal range.(Fig. 15).

Subjective questionnaries also presented better voice quality and the satisfaction of patients (Fig. 16). According to their opinion their voice changed from 'severe impairment' to acceptable, almost normal condition.
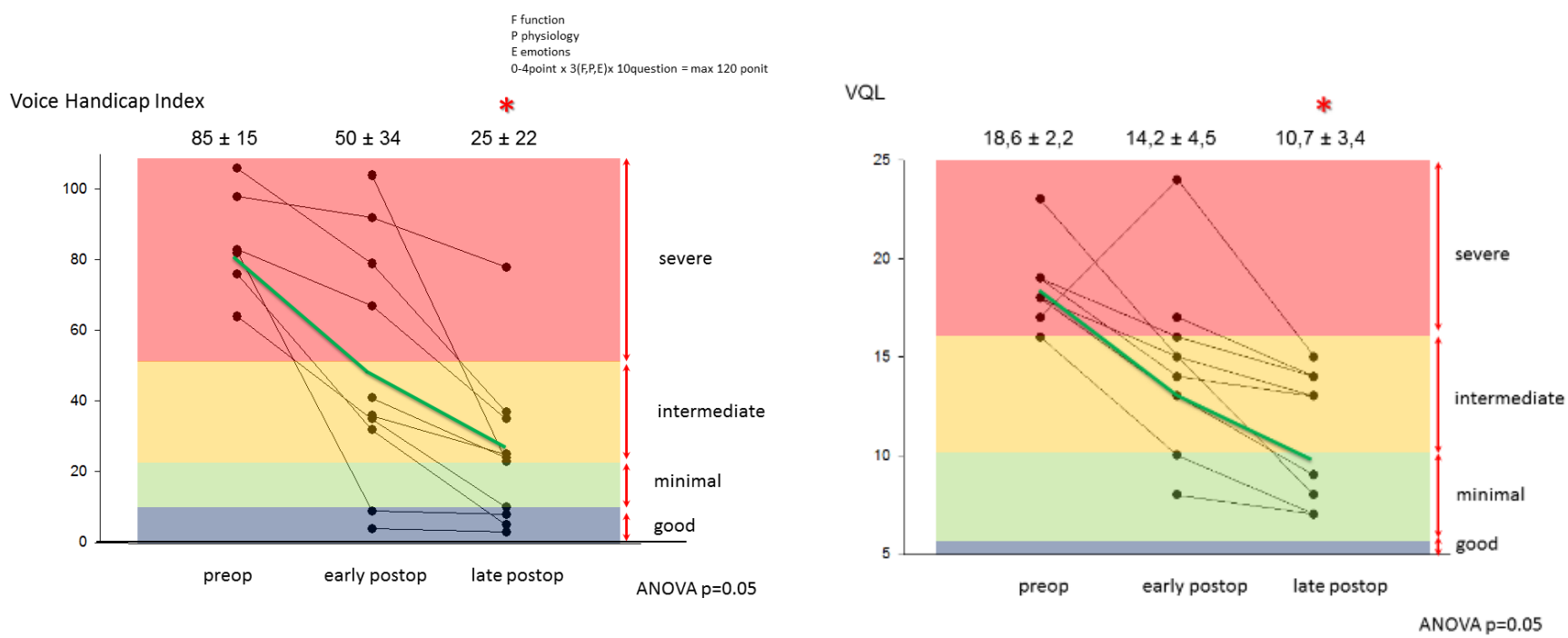

Fig. 16: Subjective phoniatric tests

The mean values (green lines) are marked

\subsection{COMPARISON OF THE RESULTS OF CADAVER AND 'REAL PATIENTS' STUDIES}
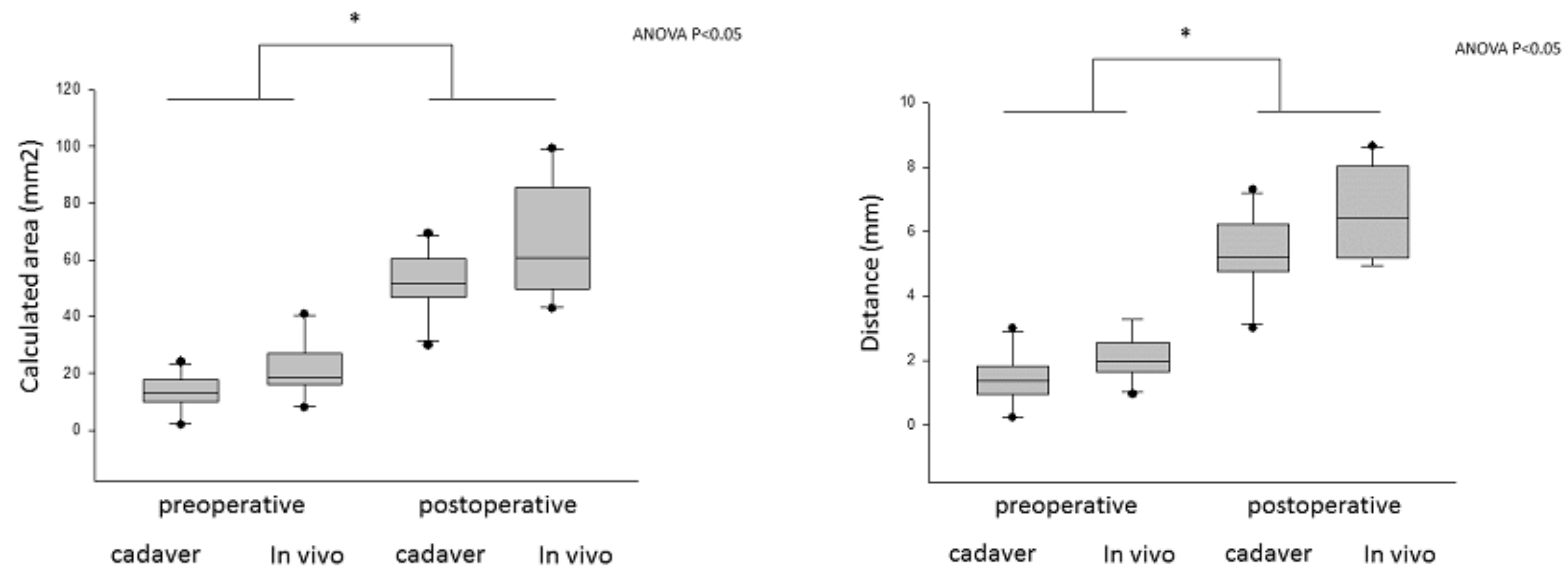


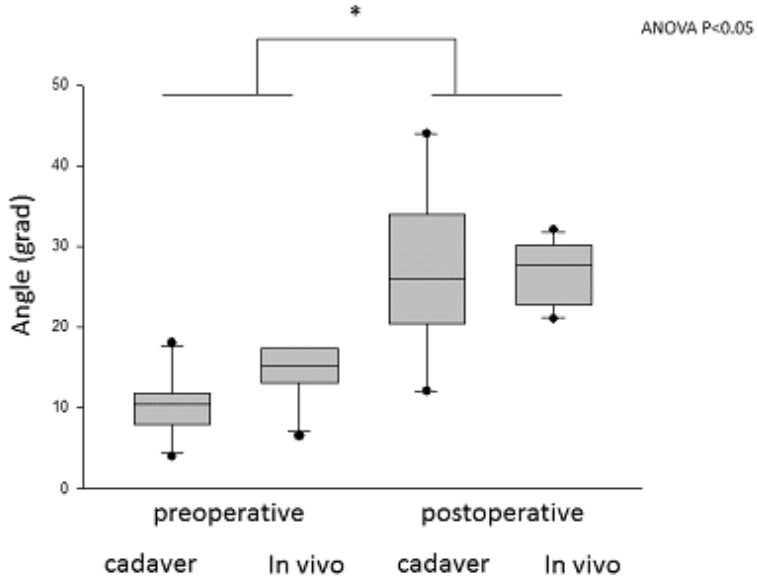

Fig. 17: Comparison of cadaver and real patient study

All of the compared parameters parameters were similar, no significant difference was found between the two groups (Fig. 17). 


\section{DISCUSSION}

\subsection{SURGICAL ANATOMICAL MORPHOMETRIC STUDIES - COMPARISON OF ENDOSCOPIC GLOTTIS ENLARGING TECHNIQUES ON CADAVER LARYNGES}

The measurement of the efficacy of glottis enlarging procedures is a challenging task because several factors influence any evaluation. These include the patients' satisfaction, their occupation, and activity level, etc. The most important factor to the clinician is doubtlessly the patient's breathing and phonation following the interventions.

The ability to surmise the effect of these surgical options on breathing is easier, because it can be described by the change of glottic cross-section area. A difficult, complex morphometric study on shock frozen cadaver larynges compared the resection of the vocal cord and the removal of arytenoid cartilage (14) in this regard. Our study is based on the assessment of the airway effect of these operations determined by a digital image analyzing method, which is more reliable, in our opinion to compare large series of different methods. This has proved that methods using physiologic arytenoid abduction (EAAL; SELP) are likely more effective (15) in improving the airway. Considering the laryngeal anatomy, the cricoid arch is located in a more distal position than the posterior surface of the cricoid lamina, which holds the arytenoid cartilages (39). This means that at the level of the glottis, resection of the vocal cord markedly increases the glottic airway area. However, in the case of arytenoidectomy, only a part of the arytenoid cartilage is located over the cricoid lumen, so only the removal of the protruding part (similar to medial arytenoidectomy) is really effective in airway widening.

Vocal cord lateralization techniques are effective in widening the airway. The insertion of a second lateralizing suture does not add significant benefit, though it may decrease the vocal cord's medialization tendency over time. This is a surgical concept rather than a direct result of this study. Having two sutures pulling the vocal cord over makes it less likely that either will cut into the tissue, the so-called "cheese wire" effect. The main limitation is that the arytenoids effectively remain in the medial position and therefore partially block the airway lumen above the cricoid. The vector of pulling that the sutures generate differs significantly from natural arytenoid abduction. Therefore, the arytenoid rotation that results is negligible. This also offers an explanation as to why the sutures 
intraoperatively tended to slip onto the membranous vocal cord even if placed directly onto the vocal process (Fig. 3B). Surprisingly the above mentioned methods do not result in significant airway area improvement compared to the cadaver position $(\mathrm{CP})$, but it must be accepted that CP is generally more lateral compared to the paramedian position observed after recurrent laryngeal nerve palsy (RLNP). However, in both cases the airway improvement values vary widely and surgery for RLNP is often indicated to improve the airway when it is a bilateral palsy, a life threatening situation. (Fig. 3).

Arytenoid abduction procedures open and fix the larynx simulating the physiological arytenoid abduction, as described by Wang (39). The vocal cord unit including the arytenoid, the vocal process and the vocal cord are not only lateralized but elevated approximately 1-2 mm cranially above the Rima Glottidis (the axial plane of the vocal cord rim). The vocal cord is pulled not only laterally but upward toward the Sinus of Morgagni, while the thyroarytenoid muscle gets passively longer and thinner, parallel with the inner surface of the thyroid cartilage. Thus, by this simple maneuver the whole arytenoid and practically the whole vocal cord are removed from the airway lumen above the cricoid. Therefore, these methods provide not only the largest improvement in the horizontal plane, as could be measured in this study, but this vertical vocal cord repositioning gives an additional enlargement of the airway compared to the other procedures. This result is consistent with the excellent spirometry results in multiple clinical studies $(10,48)$

The estimation of the voice impact of this surgery is more challenging because it is influenced by many passive and active factors. Isshiki described the length, the elasticity, and the mass of the vocal cord as the outcome-determining factors during phonosurgery, which can be justified by physical principles as well $(9,58)$. A paralyzed vocal cord subjected to surgery-related scarring, such as in cordotomy and cordectomy operations, can produce an even more chaotic vibratory pattern which deteriorates the already abnormal voice. Therefore, it is proposed that the preservation of the vocal cord's structural integrity is beneficial for postoperative voice production. These observations are well-known in the phonosurgery literature $(10,27)$. AE, TC, and VCLs are evidently disadvantageous from this perspective (Fig. 5,6). Based on this concept, the vocal cord length and angle change is found to be the smallest after the resection procedures because the anterior vocal cord segment is left in its original position. As the vocal fold heals, the scar might pull it laterally and posteriorly, increasing the angle. This may indicate that these procedures would impact the voice less. However, this is not the case because they more adversely affect the voice secondary to the loss of cord straightness and vibratory substance in contrast to cMAE, SELP, and EAAL. 
These three techniques produce a significantly larger anterior commissure angle and retain a natural vocal cord tension and straightness and therefore may support the voice quality better than the rest even in the case of a completely paralyzed larynx. The VCLs produced the poorest parameters in regard to voice potential. The resulting cord is most curved (of the cord procedures not involving tissue resection) and the vibratory surface is neutralized by the effect of the sutures themselves (particularly VCL-2).

The standard endoscopic procedures designed for static vocal cord paralysis treatment are directed only towards the above-mentioned "passive" factors. The voice is inversely diminished in proportion with the airway improvement. The "active" components, however, which may occur after the recurrent nerve is injured, may effect the postoperative voice positively by maintaining tone or adversely by synkinesis. Anatomic studies prove that the ratio of adduction and abduction fibers in the recurrent nerve is approximately 4:1 (13). This might explain Woodson's observation about a preferential adduction reinnervation after the cut of recurrent nerve in an animal study (60). Publications bring up a possible accessory parallel adduction innervation via the interior branch of superior laryngeal nerve to the interarytenoid muscles $(5,12)$. The 'communicating nerve'(between the superior and inferior laryngeal nerves), which can be identified in $50 \%$ of the population, may also provide a direct innervation to the TA muscle (12).

In clinical practice, adduction reinnervation recovery can also be observed (10). This entity can be detected generally after some months following arytenoid adduction procedures where the above-mentioned neural framework and muscular structures remain largely intact. The abducted position of the lateralized arytenoid cartilage provides not only the best airway improvement but also room for adduction beyond the midline for the contralateral side during phonation. Sine there is a straight and passively tensed vocal cord on the operated side, active adduction with improved closure and phonation can occur this way. The other tested procedures (the TC and the $\mathrm{AE}$ ) leave the arytenoids in their original paralyzed position and intrinsically injure the true cords, and thus cannot benefit from these phenomena.

\subsection{ENDOSCOPIC ARYTENOID ABDUCTION LATEROPEXY - CLINICAL RESULTS}

\subsubsection{Analysis of the postoperative laryngeal configuration - 3D-CT reconstruction}


According to the cadaver morphometric studies endoscopic arytenoid abduction lateropexy proved to be the most effective suture lateralizing procedure. Are these good results reproducible in real patients?

The development of the modern imaging technology provides a great opportunity for non-invasive morphometric measurements $(61,62,63,64,65,66)$. During conventional computer tomography the detector and X-ray tube unit are rotated round the fixed examination table. The modern helical CT enables quicker image processing, because the examination table is moved through the continuous radiation source, thus large number of slices can be made during one breathhold. It is advantageous especially in the diagnosis of the airways, because the artefacts resulting from respiratory movements can be ruled out. The total length of the trachea can be scanned within $30-50 \mathrm{sec} .(67,68,69,70,71)$. The advanced multislice CT system is aquipped with multiple parallel detectors to obtain even thinner slices (70). The high resolution and the less than $1 \mathrm{~mm}$ thickness of slices make precise analysis of even small organs possible $(68,71)$. For the correct marking out the maximal deviation of the vocal process the labelling of the arytenoid cartilage is required. The density of the arytenoid cartilages and neighboring soft tissues are almost the same or equal. According to Bakhshaee et al the acceptable arytenoid reconstruction needs plenty of postcorrections and very high definition CT scans, 0.6-1 mm slice thickness (72).

The evaluation of the airways in early childhood is a great challenge. Yunus applied helical computed tomography 2-D and 3-D images, and virtual endoscopy in the evaluation of airway disease in neonates, infants and children. The accuracy of virtual endoscopy and 3D reconstruction was $98 \%$, the classic 2D helical $\mathrm{Ct}$ imaging provided $86 \%$. He concluded that these methods could replace conventional endoscopy in the assessment of airway disease without any additional risk. Burke found that this method was suitable for analysing fixed airway lesions, but it seemed to be less useful in case of dynamic, functional stenoses (61).

Unfortunately, according to our experiences feasible high resolution CT imaging is not generally available in our country. It was really hard to find even ten appropriate quality CT scans for optimal three-dimensional processing.

For the assessment postoperative CT scans were applied. The images were feasible for the reconstruction of the glottic airway because of the high difference in density of laryngeal tissues and air; glottic air shadow could be easily labelled in Hounsfield Unit $(62,64,67)$. By choosing the appropriate range of density the three-dimensional model of the airway could be visualised. The airway could be figured in real size from every different views, so precise 
morphometric measurements were possible. All the parameters we applied in surgical anatomical cadaver study could be analyzed also in real patients.

\subsubsection{Evaluation of spirometric results}

The lung function tests have become an indispensable tool for the clinical evaluation of respiratory health and disease since the 1970s. It plays an essential role in the diagnosis and management of respiratory diseases, especially asthma and chronic obstructive pulmonary disease (COPD) $(17,57)$.

Spirometry may be applied also in cases of glottic and subglotto-tracheal stenoses, in which the cross-section diameter of the larynx and/or trachea is decreased leading to inspiratory dyspnea. Kashima (73) and Cantarella (74) proved that inspiratory flows were significantly reduced, whereas with the exception of PEF, the expiratory flows were in the normal range.

Dursun (75) found FEV1, FEV1/FVC and PEF values significantly reduced. According to Vössing (76) Peak expiratory flow was the most sensitive parameter, it reacted earlier than did peak inspiratory flow and seemed to be the most reliable parameter for detecting an extrathoracic stenosis.

In our previous work the changes of the spirometric indices were analyzed in different grades of artificial stenoses (23). They did not change too much if $25 \%$ or $50 \%$ airway stenosis was applied. But the $75 \%$ stenosis significantly decreased the values. PIF and PEF were found to be the most sensitive; their values decreased about $50 \%$. Peak inspiratory flow (PIF) was found to be the most reliable.

This simple spirometric test can be easily performed before and after the operation, it is useful for monitoring the resistance of the upper airways. In our patients an immediate significant PIF value improvement was detected after the procedure and the late results were often even better. This could be explained by the diminishing of the postoperative laryngeal edema and the advanced overall physical condition of patients.

\subsubsection{Evaluation of the phoniatric results}

The pathophysiology of the vocal cord paralysis is not completely understood despite the numerous meticulous animal and human studies $(13,74)$. According to the literature the 
intraoperative stretching, thermal damage are the main causes of laryngeal function degeneration during thyroid surgery $(1,49)$. Later some kind of reinnervation can often be observed, which generally ranges from the complete or almost complete recovery of the vocal cords to poorer outcomes with different types of synkinesises or total complete permanent paralyses at worst (13).

In his thesis Smehák (22) analyzed the postoperative voice of groups of patients with different degree of regeneration. In cases of complete or almost complete regeneration the voice became normal, but, in case of total permanent paralysis it was much worse. $(24,46,75$, 77)

Although in the literature the transverse cordotomy is considered to be one of the most voice preserving intervention (78), significant postoperative voice deterioration can be expected compared to the normal voicing. According to Harnisch et al (46) and Dursun et al (75) the early postoperative phoniatric outcomes are deteriorated, but they become later better, but the parameters do not reach the normal range. Our EAAL results were almost similar, the 'aperiodicity' values (Jitter, Shimmer) were a bit better. According to our opinion this proved that EAAL provided tensed and straightened vocal cords and despite their more lateral position a more favorable situation for phonation can be ensured than the preoperative medial, but flaccid condition.

In our study Standard Voice Panel suggested by Smehák (22) was a useful tool for the evaluation of our patients' overall voice quality. However the examined patients could have been divided into the non-regeneration group, their postoperative voice became better, socially acceptable.

\subsection{COMPARISON OF THE RESULTS OF CADAVER AND 'REAL PATIENTS' STUDIES}

The cadaver morphometric studies unambiguously proved that the most beneficial glottic configuration could be created by EAAL.

The 'real patients' study showed that in most cases the same results could be achieved as well. In some cases the postoperative endoscopy or imaging revealed that the suture loop was not placed perfectly round the vocal process, it slipped into a less favorable position, to the free edge of the the vocal cord (2/10 patients). 
According to our opinion there are two 'key factors' which could improve the efficacy. First, it is really important for the surgeon during his 'learning curve' to perform this procedure on several cadaver larynges to understand the main concept of the method. Second, the precise suture positioning is really important. In further studies the size and shape of ETGI device has been optimalized to different anatomical conditions; special infant, male and female thread guide instruments have been designed (11) (Fig. 1). The more precise intralaryngeal maneuverability of the device may make more precise suture insertion possible, which might improve the postoperative results. 


\section{CONCLUSIONS AND NEW RESULTS}

\subsection{SURGICAL ANATOMICAL MORPHOMETRIC STUDIES - COMPARISON OF ENDOSCOPIC GLOTTIS ENLARGING TECHNIQUES ON CADAVER LARYNGES}

This study demonstrates that the factors that impact the quality of life, such as voice potential and breathing comfort; fundamentally depend on the chosen method to treat the airway deficit. The outcome also depends on the post-surgical healing from the paralytic process, the multiple surgical modifications; something a cadaver study cannot address. While the TC and MAE may be technically easier and might provide acceptable voice results, it only produces a moderate airway improvement compared to those procedures, which utilize the physiological abduction of the arytenoid cartilage. The voice after SELP and EAAL would be worse in a complete BVCP; but if adduction recovery occurs, the voice might improve. Consistent with this the absence of the destructive basis to these procedures their application is considerable in potentially reversible BVCI-s as well.

\subsection{ENDOSCOPIC ARYTENOID ABDUCTION LATEROPEXY - CLINICAL RESULTS}

Analysis of postoperative high resolution CT scans proved the efficacy of EAAL, significant glottic area impovement was found.

Spirometry, objective and subjective phoniatric tests showed an improved postoperative condition as well. The postoperative voice became acceptable, the physical endurance improved, which meant that both main functions of the larynx, breathing and phonation could be preserved. The patients became satisfied with their condition.

\subsection{COMPARISON OF THE RESULTS OF CADAVER AND 'REAL PATIENTS' STUDIES}

Although the number of participants was too low for a precise statistical evaluation, all examined parameters of the cadaver and the 'real patients' studies were similar, showed high level of parity. 
EAAL provided as favorable results in 'real patients' as on cadaver larynges. With the newly designed ETGI device the same precise suture positioning can be achieved in vivo, in real patients as on cadaver larynges. 


\section{ACKNOWLEDGEMENTS}

I would never have been able to complete this work without help, support, and encouragement from several persons.

First of all, I would like to express my gratitude and thanks to my supervisor, Professor László Rovó for encouraging and supporting my scientific career.

I wish to express my gratitude to Professor Jenő Czigner and Professor Jóri József, the former Heads of Department of Oto-Rhino-Laryngology, Head and Neck Surgery who introduced me to clinical work.

I would like to express my gratitude to Professor Béla Iványi, Head of Department of Pathology for providing me the opportunity to perform the cadaver morphomeric study.

I am deeply indepted to my collegues, the members of our upper airway stenosis workgroup, especially to Dr. László Rovó, Dr. György Smehák, Dr. Balázs Sztanó and Dr. Zsófia Bere for their cooperative work.

Thanks to my colleagues at the Department of Oto-Rhino-Laryngology, Head and Neck Surgery.

Last but not least, I wish to thank my family and friends for their constant support and encouragement. 


\section{REFERENCES}

I. Szakács L, Sztanó B, Matievics V, Bere Z, Bach A, Castellanos PF, Rovó L.

A comparison between transoral glottis-widening techniques for bilateral vocal fold immobility.

Laryngoscope. 2015 Jun 8. [Epub ahead of print]

II. Sztanó B, Szakács L, Madani S, Tóth F, Bere Z, Castellanos PF, Rovó L

Comparison of endoscopic techniques designed for posterior glottic stenosis--a cadaver morphometric study.

Laryngoscope. 2014;124(3):705-10

III. Matievics Vera, Szakács László, Sztanó Balázs, Szamosközi Alice, Rovó László Arytenoid lateropexy in unilateral vocal cord palsy patients with effort dyspnoea 11th EFAS Congress, Budapest

IV. Szakács L., Sztanó B., Madani S., Rovó L.

Objective comparison of different glottis widening procedures- 3D radiological and cadaver morphometric study

3rd Congress of European ORL-HNS, Praha

1) Rosenthal LH, Benninger MS, Deeb RH. Vocal fold immobility: a longitudinal analysis of etiology over 20 years. Laryngoscope. 2007;117(10):1864-1870.

2) Gould WJ, Sataloff RT, Spiegel JR. Voice Surgery. St Louis, Mosby-Year Book; 1993.

3) Sapundzhiev N, Lichtenberger G, Eckel HE, et al. Surgery of adult bilateral vocal fold paralysis in adduction: history and trends. Eur Arch Otorhinolaryngol. 2008;265(12):1501-1514.

4) Lichtenberger G. Open and endoscopic surgical techniques for the treatment of scarred laryngeal stenosis. Operative techniques in otolaryngology-head and neck surgery. 1998; 9(3):150-153. 
5) Zalzal GH, Posterior glottic fixation in children. Ann Otol Rhinol Laryngol. 1993;102(9):680-686.

6) Sittel C, Stennert E, Thumfart WF, Dapunt U, Eckel HE. Prognostic value of laryngeal electromyography in vocal fold paralysis. Arch Otolaryngol Head Neck Surg. 2001;127(2):155-160.

7) Sellars I, Sellars S. Cricoarytenoid joint structure and function The Journal of Laryngology and Otology 1983;97:1027-34

8) Woodson GE. Configuration of the glottis in laryngeal paralysis I: Clinical study Laryngoscope 1993;103:1227-34

9) Isshiki N. Progress in laryngeal framework surgery.Acta Otolaryngol 2000;120:120-7

10) Woodson G. Arytenoid abduction for bilateral vocal cord paralysis.Operative Techniques in Otolaryngology 2012;23:178-82

11)Rovó L, Madani S, Sztanó B, Majoros V, Smehák G, Szakács L, Jóri J. A new thread guide instrument for endoscopic arytenoid lateropexy.Laryngoscope 2010;120:2002-7

12) Sanders I, Mu L. Anatomy of the human internal superior laryngeal nerve Anat Rec $1998 ; 252: 646-56$

13) Crumley RL. Laryngeal synkinesis revisited Ann Otol Rhinol Laryngol. 2000;109:36571.

14)Eckel HE, Sittel C. Morphometric studies at the level of the glottis as a principle in larynx enlarging microlaryngoscopic surgical procedures in bilateral recurrent nerve paralysis Laryngorhinootologie 1994;73:417-22 
15) Sztanó B, Szakács L, Madani S, Tóth F, Bere Z, Castellanos PF, Rovó L. Comparison of endoscopic techniques designed for posterior glottic stenosis-A cadaver morphometric study Laryngoscope 2014;124:705-10

16) Jóri J, Rovó L, Czigner J. Endolaryngeal laterofixation versus tracheostomy for treatment of acute bilateral vocal cord paralyses. Magyar Sebészet. 1997;50:227-229.

17) Jóri J, Rovó L, Czigner J. Vocal cord laterofixation as early treatment for acute bilateral abductor paralysis after thyroid surgery. Eur Arch Otorhinolaryngol. 1998;255:375-378.

18) Rovó L, Jóri J, Brzózka M, Czigner J: Minimally invasive surgery for posterior glottic stenosis. Otolaryngology-Head and Neck Surgery,1999; 121,153-156.

19) Rovó L, Jóri J, Brzózka M, Czigner J: Airway complication after thyroid surgery: Minimally invasive management of bilateral recurrent nerve injury. Laryngoscope. 2000;110:140-144.

20) Rovó L, Jóri J, Iván L, Brzózka M, Czigner J."Early" vocal cord laterofixation for the treatment of bilateral vocal cord immobility.Eur Arch Otorhinolaryngol. 2001; 258(10):509-13.

21) Rovó L, Venczel K, Torkos A, Majoros V, Sztano B, Jori J. Endoscopic arytenoid lateropexy for isolated posterior glottic stenosis. Laryngoscope. 2008;118(9):15501555.

22)Smehák G. Complex voice measurement panel for the assessment of the functional evaluation of the laryngeal surgical interventions. PhD Thesis, Szeged 2010

23) Sztanó B. Morphometric studies and a complex airway evaluation panel for objective and reliable assessment of laryngo-tracheal stenosis surgery Ph.d. Thesis Szeged 2012

24)Rovó L, Smehák Gy, Tóth L, Szamosközi A, Tóth F, Kiss J. G, Czigner J. Jóri J, A kétoldali hangszalagbénulás "korai” szakában végzett hangréstágító mütét 
következtében létrejövő elváltozások reverzibilitásának vizsgálata laryngostroboszkópiával és objektív hangelemzéssel. Fül-, orr-, gégegyógyászat 2005; 51: $85-92$

25) Rabe KF, Hurd S, Anzueto A, et al: Global strategy for the diagnosis, management, and prevention of chronic obstructive pulmonary disease: GOLD executive summary. Am J Respir Crit Care Med. 2007; 176: 532-55.

26) JacobsonBH., Johnson A, Grywalski C, Silbergleit A, Jacobson G, . Benninger MS, Newman CW The Voice Handicap Index (VHI)Development and ValidationAmerican Journal of Speech-Language Pathology, 1997, Vol. 6, 66-70

27)Vining DJ1, Liu K, Choplin RH, Haponik EF. Virtual bronchoscopy. Relationships of virtual reality endobronchial simulations to actual bronchoscopic findings. Chest. 1996;109(2):549-53.

28) Schobel H Glottiserweiterung bei beidseitiger Stimmlippenlaehmung. HNO1986; $34: 485-495$

29)Piersol G. Human Anatomy. London: Lippincott; 1907:1816.

30)Rethi A. Die operative Lösung der bei der beiderseitigen Postikuslähmung bestehenden Medianlage. Mschr Ohr Laryngorhinol. 1922; 56:200-204.

31)King B. A new and function-restoring operation for bilateral abductor paralysis. JAMA 1939; 112:814-823.

32) Woodman DA, modification of the extralaryngeal approach to arytenoidectomy for bilateral abductor paralysis. Arch Otolaryngol Head Neck Surg. 1946; 43:63-65

33)Newman MH, Work WP. Arytenoidectomy revisited.Laryngoscope. 1976; 86:840849. 
34)Pytel J, Péter J, Pytel Á. King-Schobel szerinti hangrétágító mütét a POTE Fül-OrrGégeklinika anyagában. Fül-Orr-gégegyógy.1997;3:150-161.

35)Woodson G, Weiss T, Arytenoid abduction for dynamic rehabilitation of bilateral laryngeal paralysis.Ann Otol Rhinol Laryngol. 2007;116(7):483-90.

36) Cancura von W, Eine neue Methode der Laterofixation. Mschr Ohr Laryngorhingol . 1969; 103:264-271.

37) Kirchner FR. Endoscopic lateralization of the vocal cordin abductor paralysis of the larynx. Laryngoscope 1979; 89:1779-1783.

38)Ejnell H, Mansson I, Hallen O, Bake B, Stenborg R, Lindström J. A simple operation for bilateral vocal cord paralysis. Laryngoscope. 1984; 94:954-958.

39) Geterud A, Ejnell H, Stenborg R, Bake B. Long-term results with a simple surgical treatment of bilateral vocal cordparalysis. Laryngoscope . 1990 100:1005-1008.

40)Lichtenberger G, Endo-extralaryngeal needle carrier instrument. Laryngoscope 1983; 93:1348-1350.

41)Hyodo M, Nishikubo K, Motoyoshi K. Laterofixation of the vocal fold using an endoextralaryngeal needle carrier for bilateral vocal fold paralysis.Auris Nasus Larynx. 2009; 36(2):181-6.

42)Lichtenberger G, Toohill RJ. Endo-extralaryngeal suture technique for endoscopic lateralization of paralyzed vocal cord. Operative techniques in otolaryngology-head and neck surgery. 1998; 9 No3 166-161.

43)Kull C, Breu M, Hoffmann M, Rittmann WW, Paralysis of the recurrent laryngeal nerve following strumectomy in late follow-up. Helv Chir Acta 1989; 55:545-548

44) Wang RC. Three-dimensional analysis of cricoarytenoid joint motion. Laryngoscope. 1998;108(4 Pt 2 Suppl 86):1-17. 
45)Zealear DL, Hamdan AL, Rainey CL, Effects of denervation on posterior cricoarytenoid muscle physiology and histochemistry. Ann Otol Rhinol Laryngol, $1994 ; 103: 780-788$

46) Harnisch W, Brosch S, Schmidt M, Hagen R, Breathing and voice quality after surgical treatment for bilateral vocal cord paralysis.Arch Otolaryngol Head Neck Surg. 2008;134(3):278-84.

47)Ejnell H, Tisell LE. Acute temporary laterofixation for treatment of bilateral vocal cord paralyses after surgery for advanced thyroid carcinoma. World J Surg. $1993 ; 17(2): 277-281$.

48)Lichtenberger G Reversible immediate and defintive lateralization of paralyzed vocal cords. Eur Arch Otorhinolaryngol. 1999; 256:407-411

49) Werner JA, Lippert BM, Laterofixation der Stimmlippe stat Tracheotomie bei akuter beidseitiger Stimmlippenparese. Dtsch Med Wochenschr. 2002; 127:917-922

50) Tucker HM The larynx. Thieme Medical Publisher, New York. 1987.

51) Crumley RL. Endoscopic laser medial arytenoidectomy for airway management in bilateral laryngeal paralysis. Ann Otol Rhinol Laryngol. 1993 Feb;102(2):81-84.

52) Negus VE. The Comparative Anatomy and Physiology of the Larynx. Heinemann 1949

53) Neuman TR. Hengesteg A, Kaufman KR, et al. Three-dimensional motion of the arytenoid adduction procedure in cadaver larynges. Ann Otol Rhinol Laryngol. 1994;103:265-70.

54) Von Leden H, Moore P. The mechanics of the cricoarytenoid joint. Arch Otolaryngol.1961;73:541-550. 
55)Lichtenberger G. Reversible lateralization of the paralyzed vocal cord without tracheostomy Ann Otol Rhinol Laryngol 2002;111:21-6

56) Schobel H. Dilatation of the glottis in bilateral vocal cord paralysis. Review of various surgical procedures and a report of personal experience using a functional lateral fixation surgical technic $H N O$ 1986;34:485-95

57)Dennis DP, Kashima H. Carbon dioxide laser posterior cordectomy for treatment of bilateral vocal cord paralysis Ann Otol Rhinol Laryngol 1989;98:930-4

58) Ossoff RH, Sisson GA, Duncavage JA, Moselle HI, Andrews PE, McMillan WG. Endoscopic laser arytenoidectomy for the treatment of bilateral vocal cord paralysis Laryngoscope 1984;94:1293-7

59)Liang BM, Lam DCL, Feng YL: Clinical applications of lung function tests: a revisit. Respirology 2012

60)Landau LD, Lifshitz EM. Theory of Elasticity Pergamon Press 1986

61)Burke AJ, Vining DJ, McGuirt WF Jr, Postma G, Browne JD Evaluation of airway obstruction using virtual endoscopy. Laryngoscope. 2000;110(1):23-9.

62) Yunus M, Helical CT scan with 2D and 3D reconstructions and virtual endoscopy versus conventional endoscopy in the assessment of airway disease in neonates, infants and children. J Pak Med Assoc. 2012;62(11):1154-60.

63)Erdélyi Miklós. Árnyékfejtés - a számítógépes tomográfia mint a modern orvostudomány eszköze. Fizikai Szemle 2005; 60:7. 225-8

64)Faigel Gy. Orvosi képalkotó eljárások I. Fizikai Szemle 2005; 50. 83.

65) Faigel Gy. Orvosi képalkotó eljárások II. Fizikai Szemle 2005; 50. 260. 
66) Gallivan RP1, Nguyen TH, Armstrong WB Head and neck computed tomography virtual endoscopy: evaluation of a new imaging technique. Laryngoscope. 1999;109(10):1570-9.

67)König A. H. Gröller E. 3D Medical Visualization: Breaking the Limits of Diagnostics and Treatment ERCIM New.s 2001; (44) 27-8

68) Nain D.. An Interactive Virtual Endoscopy Tool with Automatic Path Generation. Master's thesis, MIT AI Lab, 2002.

69) Silverman PM, Zeiberg AS, Sessions RB, Troost TR, Zeman RK.

70) Three-dimensional imaging of the hypopharynx and larynx by means of helical (spiral) computed tomography. Comparison of radiological and otolaryngological evaluation. Ann Otol Rhinol Laryngol. 1995;104(6):425-31.

71) Toyota K1, Uchida H, Ozasa H, Motooka A, Sakura S, Saito Y. Preoperative airway evaluation using multi-slice three-dimensional computed tomography for a patient with severe tracheal stenosis. Br J Anaesth. 2004;93(6):865-7.

72)Triglia JM, Nazarian B, Sudre-Levillain I, Marciano S, Moulin G, Giovanni A. Virtual laryngotracheal endoscopy based on geometric surface modeling using spiral computed tomography data. Ann Otol Rhinol Laryngol. 2002;111(1):36-43.

73) Bakhshaee H, Moro C, Kost K, Mongeau L. Three-dimensional reconstruction of human vocal folds and standard laryngeal cartilages using computed tomography scan data. $J$ Voice. 2013;27(6):769-77

74) Kashima HK: Documentation of upper airway obstruction in unilateral vocal cord paralysis: flow-volume loop studies in 43 subjects. Laryngoscope 1984; 94:923-37

75)Cantarella G, Fasano V, Bucchioni E, Domenichini E, Cesana BM: Spirometric and plethysmographic assessment of upper airway obstruction in laryngeal hemiplegia.Ann Otol Rhinol Laryngol. 2003;112(12):1014-20. 
76)Dursun G, Gokcan MK. Aerodynamic, acoustic and functional results of posterior transverse laser cordotomy for bilateral abductor vocal fold paralysis. J Laryngol Otol. 2006;120(4):282-288.

77) Vössing $M^{1}$, Wassermann K, Eckel HE, Ebeling O Peak flow measurement in patients with laryngeal and tracheal stenoses. A simple and valuable spirometric method. HNO. 1995;43(2):70-5

78)Pruszewicz M, Szmeja Z, Pruszewicz A, Pospiech I. Voice and spirometric examinations in patients after laser arytenoidectomy. Otolaryngol Pol. 1995;49(1):2326.

79)Kashima HK. Bilateral vocal fold motion impairment: pathophysiology and management by transverse cordotomy. Ann Otol Rhinol Laryngol. 1991;100(9 Pt 1):717-721 


\section{APPENDIX}

\section{VHI Kérdőív Dátum:}

Név:

Foglalkozás:

Diagnózis:

10.1.1. Jelölje meg azt a választ, amely megmutatja, milyen gyakran fordulnak elő a következő állítások Önnel!

Válaszok: 0 = soha, 1 = ritkán, $2=$ néha, $3=$ gyakran, 4 = mindig

F1 A hangomat nehezen hallják meg mások.

P2 Ha beszélek, kifulladok.

F3Az embereknek nehéz megérteni engem egy hangos teremben.

P4 A hangszínem változik a nap folyamán.

F5 A családomnak nehézséget okoz meghallani, ha a házban/ lakásban hívom őket.

F6 Kevesebbszer használom a telefont, mint szeretném.

E7 Feszült leszek a hangom miatt, ha másokkal beszélek.

F8 A hangom miatt hajlamos vagyok arra, hogy a nagyobb

$$
\text { társaságokat elkerüljem }
$$

E9 Az emberek felfigyelnek a hangomra, mert zavaró.

P10 Az emberek megkérdezik: „Mi történt a hangoddal?”

F11 A hangom miatt ritkábban beszélek barátokkal, szomszédokkal, rokonokkal. 
F12 Az emberek megkérnek, hogy ismételjem meg azt, amit mondtam.

P13 A hangom érdes és fakó.

P14 Úgy érzem, meg kell erőltetnem magam, ha a hangomat használom.

E15 Úgy érzem, mások nem értik meg a problémámat a hangommal.

F16 A nehézségeim a hangommal korlátoznak a magán, és üzleti életben.

P17 A hangom érthetősége kiszámíthatatlan.

P18 Megpróbálom a hangom megváltoztatni, hogy másképpen csengjen.

E28 Zavarba jövök, ha megkérnek, hogy ismételjem meg, amit mondtam.0 1234

E29 A hangom miatt úgy érzem, tehetetlen vagyok. 
VQL kérdőív

\section{- Nehézlégzés}

1. nincs

2. nehéz munkavégzés esetén

3.enyhe fizikai megeröltetés esetén

4. nyugalomban

5. tracheotomia

- Hangos légzés

1. nincs

2. nehéz munkavégzés esetén

3.enyhe fizikai megeröltetés esetén

4. nyugalomban

5. tracheotomia

\section{- Köhögés}
1. nincs köhögés
2. enyhe köhögés
3. erős köhögés
4. tracheotomia

- Hangképzési panasz

1.normális

2.kis fokú beszédzavar

3.Súlyos beszédzavar

4.Aphonia

- Nyelési panasz

1.normális

2.kisebb nehézségek, időnként félrenyelés

3.súlyos nyelészavar

- Elégedettség az állapottal

1.teljesen elégedett

2.nagyrészt elégedett

3.Kissé elégedetlen

4.elégedetlen 
I. 


\title{
A Comparison Between Transoral Glottis-Widening Techniques for Bilateral Vocal Fold Immobility
}

\author{
László Szakács, MD; Balázs Sztanó, MD, PhD; Vera Matievics, MD; Zsófia Bere, MD; Adam Bach, MD; \\ Paul F. Castellanos, MD, FCCP; László Rovó, MD, PhD
}

\begin{abstract}
Objective: Comparison of different endoscopic glottis-widening procedures designed for bilateral vocal cord immobility (BVCI) is a challenge. This is because a statistically efficient analysis and comparable clinical series is hard to obtain considering the variable aspects of the results and the evaluation methods. This study of a large number of cadaver larynges provides comparable, objective data for the evaluation of the possible postoperative breathing and voicing function.

Study Design: A morphometric study was performed on 50 male and 50 female larynges to compare the different suture lateralization and resection procedures.

Methods: The postoperative characteristic of glottic configuration was evaluated following vocal cord laterofixation, endolaryngeal arytenoid abduction lateropexy (EAAL), Schobel's external lateralization procedure (SELP), transverse cordotomy (TC), and medial and total arytenoidectomies (AE). The glottic area and the parameters determining the phoniatric outcomes were assessed by a digital image analyzer program.

Results: Improvement of glottic area was observed after all procedures, but arytenoid abduction procedures were significantly the most effective. However, the smallest vocal cord angles were found in TC and AE; the injury of the voicing structures results in a deterioration of vocal mechanics and can be reasonably assumed to negatively influence the voice. Endolaryngeal arytenoid abduction lateropexy and SELP may provide the best phonation closure when residual adduction regeneration can occur.

Conclusion: This study demonstrates the complexity of the correct surgical decision making in BVCI. Procedures that utilize physiological abduction of the arytenoid cartilage seem to be more advantageous, especially if recovery of adductor function occurs.

Key Words: Arytenoid abduction lateropexy, arytenoidectomy, endoscopic laryngeal microsurgery, glottis-enlarging procedures, vocal cord paralysis, vocal cord suture lateralization, transverse cordotomy, bilateral vocal cord motion impairment, bilateral vocal cord immobility.

Level of Evidence: N/A.
\end{abstract}

Laryngoscope, 00:000-000, 2015

\section{INTRODUCTION}

The treatment of bilateral vocal cord immobility (BVCI) is a great surgical challenge to find the ideal balance between breathing and voicing. ${ }^{1}$ Since the mid20th century, there have been surgical innovations from the tracheostomy, once done purely by open techniques, to the common use of minimally invasive endoscopic techniques. $^{2,3}$ Recently, there have been experimental trials to reanimate the neurologically impaired larynx by reinnervation procedures ${ }^{4,5}$ or laryngeal pacing. ${ }^{6}$ Additionally, endoscopic glottic aperture-enlarging procedures can also be the basis for the treatment of BVCI. The sur-

From the Department of Otorhinolaryngology-Head and Neck Surgery (L.S., B.S., V.M., Z.B., A.B., L.R.), University of Szeged, Hungary; and the Department of Surgery, Division of Otolaryngology-Head and Neck Surgery (P.F.c.), University of Alabama at Birmingham, Birmingham, Alabama, U.S.A.

Editor's Note: This Manuscript was accepted for publication May $1,2015$.

The authors have no funding, financial relationships, or conflicts of interest to disclose.

Send correspondence to Dr. László Szakács, 111. Tisza L. krt, Szeged, H-6725, Hungary. E-mail: sztano.balazs@med.u-szeged.hu

DOI: 10.1002/lary.25401 gical choice should depend on the patient's overall health and the personal voicing needs because the airway achieved is considered inversely proportional to the postoperative voice. The efficacy of different glottis-enlarging techniques cannot easily be compared clinically. Generally, only one procedure can be performed on one patient, and considering the variable anatomical factors ${ }^{7}$ and evaluation methods, clinical case series are often statistically insufficient. This results in difficulties in the creation of proper study groups for the metaanalysis.

An easier objective comparison would be possible by assessing the effectiveness of different endoscopic procedures, each being performed on the same cadaver larynx. The glottic area achieved is proportional with the breathing improvement, but voicing effects are a more complex question. One of the most predictive factors is the postoperative angle of the vocal cords at the anterior commissure. ${ }^{8}$ Conversely, Isshiki described the importance of the integrity, tension, and mass in paralyzed vocal cord dynamics during phonosurgery. ${ }^{9}$ Additionally, studies in the last decades have revealed that vocal cord paralysis is not a static condition. Possible residual motion $^{10,11}$ due to additional or residual innervation, ${ }^{12}$ 


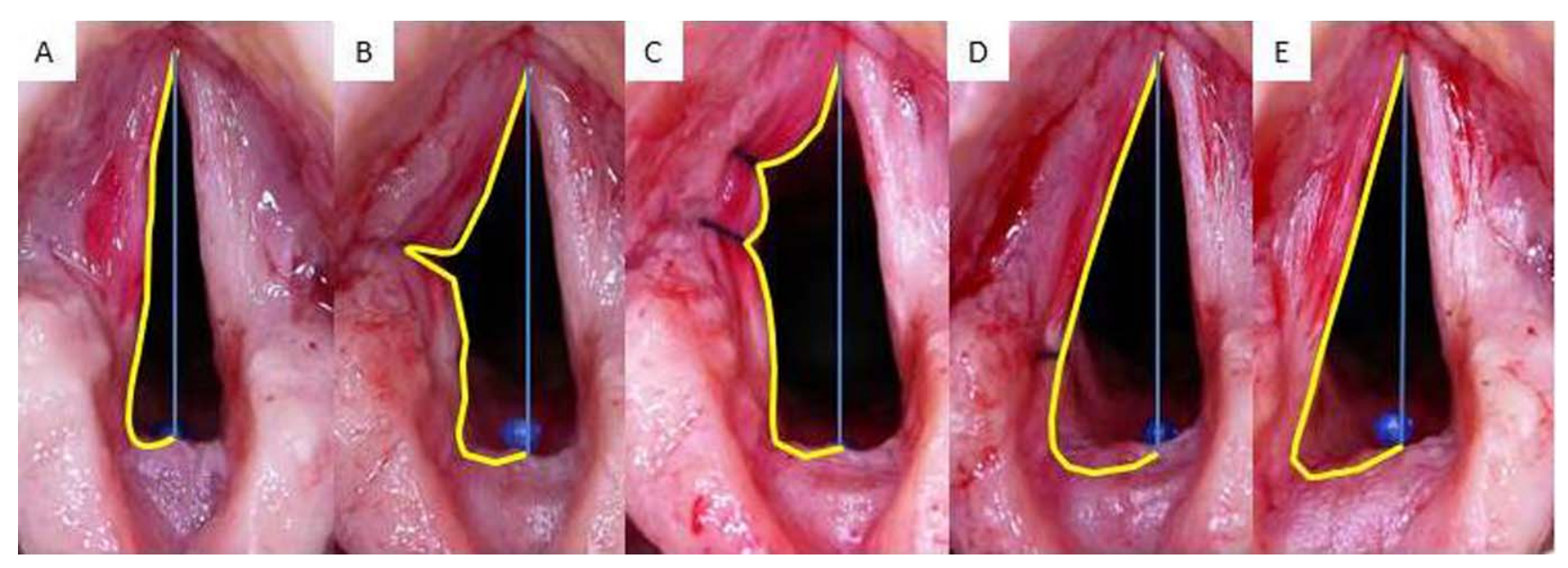

Fig. 1. Four different suture lateralizing techniques performed on the left side of the same cadaver larynx (larynx no. 19, male, 67 years of age). The analyzed half of the glottic gap is labeled. (A) CP = cadaver position $\left(38,78 \mathrm{~mm}^{2}\right)$; (B) VCL-1 suture $\left(78,60 \mathrm{~mm}^{2}\right)$; $(\mathrm{C}) \mathrm{VCL}-2$ sutures $\left(76,33 \mathrm{~mm}^{2}\right)$; (D) EAAL $\left(132,18 \mathrm{~mm}^{2}\right)$; (E) SELP $\left(113,50 \mathrm{~mm}^{2}\right)$.

$\mathrm{CP}=$ cadaveric position; $\mathrm{EAAL}=$ endoscopic arytenoid abduction lateropexy; SELP $=$ Schobel's external lateralization procedure; VCL1 = vocal cord laterofixation 1 ; VCL-2 = vocal cord laterofixation 2 . [Color figure can be viewed in the online issue, which is available at www.laryngoscope.com.]

reinnervation, ${ }^{10}$ and synkinesis ${ }^{13}$ might influence the postoperative voice, especially in larynges with otherwise intact structures.

A cadaver study has been designed to provide an objective answer to these questions ${ }^{14,15}$ by applying these methods to the anticipated breathing and phonatory characteristics of the basic endoscopic glottisenlarging procedures designed for BVCI.

\section{MATERIALS AND METHODS}

\section{Cadaver Workup}

A task-orientated modification of the prior study design was used. ${ }^{15}$ One hundred freshly excised cadaver larynges (50 male, 50 female) were analyzed. Larynges were inserted into a fixation device and secured with three screws along the cricoid cartilage, avoiding deformation caused by the screws. The screw positions were always kept constant in each larynx. Highresolution digital photos were taken from a top view by a Nikon D60 camera fixed onto a tripod. This made it possible to take all photos from a constant perspective.

The effect of simple suture-based techniques was measured in 60 larynges ( 30 male, 30 female). First, the normal cadaveric position of the larynges was documented. Then, four different suture lateralization maneuvers were performed one by one on the left side on each larynx (Fig 1). Suture placement was performed according to the techniques described in the literature by typical needle holders and suture materials.

\section{Group 1: Suture Lateralization Procedures (SLP).}

1. Classic vocal cord laterofixation (VCL-suture 1). The vocal cord is lateralized and fixed by a thread loop inserted at or just anterior to the vocal process. ${ }^{16,17}$ The suture loop was placed according to Lichtenberger's endo-extralaryngeal concept ${ }^{16}$ which allows for a more precise loop formation around the vocal process (Fig. 1B).

2. Modified vocal cord laterofixation (VCL-suture 2), ${ }^{18}$ in which a second suture was inserted anteriorly from the original position (Fig. 1C).

3. Endoscopic arytenoid abduction lateropexy (EAAL). ${ }^{19}$ The arytenoid cartilage was rocked into its abducted position, and then a suture loop was placed round the vocal process (Fig. 1D).

The minimally destructive procedures (above-mentioned nos. 1-3) were performed on each larynx. They were taken in a quasirandom sequence (see no. 4 below for exception) so that the prior surgical technique would not affect the results (Fig. 1). The suture loops were knotted on the outer surface of the thyroid cartilage until maximal lateralization occurred.

4. Schobel's external arytenoid lateropexy (SELP) exposes the arytenoid body posteriorly ${ }^{20}$ and abducts it by two to three horizontal submucosal suture loops to holes drilled on the edge of thyroid cartilage (Fig. 1E). It was used finally as a comparison group due to the greater amount of tissue damage.

Group 2: Resection Procedures. Because of the irreversibility of the subsequent procedures, two subgroups were created: the transverse cordectomy (TC) and the total arytenoidectomy (AE). The glottic area created was measured after each surgery on 20 to 20 cadaver larynges.

5. Transverse cordectomy (TC). ${ }^{21}$ A wedge-shaped defect was created by the removal of the middle third of the vocal cord until the thyroid cartilage (Fig. 2D).

6. Arytenoidectomy procedures.

a. Total arytenoidectomy (AE). ${ }^{22}$ In order to simplify the procedure and for the maximal efficacy, the left arytenoid was completely removed along with the surface mucosa (Fig. 2B).

b. Calculated medial arytenoidectomy (cMAE), according to Crumley. ${ }^{23}$ The partial resection of arytenoid cartilage is presently considered a popular method. The images gained after total $\mathrm{AE}$ provided a simple calculation for their efficacy as well. Considering the anatomical structure of the cricoarytenoid joint, only the real airway improvement was measured (see Fig. 2B), which could be achieved by removal of the medial obstructing part of the arytenoid cartilage. ${ }^{23}$

\section{Digital Image Analysis}

To exclude the measurement errors that may arise from the position change of the contralateral vocal cord, the values were measured to the median-sagittal line. 
Fig. 2. EAAL and resection methods.

EAAL (A) and AE (B) (larynx no. 86, female, 68 years of age; EAAL: $131,43 \mathrm{~mm}^{2}$; $\mathrm{AE}$ : $161,35 \mathrm{~mm}^{2}$; CMAE: $114,63 \mathrm{~mm}^{2}$ ). EAAL (C) and TC (D) (larynx no. 69, male, 71 years of age; EAAL: $131,80 \mathrm{~mm}^{2}$, TC: $101,84 \mathrm{~mm}^{2}$ ). The analyzed glottic gap is labeled. In (B), CMAE is also shown (green).

$\mathrm{AE}=$ arytenoidectomy; $\quad \mathrm{CMAE}=$ calculated medial arytenoidectomy; $\mathrm{EAAL}=$ endoscopic arytenoid abduction lateropexy; TC $=$ transverse cordectomy. [Color figure can be viewed in the online issue, which is available at www. laryngoscope.com.]
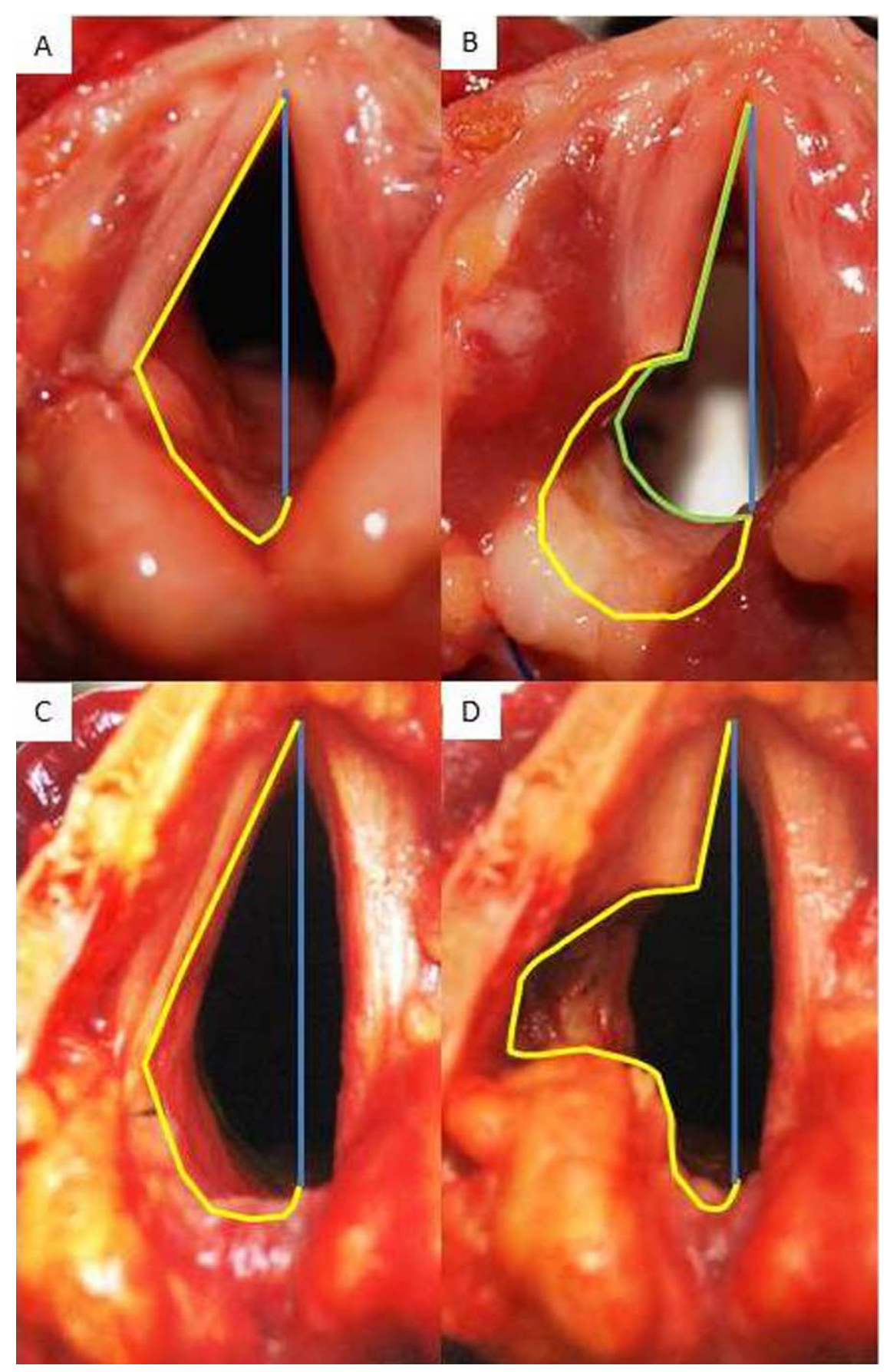

Measurement of Glottic Enlargement. Image $\mathrm{J}$ software for analyzing digital images was used to measure the glottic configuration changes. First, the glottic area changed was measured on the lateralized side of the larynx from the midline (Figs. 1, 2).

Proposed Phoniatric Effect. According to Isshiki's and Woodson's suggestion, the most important determining parameters were examined ${ }^{10}$ (Figs. 3, 4):

1. The angle (A) at the anterior commissure between the lateralized vocal cord and the midline (Figs. 3,4-red $\alpha$ angle).

2 . The length $(\mathrm{L})$ of the vibrating part of the vocal cord is determined by the two fixation points, which are normally the anterior commissure and the vocal process. This value is pro- portional to the passive (e.g., not neuromuscular) strain of the vocal cord. After SLP, the vibration length is reduced to the anterior commissure and the closest lateralizing suture (Fig. 3B,C; yellow line). In the case of $\mathrm{AE}$ and $\mathrm{TC}$, the anterior fixation point remains unchanged, but the posterior fixation point changes to the attachment of remaining vocal cord at the thyroid cartilage (Fig. 4). Theoretically, in case of cMAE, this latter point stays at the remnant of vocal process.

3. The maximal deviation (D) of the free margin of the vibrating part from the line between the two fixating points (Figs. 3, 4; small yellow arrows).

4. Maximal deviation to length ratio (D/L) provides a more precise comparison. The $\mathrm{L}$ and the $\mathrm{D}$ together determine the 


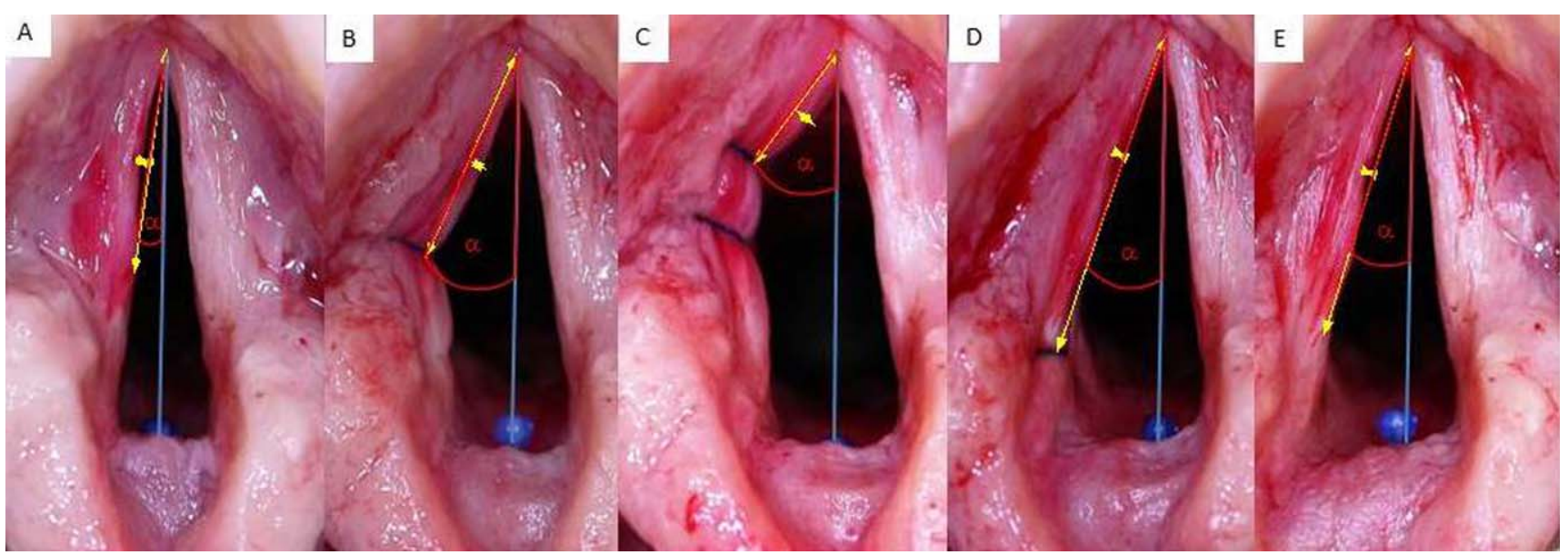

Fig. 3. Parameters determining the phoniatric outcome: comparison of different glottis enlarging procedures. Angle of the half-anterior commissure (red angle); length of the vibrating part of vocal cord (yellow arrow); maximal deviation of the vocal cord's free edge from line of fixating points (short yellow arrow).

(A) CP; (B) VCL-1; (C) VCL-2; (D) EAAL; (E) SELP.

$\mathrm{CP}=$ cadaveric position; EAAL = endoscopic arytenoid abduction lateropexy; SELP = Schobel's external lateralization procedure; VCL$1=$ vocal cord laterofixation 1 ; VCL-2 = vocal cord laterofixation 2. [Color figure can be viewed in the online issue, which is available at www.laryngoscope.com.]

possible outcome; thus, their proportion is the normalization of $\mathrm{D}$ to the actual vibrating length of the vocal folds (e.g., the same D on a shorter vocal fold segment can cause a more chaotic vibrating pattern).

Statistical analysis was performed (pairwise comparisons; repeated measure analysis of variance; Sidak adjustment for multiple comparisons) by SPSS Statistics for Windows 20.0 (IBM Corp. Armonk, NY) .

\section{RESULTS}

\section{Glottic Enlargement}

All SLP provided larger glottic area compared to cadaveric position (Fig. 5). However, a significant enlargement $(P<0.05)$ was found with EAAL, SELP, and $\mathrm{AE}$. At the glottic level, $\mathrm{AE}$ provided the largest gap; but considering the anatomy of the cricoarytenoid joint, the large part of the improvement is located on the cricoid plate on the lower facet of the joint. Therefore, the real improvement was effectively the same as achieved by cMAE. There was no significant difference comparing $\mathrm{CP}, \mathrm{VCLs}, \mathrm{TC}$, and cMAE. The arytenoid abduction methods produced the largest area increases $(P<0.05)$. Endolaryngeal arytenoid abduction lateropexy was found to be a bit more effective than SELP. This was thought to be due to the more effective rotation of the arytenoid, but the difference was not statistically significant (Fig. 5B).

\section{Phoniatric Parameters}

All SLPs significantly increase the anterior glottic commissure's angle; however, TC and AE do not significantly change it $(P<0,05)$ (Figs. 6,7$)$.

The largest angle, the worst configuration from a voicing perspective, was found after VCL-suture 2. Schobel's external lateralization procedure provided a smaller angle change than EAAL due to the slightly more medial vocal process $(P<0.05)$.

The length of the vibrating cord: The VCL-suture 2 and TC significantly shortened the vibrating length of the vocal cord. The VCL-suture 1 and AE caused insignificant changes. The vocal cord length was significantly greater and higher in tension after SELP and EAAL.

Unfavorable curving of the altered cord resulted from the VCLs, TC, and AE. This curving was negligible after EAAL and SELP. Arytenoidectomy caused the maximal deviation (from straightness) in this series. Considering D/L, SELP and EAAL were the most advantageous $(P<0.05)$ (Figs. 6, 7).

\section{DISCUSSION}

The measurement of the efficacy of glottis-enlarging procedures is a challenging task because several factors influence any evaluation, including the patients' satisfaction, occupation, and activity level. The most important factor to the clinician is doubtlessly the patient's breathing and phonation following the interventions.

The ability to surmise the effect of these surgical options on breathing is easier because it can be described by the change of glottic cross-sectional area. A difficult, complex morphometric study on shock frozen cadaver larynges compared the resection of the vocal cord and the removal of arytenoid cartilage ${ }^{14}$ in this regard. Our study is based on the assessment of the airway effect of these operations, as determined by a digital image-analyzing method, which in our opinion is more reliable to compare large series of different methods. This has proven that methods using physiologic arytenoid abduction (EAAL, SELP) are likely more effective ${ }^{15}$ in improving the airway. Considering the laryngeal anatomy, the cricoid arch is located in a more distal position than the posterior surface of the cricoid lamina, which 
Fig. 4. Parameters determining the phoniatric outcome: comparison of EAAL and resection methods

Angle of the half-anterior commissure (red angle); length of the vibrating part of vocal cord (yellow arrow); maximal deviation of the vocal cord's free edge from the line of fixating points (short yellow arrow).

(A) EAAL; (B) AE; (C) EAAL; (D) TC.

$\mathrm{AE}=$ arytenoidectomy; $\quad \mathrm{EAAL}=$ endoscopic arytenoid abduction lateropexy; TC = transverse cordectomy. [Color figure can be viewed in the online issue, which is available at www. laryngoscope.com.]

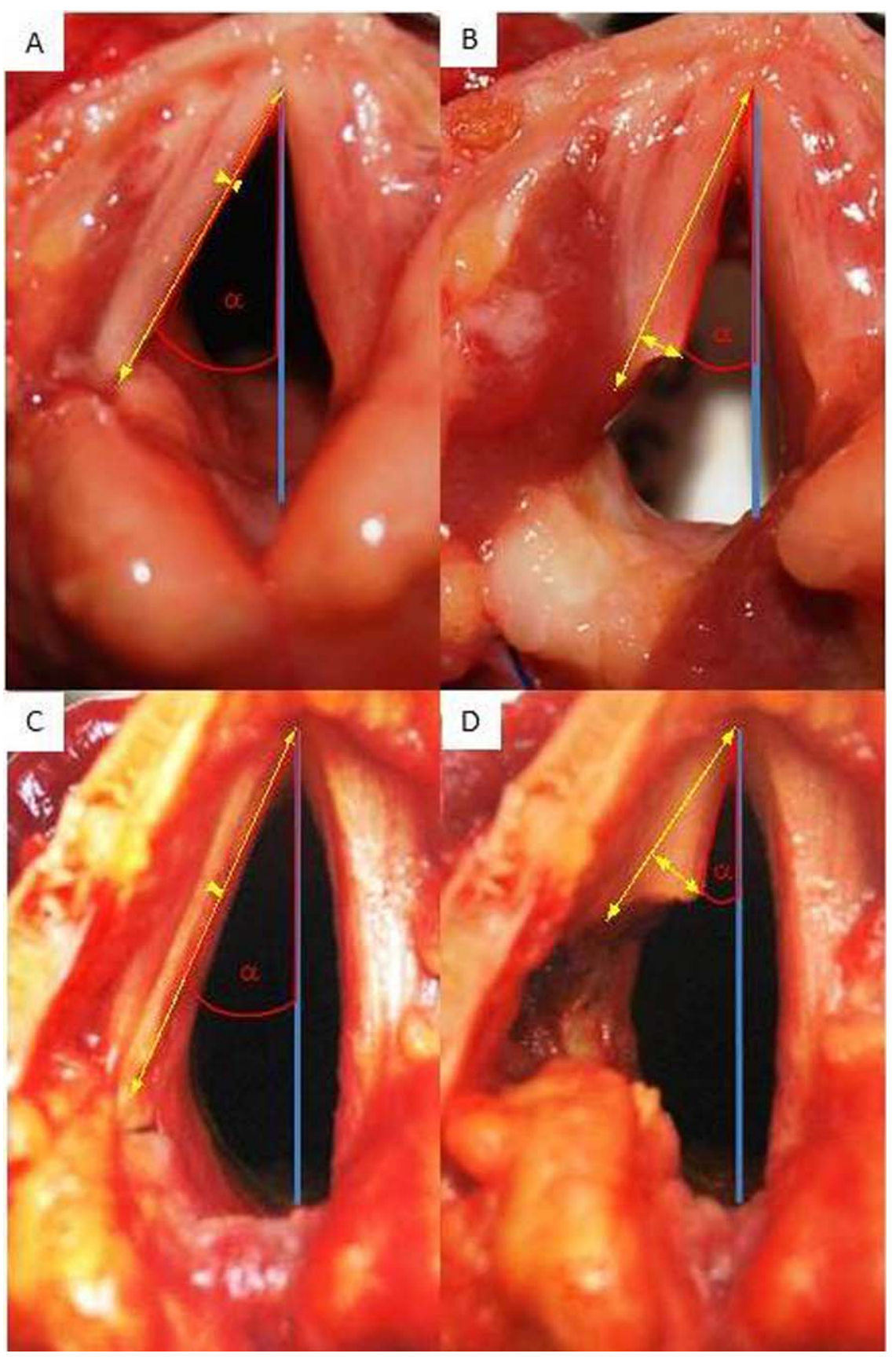

holds the arytenoid cartilages. ${ }^{24}$ Thus, at the level of the glottis, resection of the vocal cord (TC) markedly increases the glottic airway area. However, in the case of arytenoidectomy, only a part of the arytenoid cartilage is located over the cricoid lumen; therefore, only removal of the protruding part (similar to medial arytenoidectomy) is really effective in airway widening.

Vocal cord lateralization techniques are effective in widening the airway. The insertion of a second lateralizing suture does not add significant benefit, although it may decrease the vocal cord's medialization tendency over time. This is a surgical concept rather than a direct result of this study. Having two sutures pulling over the vocal cord makes it less likely that either will cut into the tissue, the so-called cheese-wire effect. The main limitation is that the arytenoids effectively remain in the medial position and therefore partially block the airway lumen above the cricoid. The vector of pulling that the sutures generate differs significantly from natural arytenoid abduction. Therefore, the arytenoid rotation that results is negligible. This also offers an explanation as to why the sutures intraoperatively tended to slip onto the membranous vocal cord, even if placed directly onto the vocal process (Fig. 1B). Surprisingly, the-above mentioned methods do not result in significant airway area improvement compared to the cadaver position (CP), but it must be accepted that the CP is generally more lateral compared to the paramedian position 
A

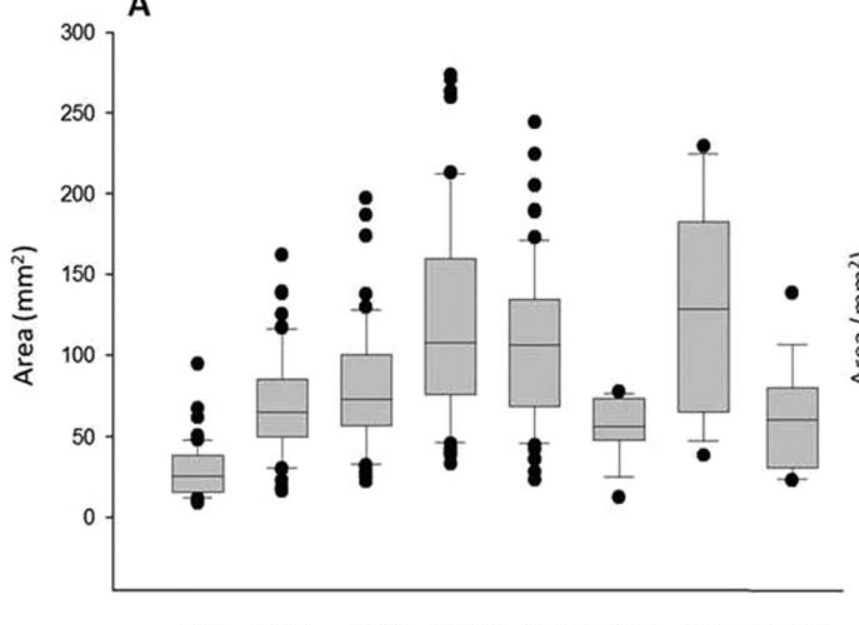

B

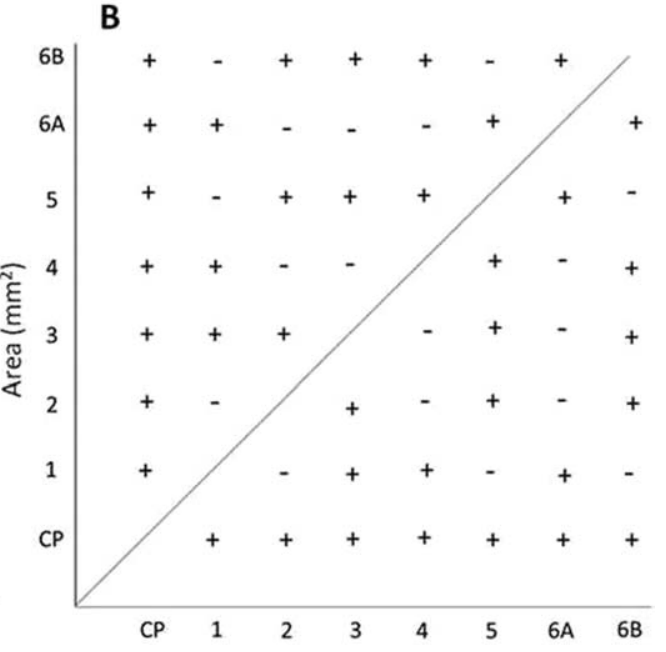

Fig. 5. The area of half-glottis after different glottis-enlarging procedures. (A) Box plot displaying the extremes, upper and lower quartiles, and medians. (B) Intergroup significance. Numbers of the axis represent the groups, as presented in Table $(A)$. $(+)$ indicates significant differences; (-) indicates no significance between tested groups. Analysis of variance, $P<0.05$.

$1=\mathrm{CP} ; 2$ = VCL; $3=\mathrm{SELP} ; 4=\mathrm{EAAL} ; 5=\mathrm{TC} ; 6=\mathrm{AE} ; 7$ = cMAE.

$\mathrm{AE}=$ arytenoidectomy; $\mathrm{CMAE}=$ calculated medial arytenoidectomy; $\mathrm{CP}=$ cadaveric position; $\mathrm{EAAL}=$ endoscopic arytenoid abduction lateropexy; SELP = Schobel's external lateralization procedure; TC = transverse cordectomy; VCL = vocal cord laterofixation.
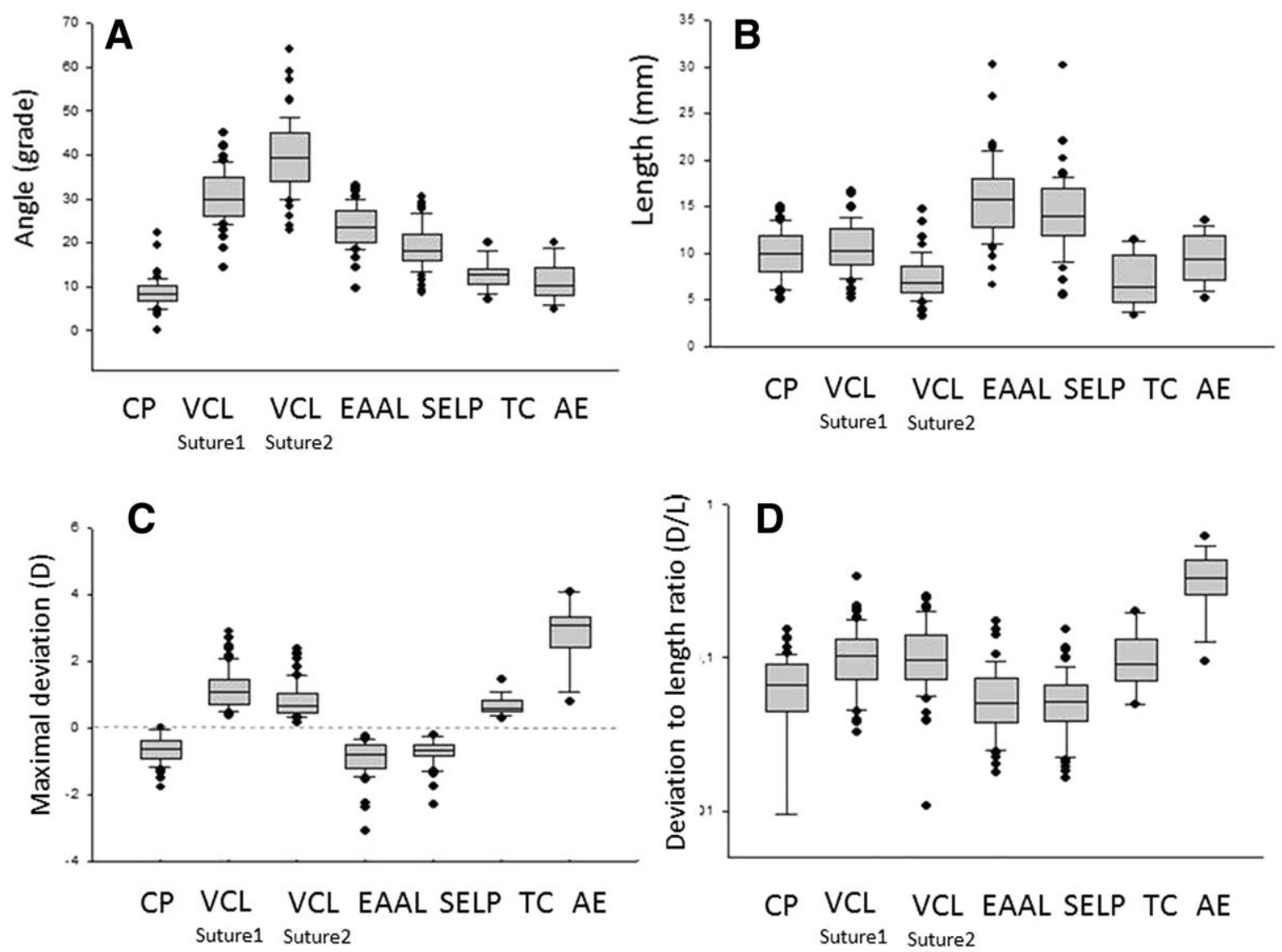

Fig. 6. Parameters determining the phoniatric outcome: comparison of different glottis enlarging procedures. (A) Angle of the half-anterior commissure, as defined by the midline and the position or its change the various surgical maneuvers. (B) Length of the membranous (vibrating) vocal cord. (C) Maximal deviation of the vocal cord's free edge from the line of fixating points (D/L) (negative: lateral deviation or concavity, positive: medial deviation or convexity). (D) The phonation closure ratio is a function of the proportion of the effective maximal curve (deviation of vibrating vocal cord position divided by its length) and its length (C/L), with $C$ being the curve of the cord (D/L) in panel C. Box plot displaying the extremes, upper and lower quartiles, and the medians.

$\mathrm{AE}=$ arytenoidectomy; $\mathrm{CP}=$ cadaver position; $\mathrm{D}=$ deviation; $\mathrm{EAAL}=$ endoscopic arytenoid abduction lateropexy; $\mathrm{L}=$ length; $\mathrm{SELP}=\mathrm{Scho}-$ bel's external lateralization procedure; TC = transverse cordectomy; $\mathrm{VCL}=$ vocal cord laterofixation. 

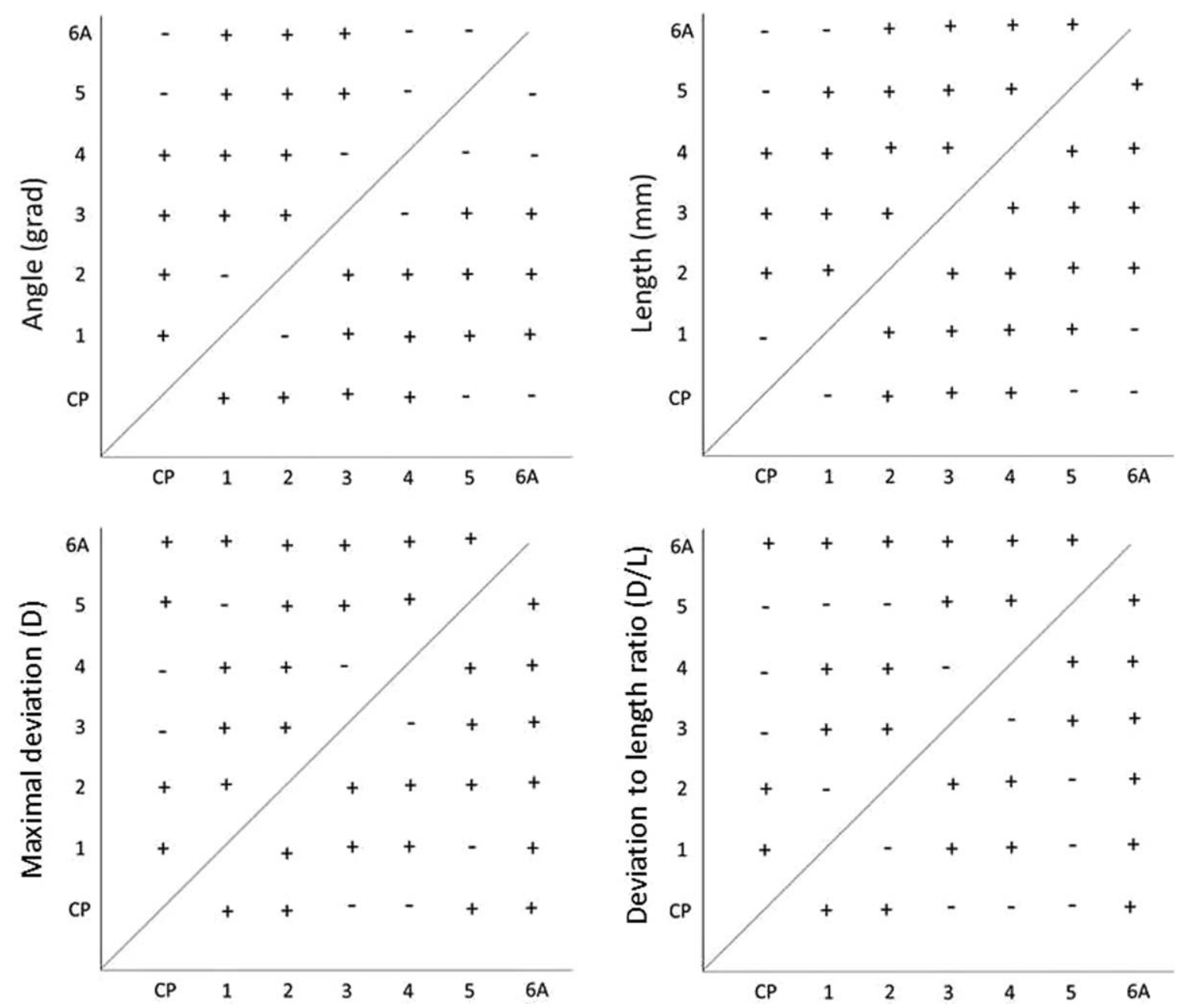

Fig. 7. Statistical supplement for Fig. 6. Parameters determining the phoniatric outcome. Numbers of the axis represent the tested groups: $(+)$ significant difference, $(-)$ no significant difference between groups. Analysis of variance, $P<0.05$.

$1=\mathrm{VCL}-1 ; 2=\mathrm{VCL}-2 ; 3=\mathrm{SELP} ; 4=\mathrm{EAAL} ; 5=\mathrm{TC} ; 6=\mathrm{AE}$.

$\mathrm{AE}=$ arytenoidectomy; $\mathrm{CP}=$ cadaveric position; $\mathrm{D}=$ deviation; $\mathrm{EAAL}=$ endoscopic arytenoid abduction lateropexy; $\mathrm{L}=$ length; $\mathrm{SELP}=\mathrm{Scho-}$ bel's external lateralization procedure; $\mathrm{TC}=$ transverse cordectomy; VCL-1 = vocal cord laterofixation 1 ; VCL-2 = vocal cord laterofixation 2.

observed after recurrent laryngeal nerve palsy (RLNP). However, in both cases the airway improvement values vary widely, and surgery for RLNP is often indicated to improve the airway when it is a bilateral palsy, a lifethreatening situation (Fig. 1).

Arytenoid abduction procedures open and fix the larynx, simulating the physiological arytenoid abduction, as described by Wang. ${ }^{24}$ The vocal cord unit, including the arytenoid, vocal process, and the vocal cord, are not only lateralized but elevated approximately 1 to $2 \mathrm{~mm}$ cranially above the rima glottidis (the axial plane of the vocal cord rim). The vocal cord is pulled not only laterally but upward toward the sinus of Morgagni, whereas the thyroarytenoid muscle gets passively longer and thinner, parallel with the inner surface of the thyroid cartilage. Thus, by this simple maneuver the whole arytenoid and practically the whole vocal cord are removed from the airway lumen above the cricoid. Therefore, these methods provide the largest improvement in the horizontal plane that could be measured in this study, and the vertical vocal cord repositioning gives an addi- tional enlargement of the airway compared to the other procedures. This result is consistent with the excellent spirometry results in multiple clinical studies. ${ }^{10,19,25}$

The estimation of the voice impact of this surgery is more challenging because it is influenced by many passive and active factors. Isshiki described the length, elasticity, and mass of the vocal cord as the outcome-determining factors during phonosurgery, which can be justified by physical principles as well. ${ }^{9,26}$ A paralyzed vocal cord subjected to surgery-related scarring, such as in cordotomy and cordectomy operations, can produce an even more chaotic vibratory pattern, which deteriorates the already abnormal voice. Therefore, it is proposed that the preservation of the vocal cord's structural integrity is beneficial for postoperative voice production. These observations are well-known in the phonosurgery literature. ${ }^{10,27}$ Arytenoidectomies, TCs, and VCLs are evidently disadvantageous from this perspective (Figs. 3, 4). Based on this concept, the vocal cord angle change is found to be the smallest after the resection procedures because the anterior vocal cord segment is left in its original position. This may 
indicate that these procedures would impact the voice less. However, the vocal fold healing may alter this angle, and they more adversely affect the voice secondary to the loss of anatomical vibratory substance and cord straightness in contrast to cMAE, SELP, and EAAL.

The arytenoid lateropexies produce a significantly larger anterior commissure angle, but they retain a natural vocal cord tension and straightness and therefore may support the voice quality better than the rest, even in the case of a completely paralyzed larynx. The VCLs produced the poorest parameters with regard to voice potential. The resulting cord is most curved (of the cord procedures not involving tissue resection), and the vibratory surface is neutralized by the effect of the sutures themselves (particularly VCL-2).

The standard endoscopic procedures designed for static vocal cord paralysis treatment are directed only toward the above-mentioned passive factors. The voice is inversely diminished in proportion with the airway improvement. The active components, however, which may occur after the recurrent nerve is injured, may affect the postoperative voice positively by maintaining tone or adversely by synkinesis. Anatomic studies prove that the ratio of adduction and abduction fibers in the recurrent nerve is approximately $4: 1{ }^{13}$ This might explain Woodson's observation about a preferential adduction reinnervation after the cut of recurrent nerve in an animal study. ${ }^{28}$ Publications bring up a possible accessory parallel adduction innervation via the interior branch of superior laryngeal nerve to the interarytenoid muscles. ${ }^{5,12}$ The communicating nerve (between the superior and inferior laryngeal nerves), which can be identified in $50 \%$ of the population, may also provide a direct innervation to the TA muscle. ${ }^{12}$

In clinical practice, adduction reinnervation recovery can also be observed. ${ }^{10}$ The entity generally can be detected after some months following arytenoid adduction procedures, where the above-mentioned neural framework and muscular structures remain largely intact. The abducted position of the lateralized arytenoid cartilage provides not only the best airway improvement but also room for adduction beyond the midline for the contralateral side during phonation. Because there is a straight and passively tensed vocal cord on the operated side, active adduction with improved closure and phonation can occur this way. The other tested procedures (the TC and the AE) leave the arytenoids in their original paralyzed position and intrinsically injure the true cords; thus, they cannot benefit from these phenomena.

\section{CONCLUSION}

As surgeons, we labor under the dictum "first do no harm." This study demonstrates that the factors that impact quality of life, such as voice potential and breathing comfort, fundamentally depend on the method chosen to treat the airway deficit. The outcome also depends on the postsurgical healing from the paralytic process, which a cadaver study cannot address. Although the medial arytenoidectomy (MAE) may be technically easier and might provide acceptable voice results, it only produces a moderate airway improvement compared to those lateralizing procedures that utilize the physiological abduction of the arytenoid cartilage. The voice after SELP and EAAL would be worse in a patient with complete BVCP. If recovery occurs, these procedures are easily reversed because they are not destructive, as are TC and AE. This therefore simplifies the complexity of the surgical decision-making process. The surgeon is able to choose between airway effect and voice impact, as well as reversibility, while providing time for further investigations and surgical reconsiderations.

\section{BIBLIOGRAPHY}

1. Belafsky PC. Bilateral vocal fold immobility. Curr Opin Otolaryngol Head Neck Surg 2011;19:415.

2. Sapundzhiev N, Lichtenberger G, Eckel HE, et al. Surgery of adult bilateral vocal fold paralysis in adduction: history and trends. Eur Arch Otorhinolaryngol 2008;265:1501-1514.

3. Damrose EJ. Suture laterofixation of the vocal fold for bilateral vocal fold immobility. Curr Opin Otolaryngol Head Neck Surg 2011;19:416-421.

4. Tucker H. The Larynx. New York, NY: Thieme Medical Publishers; 1987.

5. Traissac L. [Neuroanatomy of the larynx]. Neuro-Anatomie du larynx. [Article in French]. Rev Laryngol Otol Rhinol (Bord) 1987;108:361-364.

6. Zealear DL, Kunibe I, Nomura K, et al. Rehabilitation of bilaterally paralyzed canine larynx with implantable stimulator. Laryngoscope 2009; 119:1737-1744.

7. Sellars I, Sellars S. Cricoarytenoid joint structure and function. J Laryngol Otol 1983;97:1027-1034.

8. Woodson GE. Configuration of the glottis in laryngeal paralysis I: clinical study. Laryngoscope 1993;103:1227-1234.

9. Isshiki N. Progress in laryngeal framework surgery. Acta Otolaryngol 2000;120:120-127.

10. Woodson G. Arytenoid abduction for bilateral vocal cord paralysis. Otolaryngol Head Neck Surg 2012;23:178-182.

11. Rovo L, Madani S, Sztano B, et al. A new thread guide instrument for endoscopic arytenoid lateropexy. Laryngoscope 2010;120:2002-2007.

12. Sanders I, Mu L. Anatomy of the human internal superior laryngeal nerve. Anat Rec 1998;252:646-656.

13. Crumley RL. Laryngeal synkinesis revisited. Ann Otol Rhinol Laryngol 2000;109:365-371.

14. Eckel HE, Sittel C. Morphometric studies at the level of the glottis as a principle in larynx enlarging microlaryngoscopic surgical procedures in bilateral recurrent nerve paralysis. Laryngorhinootologie 1994;73:417-422.

15. Sztano B, Szakacs L, Madani S, et al. Comparison of endoscopic techniques designed for posterior glottic stenosis-A cadaver morphometric study. Laryngoscope 2014;124:705-710.

16. Lichtenberger G. Reversible lateralization of the paralyzed vocal cord without tracheostomy. Ann Otol Rhinol Laryngol 2002;111:21-26.

17. Ejnell H, Mansson I, Hallen O, Bake B, Stenborg R, Lindstrom J. A simple operation for bilateral vocal cord paralysis. Laryngoscope 1984;94:954-958.

18. Lichtenberger G. Open and endoscopic surgical techniques for the treatment of scarred laryngeal stenosis. Otolaryngol Head Neck Surg 1998;9: $150-153$.

19. Rovo L, Venczel K, Torkos A, Majoros V, Sztano B, Jori J. Endoscopic arytenoid lateropexy for isolated posterior glottic stenosis. Laryngoscope 2008;118:1550-1555.

20. Schobel H. Dilatation of the glottis in bilateral vocal cord paralysis. Review of various surgical procedures and a report of personal experience using a functional lateral fixation surgical technic. HNO 1986;34: 485-495.

21. Dennis DP, Kashima H. Carbon dioxide laser posterior cordectomy for treatment of bilateral vocal cord paralysis. Ann Otol Rhinol Laryngol 1989;98:930-934

22. Ossoff RH, Sisson GA, Duncavage JA, Moselle HI, Andrews PE, McMillan WG. Endoscopic laser arytenoidectomy for the treatment of bilateral vocal cord paralysis. Laryngoscope 1984;94:1293-1297.

23. Crumley RL. Endoscopic laser medial arytenoidectomy for airway management in bilateral laryngeal paralysis. Ann Otol Rhinol Laryngol 1993; 102:81-84

24. Wang R. Three-dimensional analysis of cricoarytenoid joint motion. Laryn goscope 1998;108(suppl 86):1-17.

25. Rovo L, Venczel K, Torkos A, Majoros V, Sztano B, Jori J. Endoscopic arytenoid lateropexy for isolated posterior glottic stenosis. Laryngoscope 2008;118:1550-1555.

26. Landau LD, Lifshitz EM. Theory of Elasticity. Oxford, UK: Pergamon Press; 1986.

27. Isshiki N. Vocal mechanics as the basis for phonosurgery. Laryngoscope 1998;108:1761-1766.

28. Woodson GE. Spontaneous laryngeal reinnervation after recurrent laryngeal or vagus nerve injury. Ann Otol Rhinol Laryngol 2007;116:57-65. 
II. 


\title{
Comparison of Endoscopic Techniques Designed for Posterior Glottic Stenosis-A Cadaver Morphometric Study
}

\author{
Balázs Sztanó, MD, PhD; László Szakács, MD; Shahram Madani, MD; Ferenc Tóth, PhD; Zsófia Bere, MD; \\ Paul F. Castellanos, MD, FCCP; László Rovó, MD, PhD
}

\begin{abstract}
Objectives/Hypothesis: Posterior glottic stenosis may cause more or less severe dyspnea. The popular endoscopic procedures have only a limited role in the treatment. Considering our clinical experiences, endoscopic arytenoid abduction lateropexy (EAAL) after proper mobilization of the fixed joints provides an effective option even in high-grade stenoses.

Study Design: To confirm these clinical observations, a morphometric study was performed in 100 cadaver larynges (50 male, 50 female) to objectively compare the endoscopic glottis-widening procedures.

Methods: The postoperative measurements of the posterior commissure following EAAL, classic vocal cord laterofixation (VCL), transverse cordotomy (TC), and arytenoidectomy (AE) were assessed by a digital image analyzer program. The distance between the vocal process of the lateralized vocal fold and the midline, the angle between the axis of the posterior commissure midpoint, and the vocal process and laryngeal median sagittal line were measured.

Results: EAAL was found to be more effective in improving the posterior glottis configuration; however, AE and VCL were beneficial as well.

Conclusions: Our morphometric study proved that organ-preserving EAAL provided more space in the posterior glottic area. Fibrous reconnection and contraction of the scar can be minimized in this way, which may be the clinical efficacy explanation.
\end{abstract}

Key Words: Arytenoid lateropexy, endoscopic laryngeal microsurgery, posterior glottic stenosis.

Level of Evidence: N/A.

Laryngoscope, 124:705-710, 2014

\section{INTRODUCTION}

The posterior commissure involves the dorsal third of the vocal cords, the cricoid lamina, the arytenoid cartilages, and the interarytenoid area with the interarytenoid muscles and their covering mucosa. ${ }^{1,2}$ Injury may lead to scar and to posterior glottic stenosis (PGS), limiting normal glottic motion by resulting in one or both arytenoid cartilages becoming fixed in an adducted position. Bilateral fixation commonly causes severe dyspnea, which may require tracheostomy. In the past decades, prolonged intubation, because of the increase of patients undergoing assisted ventilation, has become the most frequent cause of PGS, occurring in approximately $1 \%$ of cases. ${ }^{3}$ The effect is a pseudoparalysis of normally innervated vocal cords. ${ }^{3-5}$

The moderate to severe dyspnea caused by bilateral vocal cord fixation generally requires surgical intervention depending on the grade of the stenosis (e.g.,

From the Department of Otorhinolaryngology-Head and Neck Surgery (B.S., L.S., S.M., F.T., Z.B., L.R.), University of Szeged, Szeged, Hungary; and the Department of Surgery (P.F.C.), Division of OtolaryngologyHead and Neck Surgery, University of Alabama at Birmingham, Birmingham, Alabama, U.S.A.

Editor's Note: This Manuscript was accepted for publication May 30, 2013.

The authors have no funding, financial relationships, or conflicts of interest to disclose.

Send correspondence to Balázs Sztanó, MD, 111 Tisza L. krt, Szeged, H-6725, Hungary. E-mail: office@orl.szote.u-szeged.hu

DOI: 10.1002/lary.24270
Bogdasarian-Olson classification ${ }^{6}$ [Table I]) and the experience of the surgical team. Several different procedures have been introduced, ${ }^{7,8}$ but the treatment of this hazardous vocal fold fixation still poses a great challenge even today. A simple scar transection provides limited and short-lived success even in mild cases because of the destruction of the deeper layers of the posterior glottis and cricoarytenoid joints. Also, the connecting raw wound surfaces increase the risk for restenosis. This is a well-known problem of other widely used procedures such as the transverse cordotomy (TC) ${ }^{9,10}$ or the arytenoidectomy (AE). ${ }^{5}$ Moreover, due to the originally damaged state of the posterior commissure, the effect of these procedures may be to worsen the stenosis. Eckel et al., in a consecutive series of 32 bilateral vocal cord mechanical fixations (limitation of the cricoarytenoid joint's movements) only $44 \%$ decannulation rate could be achieved with these methods. ${ }^{11}$ However, by open techniques these results could be improved to $100 \%,{ }^{11-13}$ but tracheostomy might have to be sustained for weeks, and many of these patients had to face a significant deterioration of laryngeal function and voice. By contrast, in our earlier studies ${ }^{14,15}$ we presented a consecutive series of 42 patients with different grades of stenosis. All were treated successfully by a minimally invasive endoscopic method following the resection of fixating scar, and mobilization of the cricoarytenoid joints and a temporary endoscopic bilateral arytenoid lateropexy. This approach provided not only significant airway improvement but also a functional larynx secondary to vocal cord motion 
TABLE I.

Bogdasarian-Olson Classification for Posterior Glottic Stenosis.

Bogdasarian and Olson classified the extent of posterior glottic stenosis into the following four types:

Type I: Vocal process adhesion

Type II: Posterior commissure stenosis with scarring in the interarytenoid plane and internal surface of the posterior cricoid lamina

Type III: Posterior commissure stenosis with unilateral cricoarytenoid joint ankylosis

Type IV: Posterior commissure stenosis with bilateral cricoarytenoid joint ankylosis

recovery. The rate of success was found to be more favorable compared to other procedures. Many authors have previously suggested a stent, a keel, ${ }^{12,13,16-18}$ or a mucosal flap ${ }^{19}$ to keep open the posterior glottis space after the scar resection, but these interventions succeeded only in low-grade stenosis and also often required tracheostomy.

The purpose of our method is to provide the largest possible space in the posterior commissure, thus keeping the wounds apart until healing, ${ }^{14,20}$ diminishing the chance of developing a fibrin cicatrix. Moreover, the durable separation of the opposing wound surfaces over a period of weeks counters the contraction forces of the scarring process due to the myofibroblasts in early healing. ${ }^{21}$

The widest aperture means maximal inspiratory abduction of the arytenoid cartilage relative to the cricoarytenoid joint anatomy. Our operation, referred to as arytenoid abduction lateropexy, which is based on physiological abduction, confers a better effect than the other endoscopic methods. The effectiveness of different glottis-enlarging techniques described in the literature cannot be analyzed easily. The case numbers are generally so low as to make it hard to study common groups. Only one procedure can be performed on one patient, so the different methods cannot be reasonably compared in clinical practice. The aim of this study, which was based on a large number of cadaver larynges, was to avoid this limitation. By assessing the effectiveness of different endoscopic procedures, each performed on the same cadaver larynx, an objective comparison was possible. This has not been done previously.

\section{MATERIALS AND METHODS}

\section{Cadaver Workup and Documentation}

One hundred freshly excised cadaver larynges (50 male and 50 female) were analyzed. For a better view of the glottic area the epiglottis and the vestibular folds were removed (Fig. 1). Larynges were inserted into a fixation device and secured with three screws along the cricoid cartilage, which resisted deformation caused by the screws. The screws were always in the same position in each larynx. High-resolution digital photos were taken from a top view with a Nikon D60 camera (Nikon Corp., Tokyo, Japan) fixed on a tripod, with a Nikon 18-55/ F3.5-5.6 AF-S DX G VR lens. The fixation device made it possible to take all photos from a consistent position.

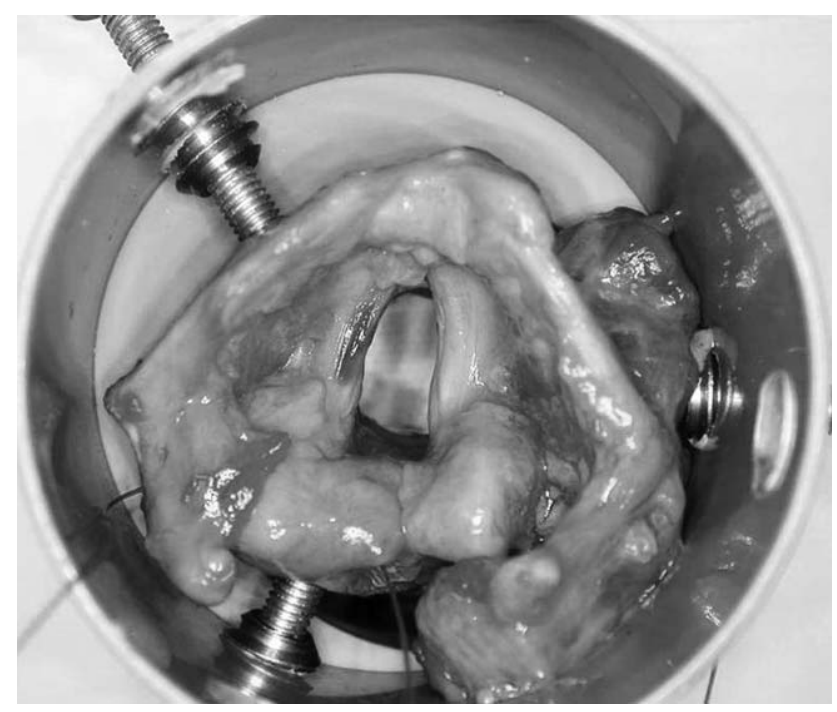

Fig. 1. Cadaver larynx in the fixating device. The supraglottic soft tissues and cartilages were removed to improve visualization.

In the first study, the effect of different simple suturebased glottis-widening techniques on the posterior glottic aperture were measured in 60 larynges (30 male and 30 female). First, the normal cadaveric position of the larynges was documented. Then four different suture lateralization maneuvers were performed, one by one, on the left side on each larynx. Typical needle holder and suture materials were used; the readily accessible glottis obviated the need for special instruments.

All procedures were performed according to the techniques described in the literature.

\section{Suture Lateralization Procedures}

Classic vocal cord laterofixation. The vocal cord was lateralized and fixed by a thread loop inserted on the vocal process or just anterior to it. There are two types: Lichtenberger's endo-extralaryngeal ${ }^{22}$ and Ejnell's exo-endolaryngeal procedure. ${ }^{23}$ In this study, the suture loop was placed according to Lichtenberger's concept, ${ }^{22}$ which allows for a more precise loop formation around the vocal process (Fig. 2A).

Modified vocal cord laterofixation. Lichtenberger's later modification of vocal cord laterofixation (VCL) ${ }^{12}$ was also examined, in which a second thread was inserted a couple of millimeters anteriorly from the original one (Fig. 2B).

Endoscopic arytenoid abduction lateropexy. In the endoscopic arytenoid abduction lateropexy procedure (EAAL), ${ }^{14}$ the arytenoid cartilage was rocked into its maximally abducted position, and then a thread loop was placed round the vocal process (Fig. 2C)

These minimally destructive procedures were performed on each larynx. They were taken in turns so that the prior surgical technique would not affect the results. The thread loops were positioned into the position described in the original publications, and then knotted on the outer surface of the thyroid cartilage.

Schobel's external lateralization procedure (SELP). As the control group of the endoscopic methods, Schobel's external lateralization procedure ${ }^{8}$ was performed last because it causes a greater amount of tissue damage. The arytenoid cartilage is tilted and fixed laterally with two submucosally placed sutures; one is knotted on the posterior margin and the second is placed around the superior horn of the thyroid cartilage (Fig. 2D). 
Fig. 2. Four different suture lateralizing techniques performed on the left side of the same cadaver larynx (larynx no. 18, male, 63 years old). The analyzed parameters describing the posterior glottis are marked: the midline-left vocal process distance (arrow), and the angle between vocal process-posterior commissure line and midline $(\alpha)$. (A) Vocal cord laterofixation (VCL), 1 suture. (B) VCL, 2 sutures. (C) Endoscopic arytenoid abduction lateropexy. (D) Schobel's method.

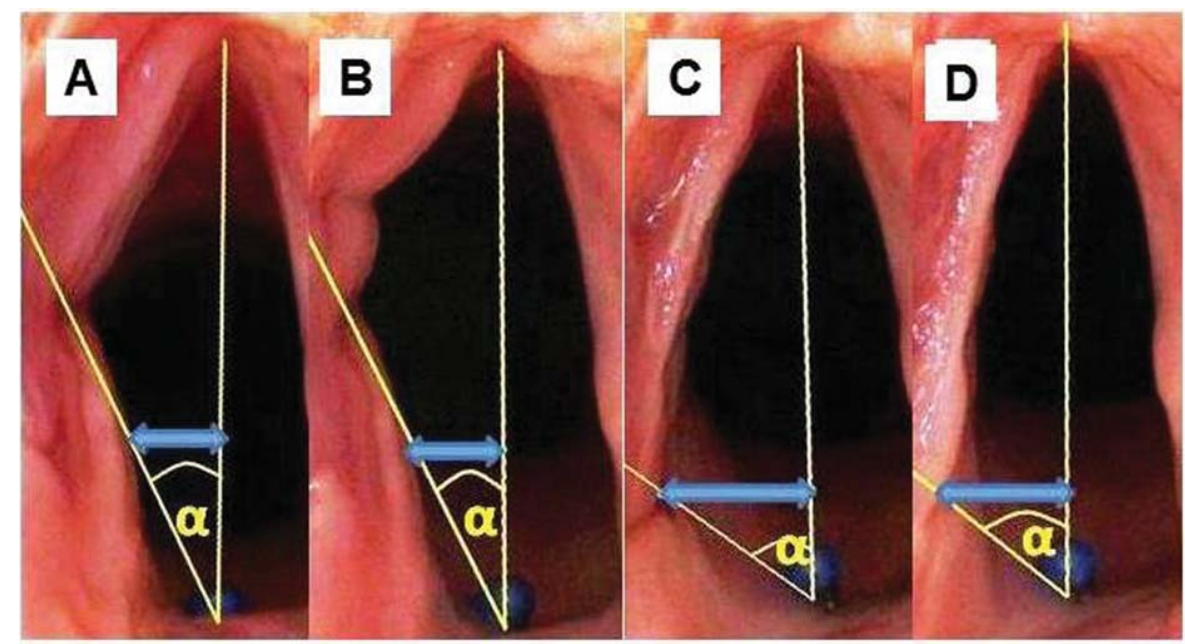

\section{Resection Procedures}

In the next part of the study, TC was compared to EAAL on 20 cadaver larynges, and finally $\mathrm{AE}$ was compared to EAAL on 20 different larynges. Because of the irreversibility of these procedures, two subgroups were created. Prior to the surgery, the supraglottic parts were also removed, and the same instrumentation was used for the fixation and documentation.

The Dennis and Kashima TC. In the Dennis and Kashima TC, ${ }^{10}$ an incision was made at the vocal process, and a wedge-shaped defect was created by the removal of the middle third of the vocal cord (Fig. 3).

The Ossoff total $\boldsymbol{A E}$. In order to simplify the procedure, the left arytenoid was completely removed along with the surface mucosa in the Ossoff total AE. ${ }^{24}$ In common surgical practice, the medial mucosa is normally kept in place, but we wanted to evaluate the theoretical maximum efficacy of the surgical method so we removed it. In this study, cold instruments were used for the procedures (Fig. 4).

\section{Digital Image Analysis}

ImageJ digital picture analyzer software (National Institutes of Health, Bethesda, MD) was applied to measure the cho- sen parameters describing the posterior commissure; in the plane perpendicular to the median-sagittal plane of the larynges, the distance between the left vocal process and sagittal midline of the larynx was measured (Fig. 2, arrow). Then, the angles between the long axis of the vocal process, the posterior commissure midpoint, and the laryngeal median-sagittal line were measured (Fig. 2, $\alpha$ ). In the 20 larynges treated with $\mathrm{AE}$, the furthest point of the gained glottic area (for distance measurement) and the most posterior point of the left vocal cord (for the angle) were chosen (Fig. 4A). Repeated measure analysis of variance was used to compare the surgical results. Pairwise comparisons were performed based on estimated marginal means using the Sidak adjustment for multiple comparisons. SPSS 20.0 (IBM SPSS, Armonk, NY) was used for calculations.

\section{RESULTS}

All suture-based glottis-widening techniques provided a significantly larger posterior glottic area compared to the area in the cadaveric position (Fig. 5 and Fig. 6). In the case of VCL, no difference occurred in the results of the one- and two-sutures methods, and the second loop did not provide additional space in the
Fig. 3. Transverse cordotomy (A) and endoscopic arytenoid abduction lateropexy (B) (larynx no. 68, male, 74 years old). The analyzed parameters describing the posterior glottis are marked: the midline-left vocal process distance (blue arrows), and the angle between vocal processposterior commissure line and midline (yellow).

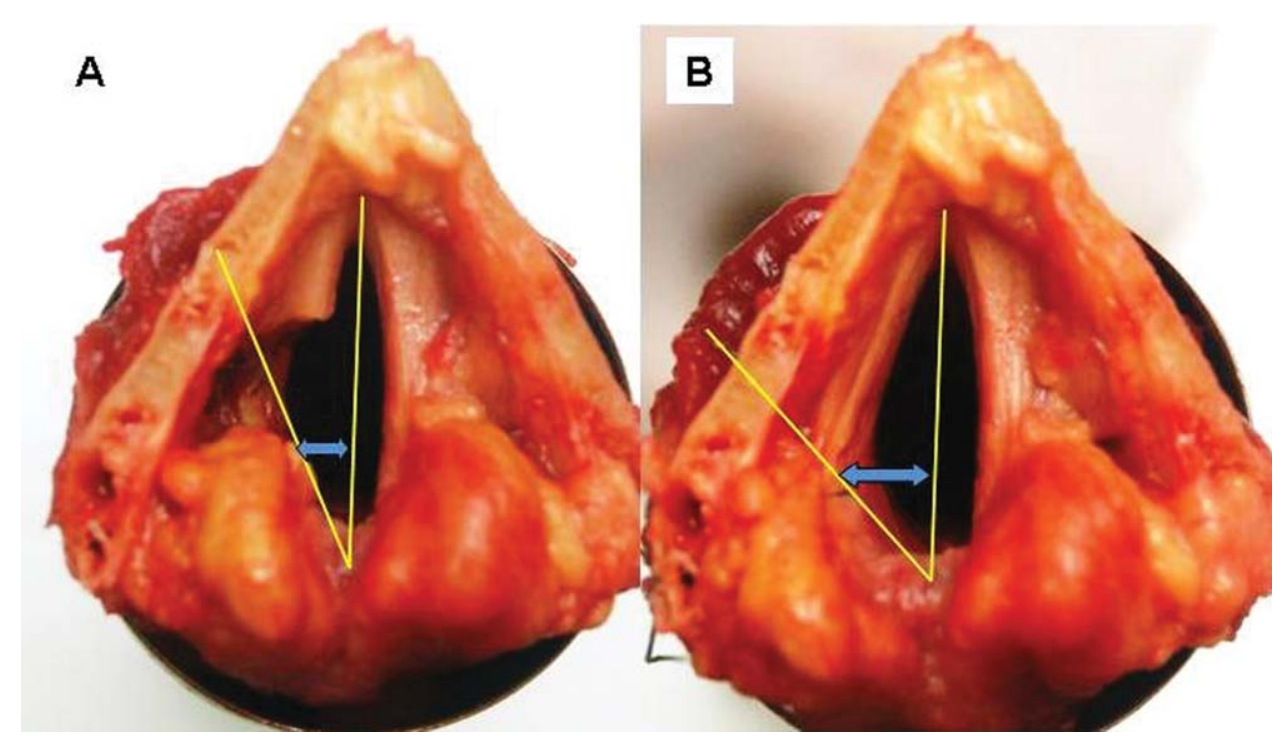

Sztanó et al.: Endoscopic Techniques Designed for PGS 


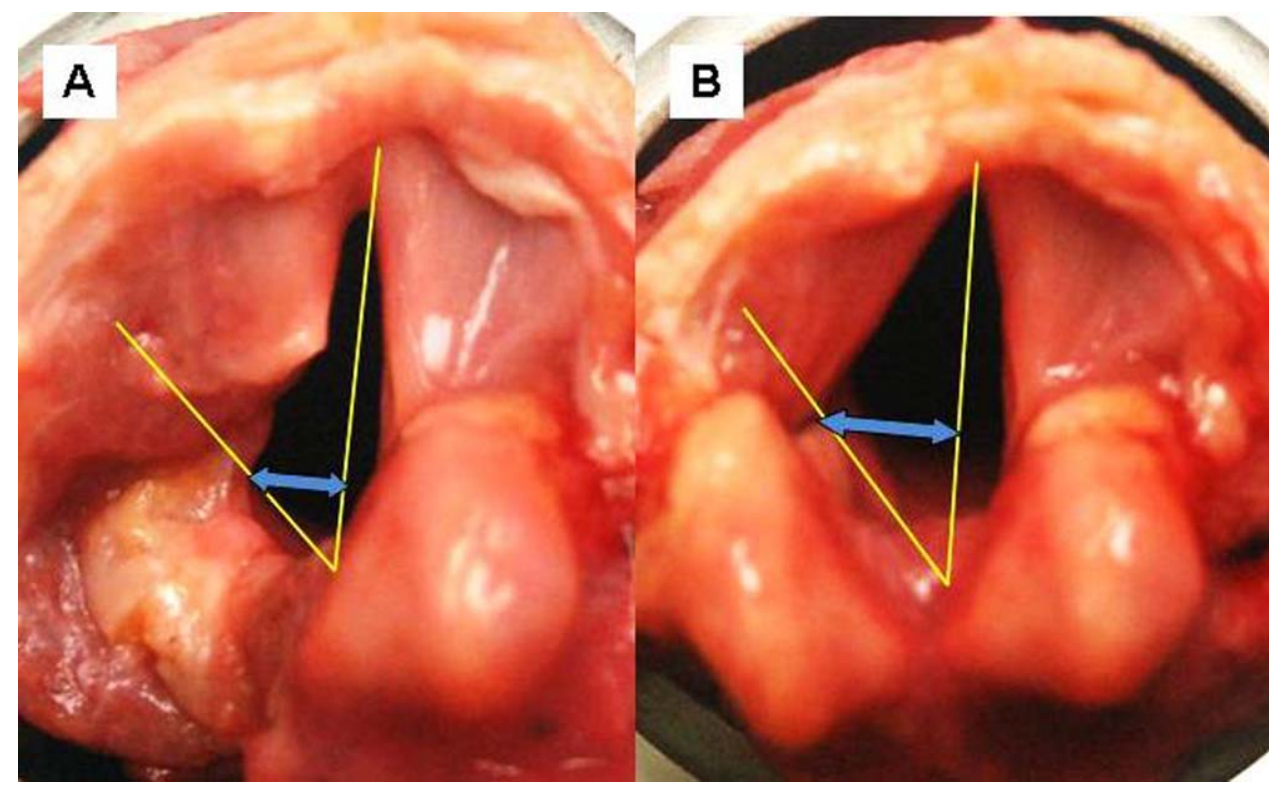

Fig. 4. Arytenoidectomy (A) and endoscopic arytenoid abduction lateropexy (B) (larynx no. 83, female, 68 years old). The analyzed parameters describing the posterior glottis are marked: the midline-left vocal process distance (blue arrows), and the angle between the vocal process-posterior commissure line and midline (yellow). [Color figure can be viewed in the online issue, which is available at wileyonlinelibrary.com.] posterior glottis. EAAL and Schobel's method were proven to be significantly more effective than VCL. The measurements after EAAL were not significantly better than the change after SELP (Table II).

In the second part of the study, EAAL was compared to the resection surgical techniques. This proved to be the most effective suture lateralizing method (Table III). After TC, the configuration of the posterior glottic area essentially did not change. AE seemed to be less effective than EAAL because it caused no lateralization of the rest of the vocal cord.

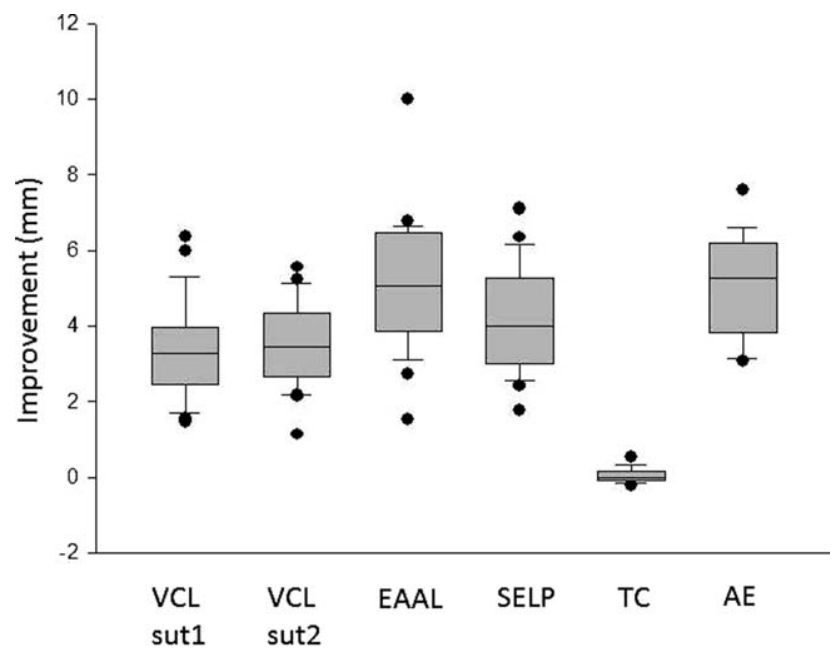

Fig. 5. The improvement of midline-vocal process distance after left-side manipulation. Box plot displaying the extremes, upper and lower quartiles, and the median of the difference between the cadaver and postoperative status. $\mathrm{AE}=$ arytenoidectomy; $\mathrm{EAAL}=$ endoscopic arytenoid abduction lateropexy; SELP = Schobel's method; sut $=$ suture; $\mathrm{TC}=$ transverse chordotomy; $\mathrm{VCL}=$ vocal cord laterofixation.

\section{DISCUSSION}

Morphometric studies analyzing the results of different glottis-widening procedures had already been published. Eckel and Sittel used shock-frozen cadaver larynges to measure the efficacy of cordotomy and AE. Horizontal sections were produced, and cross-sectional areas of the vocal cords and arytenoids were measured using a computer-aided morphometry device. ${ }^{25}$ Their method provided an objective comparison between the examined procedures, but it was expensive and time consuming, which likely limited the extension of the study as evidenced by the lack of follow-up work. The great anatomical variability of the larynx requires a large number of study specimens. ${ }^{26}$ Other deficiencies were that the horizontal projection of the three-dimensional

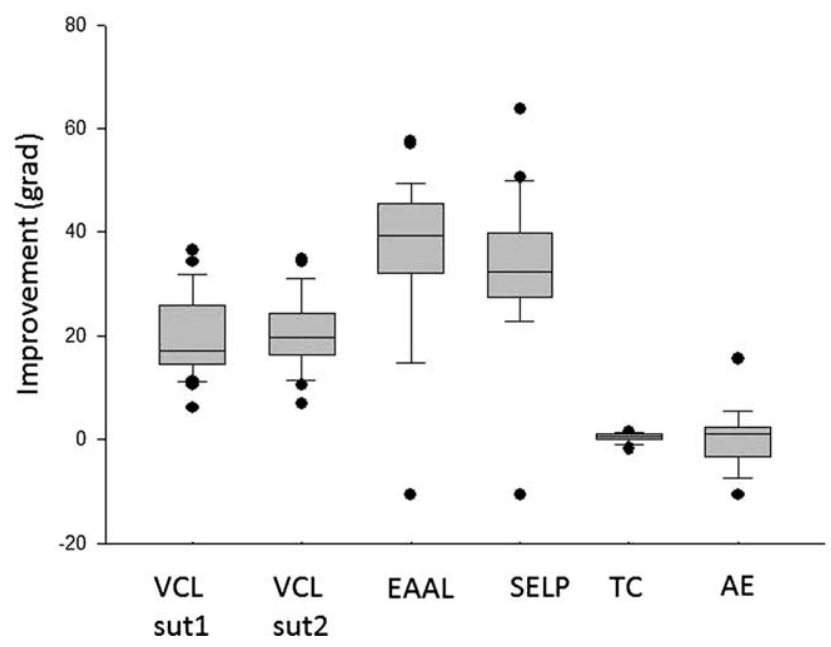

Fig. 6. The improvement of the angle of the posterior commissure $(\mathrm{o}=\mathrm{grad}) . \mathrm{AE}=$ arytenoidectomy; $\mathrm{EAAL}=$ endoscopic arytenoid abduction lateropexy, grad = gradian; SELP = Schobel's method; $\mathrm{TC}=$ transverse cordotomy; $\mathrm{VCL}=$ vocal cord laterofixation. 
TABLE II.

Statistical Correlations of the Results of Suture Lateralizing Procedures $(n=60)$ : Comparison of the Horizontally Signed Method to the Vertically Written Method.

\begin{tabular}{|c|c|c|c|c|}
\hline & VCL 1 & VCL 2 & SELP & EAAL \\
\hline \multicolumn{5}{|c|}{ Midline-vocal process distance } \\
\hline $\mathrm{CP}$ & * & * & * & * * \\
\hline VCL 1 & & NS & NS & $\dagger$ \\
\hline VCL 2 & NS & & NS & $\dagger$ \\
\hline SELP & NS & NS & & NS \\
\hline \multicolumn{5}{|c|}{ Angle in the posterior commissure } \\
\hline $\mathrm{CP}$ & * & . & * & * \\
\hline VCL 1 & & NS & $\dagger$ & $\dagger$ \\
\hline VCL 2 & NS & & $\dagger$ & $\dagger$ \\
\hline SELP & $\ddagger$ & $\ddagger$ & & NS \\
\hline
\end{tabular}

*Significantly higher, $P<.0001$

${ }^{\dagger}$ Significantly higher, $P<.01$

₹Significantly lower, $P<.01$

$\mathrm{CP}=$ cadaver position; $\mathrm{EAAL}=$ endoscopic arytenoid abduction lateropexy; NS = not significant; SELP $=$ Schobel's method; $\mathrm{VCL}=$ vocal cord laterofixation.

movements of the arytenoids might not have been analyzed by their method, and different glottis-widening methods could not be performed on the same organ.

These technical limitations were avoided by applying our simple digital image-based morphometric analysis method. When the fresh cadaver larynges are fixated in a standard position and in sharp high resolution, distortionless photos can be taken. The surgical anatomical parameters of different procedures can therefore be assessed in the plane perpendicular to the mediansagittal plane of the larynges. A large number of larynges were used, which allowed appropriate statistical comparison between procedures. Considering the anatomical variability of each larynx, repeated measures with each organ further strengthened our study.

Theoretically, an open posterior commissure after surgery for PGS should be tractioned in its new configu-

\section{TABLE III.}

The Statistical Correlations Between the Results of EAAL and Resection Procedures $(\mathrm{N}=20)$ : Comparison of the Horizontally Signed Method to the Vertically Written One.

\begin{tabular}{|c|c|c|c|}
\hline & $\mathrm{AE}$ & $\mathrm{TC}$ & EAAL \\
\hline \multicolumn{4}{|c|}{ Midline-vocal process distance } \\
\hline $\mathrm{AE}$ & & * & NS \\
\hline TC & $\dagger$ & & $\dagger$ \\
\hline EAAL & NS & * & \\
\hline \multicolumn{4}{|c|}{ Angle in the posterior commissure } \\
\hline $\mathrm{AE}$ & & $\ddagger$ & $\S$ \\
\hline $\mathrm{TC}$ & $\S$ & & $\dagger$ \\
\hline EAAL & $\ddagger$ & ${ }^{\dagger}$ & \\
\hline \multicolumn{4}{|c|}{$\begin{array}{l}\text { *Significantly lower, } P<.0001 \\
\text { †Significantly higher, } P<.0001 \text {. } \\
\text { ‡Significantly lower, } P<.01 \\
\text { \$Significantly higher, } P<.01\end{array}$} \\
\hline
\end{tabular}

ration to prevent restenosis. This can clearly be achieved when the arytenoid cartilages are repositioned to that of maximal. The movement of the cricoarytenoid joint is not a simple rotation around the vertical axis. This is generally considered to be the theoretical basis for simple VCL techniques and exists only in standard anatomy textbooks. ${ }^{27}$ Wang has convincingly demonstrated that during abduction, the lateral sliding motion of the vocal process is accompanied by an upward and occasionally slightly posterior movement. Simultaneously, the arytenoid cartilage turns laterally and upward on the cricoid cartilage facet. $^{28,29}$

Our cadaver studies focused on the morphological configuration changes of the posterior glottic area caused by different glottis-widening procedures. They proved that this abducted position of the joint could be accomplished by tilting the arytenoid cartilage backward and then fixating it with a suture loop. EAAL is based on these maneuvers, ${ }^{15}$ and therefore, in our opinion, provides better results than other suture lateralization methods. This technique spares the phonatory surface of the vocal cords, which should enable a better postoperative voice than procedures involving the resection of the glottis. When treating posterior glottic stenosis the procedure is performed bilaterally, ${ }^{14}$ so the contrast with the results of different techniques is even more distinct. This study was performed on normal cadaver larynges, but these results can be extended to actual clinical circumstances when the posterior commissure is not pliable or stretchable. Our method, which cut the posterior glottic and cricoarytenoid intracapsular scars by $\mathrm{CO}_{2}$ laser and a rightangle endoscopic blade, ${ }^{14}$ allows the creation of this widened glottic configuration.

The analysis of VCL showed some improvement, but the second suture loop does not enlarge the posterior glottis. Schobel's method of external arytenoid lateropexy proved to be more effective, with the results being comparable to the results of minimally invasive EAAL. TC produced no significant area increase in the posterior commissure compared to the initial cadaveric position. TC may be effective in the treatment of dyspnea, but the configuration of the damaged posterior glottic area did not change. The arytenoid remained in a median position. As such, the expected postsurgical scar formation ${ }^{10}$ may cause more severe dyspnea in the long run than in the case of bilateral vocal cord paralysis.

AE provided better results than VCL, but worse than EAAL. This intervention does not really change the position of the rest of the vocal cord. In some cases, vocal fold adduction happened because of the lack of connection between the arytenoid joint and the rest of the vocal cord. The scarred posterior commissure makes it difficult to create a mucosal flap, preserving the medial mucosa of the arytenoid, especially in the case of a fixed contralateral arytenoid. This clinical situation promotes significant restenosis. Another basic handicap of all the techniques involving vocal fold resection is that the removal of glottic tissue commonly causes irreversible loss of vocal function. 


\section{CONCLUSION}

These morphometric cadaver studies confirmed that special maneuvers and suture fixation by EAAL can rock the arytenoid cartilage into its maximally abducted position, thereby providing the largest posterior glottic configuration compared to other endoscopic glotticwidening techniques. Fibrous reconnection and contraction of the scar tissue can be minimized in this way.

\section{BIBLIOGRAPHY}

1. Sellars I, Sellars S. Cricoarytenoid joint structure and function. $J$ Laryngol Otol 1983;97:1027-1034.

2. Sonneson B. Die Functionelle Anatomie Des Cricoarytenoidgelenkes. Z Anat Entwickl 1959;121:292-302.

3. Whited RE. Posterior commissure stenosis post long-term intubation. Laryngoscope 1983;93:1314-1318.

4. Crumley RL. Endoscopic laser medial arytenoidectomy for airway management in bilateral laryngeal paralysis. Ann Otol Rhinol Laryngol 1993 102:81-84.

5. Whited ER. Laryngeal dysfunction following prolonged intubation. Ann Otol 1979;88:474-478.

6. Bogdasarian RS, Olson NR. Posterior glottic laryngeal stenosis. Otolaryn gol Head Neck Surgery 1980;18:765-772.

7. Sapundzhiev N, Lichtenberger G, Eckel HE, et al. Surgery of adult bilateral vocal fold paralysis in adduction: history and trends. Eur Arch Otorhinolaryngol 2008;265:1501-1514

8. Schobel H. Dilatation of the glottis in bilateral vocal cord paralysis Review of various surgical procedures and a report of personal experience using a functional lateral fixation surgical technic [in German]. HNO 1986;34:485-495.

9. Laccourreye O, Paz Escovar MI, Gerhardt J, Hans S, Biacabe B, Brasnu D. CO2 laser endoscopic posterior partial transverse cordotomy for bilateral paralysis of the vocal fold. Laryngoscope 1999;109:415-418.

10. Dennis DP, Kashima H. Carbon dioxide laser posterior cordectomy for treatment of bilateral vocal cord paralysis. Ann Otol Rhinol Laryngol 1989;98(12 pt 1):930-934.

11. Eckel HE, Wittekindt C, Klussmann JP, Schroeder U, Sittel C. Management of bilateral arytenoid cartilage fixation versus recurrent laryngeal nerve paralysis. Ann Otol Rhinol Laryngol 2003;112:103-108.

12. Lichtenberger G. Open and endoscopic surgical techniques for the treatment of scarred laryngeal stenosis. Otolaryngol Head Neck Surg 1998;9: $150-153$.
13. Rethi A. A new surgical method for bilateral paramesial fixation of the vocal cords with reference to the operation for cicatricial laryngeal stenosis [in German]. Z Laryngol Rhinol Otol 1955;34:464-472.

14. Rovo L, Venczel K, Torkos A, Majoros V, Sztano B, Jori J. Endoscopic arytenoid lateropexy for isolated posterior glottic stenosis. Laryngoscope 2008;118:1550-1555.

15. Rovo L, Madani S, Sztano B, Majoros V, Smehak G, Szakacs L, Jori J. A new thread guide instrument for endoscopic arytenoid lateropexy. Laryngoscope 2010;120:2002-2007.

16. Maren AGD, Glover GW. A modified McNaught keel for posterior glottic stenosis. J Laryngol Otol 1973;87:695-698.

17. Woodson BT, McFadden EA, Toohill RJ. Clinical experience with the Lichtenberger endo-extralaryngeal needle carrier. Laryngoscope 1991;101: 1019-1023.

18. Zalzal GH. Posterior glottic fixation in children. Ann Otol Rhinol Laryngol 1993;102:680-686.

19. Dedo HH, Sooy CD. Endoscopic laser repair of posterior glottic, subglottic and tracheal stenosis by division or micro-trapdoor flap. Laryngoscope 1984;94:445-450

20. Rovo L, Brzozka M, Czigner J. Airway complication after thyroid surgery: minimally invasive management of bilateral recurrent nerve injury. Laryngoscope 2000;110:140-144.

21. Singh T, Sandulache VC, Otteson TD, et al. Subglottic stenosis examined as a fibrotic airway mucosal response to injury characterized by altered mucosal fibroblast activity. Arch Otolaryngol Head Neck Surg 2010;136: $163-170$.

22. Lichtenberger G. Reversible lateralization of the paralyzed vocal cord without tracheostomy. Ann Otol Rhinol Laryngol 2002;111:21-26.

23. Ejnell H, Mansson I, Hallen O, Bake B, Stenborg R, Lindstrom J. A simple operation for bilateral vocal cord paralysis. Laryngoscope 1984;94:954958.

24. Ossoff RH, Sisson GA, Duncavage JA, Moselle HI, Andrews PE, McMillan WG. Endoscopic laser arytenoidectomy for the treatment of bilateral vocal cord paralysis. Laryngoscope 1984;94:1293-1297.

25. Eckel HE, Sittel C. Morphometric studies at the level of the glottis as a principle in larynx enlarging microlaryngoscopic surgical procedures in bilateral recurrent nerve paralysis [in German]. Laryngorhinootologie 1994;73:417-422

26. Sellars IE, Keen EN. The anatomy and movements of the cricoarytenoid joint. Laryngoscope 1978;88:667-674.

27. Von Leden H, Moore P. The mechanics of the cricoarytenoid joint. Arch Otolaryngol 1961;73:541-550.

28. Wang R. Three-dimensional analysis of cricoarytenoid joint motion. Laryngoscope 1998;108(4 pt 2 suppl 86):1-17.

29. Woodson G. Arytenoid abduction for bilateral vocal cord paralysis. Oper Tech Otolaryngol 2012;23:178-182. 